Breno Teixeira Santos

Estudo in silico de Centros, Geradores

de Padrão: arquiteturas mínimas de funcionamento e fluxo interno de informação 

Breno Teixeira Santos

\section{Estudo in silico de Centros, Geradores de Padrão: arquiteturas mínimas de funcionamento e fluxo interno de informação}

Tese apresentada ao Instituto de Biociências da Universidade de São Paulo, para a obtenção de Título de Doutor em Ciências, na Área de Fisiologia Geral.

Orientador: Prof. Dr. José Guilherme de Souza Chaui Mattos Berlinck

São Paulo

2013 
Santos, Breno T.

Estudo in silico de Centros Geradores de Padrão: arquiteturas mínimas de funcionamento e fluxo interno de informação

83 páginas

Tese (Doutorado) - Instituto de Biociências da Universidade de São Paulo. Departamento de Fisiologia.

1. Palavra-chave

2. Palavra-chave

3. Palavra-chave

I. Universidade de São Paulo. Instituto de Biociências. Departamento de Fisiologia.

\section{Comissão Julgadora:}

Prof. Dr.

Nome

Prof. Dr.

Nome
Prof. Dr.

Nome

Prof. Dr.

José Guilherme de Souza Chaui

Mattos Berlinck

Prof. Dr.

Nome 


\section{Epígrafe}

0 que é bonito?

É $O$ que persegue o infinito;

Mas eu não sou

Eu não sou, não...

$\mathrm{Eu}$ gosto é do inacabado,

0 imperfeito, o estragado, o que dançou

0 que dançou...

Eu quero mais erosão

Menos granito.

Namorar o zero e o não,

Escrever tudo o que desprezo

E desprezar tudo o que acredito.

Eu não quero a gravação, não,

$\mathrm{Eu}$ quero o grito.

Que a gente vai, a gente vai

E fica a obra,

Mas eu persigo o que falta

Não o que sobra.

Eu quero tudo que dá e passa.

Quero tudo que se despe,

Se despede, e despedaça.

0 que é bonito...

Lenine e Bráulio Tavares 


\section{Agradecimentos}

Impossível não começar agradecendo à minha esposa, Ana Carolina, pelo sempre incondicional apoio. Pelos nossos 2 filhos lindos, por uma vida que, caso não existisse, esse título de nada valeria.

Aos meus irmãos por opção, Zé e Fefex, meus mais sinceros votos de agradecimento. Por tornar as coisas mais leves quando necessário, ou até mesmo mais pesadas. Sinto enorme pesar em deixá-los...

Ao meu mestre e meu amigo, ZéGui, que antes de tudo é um dos maiores exemplos que tenho como Homem e Profissional, por tudo que fez por mim nesses últimos 11 anos e, acima de tudo, pelos momentos de silêncio, quando isso era a única coisa que eu podia oferecer!

Ao meu sogro, Seu Gilson, grande apoiador nas correrias da vida prática!

Não poderia esquecer de agradecer a Roseli pelos galhos e galhos e galhos e árvores quebrados.

A todos que sempre estiveram dando apoio em maior ou menor grau, meu muito obrigado!!! 


\section{Resumo}

O estudo dos centros geradores de padrão, CPGs, é um excelente exemplo das limitações do método reducionista, na tentativa de explicar um comportamento de ordem mais global. Não queremos, com isso, relegar a descrição esmiuçada dos mecanismos biofísicos e moleculares ao ostracismo. Muito pelo contrário, iremos nos apropriar de um subconjunto desses conceitos, na forma do modelo de Hodgkin \& Huxley, para construir um sistema de simulação computacional de redes neurais, em pequena escala, passível de realizar duas métricas. Uma destinada a medir a complexidade da geração de informação circulante interna a rede, enquanto a outra traz dados relativos ao consumo energético das células neurais. Espera-se, com isso, alguma resposta para a seguinte questão: existe algum mecanismo, algum princípio básico em redes que oscilam, capaz de mapear um mínimo de uma grandeza física externa em algum outro mínimo interno a rede? Ao que tudo indica a resposta é afirmativa. Apresentaremos um tal ponto de minimização, juntamente com um formalismo, ainda em desenvolvimento, que justifica os resultados.

Palavras-chave: CPGs, Entropia Informacional, Minimização 


\section{Abstract}

The study of central pattern generators is a great example of the limitations in a reductionist approach, to achieve global knowledge about a system. We are not neglecting the importance of biophysical and molecular mechanisms. Quite the contrary, we will apply some of this concepts by means of Hodgkin \& Huxley formalism, to build up a small form factor neural network software simulator. This platform will be able to perform two measurements, informational complexity and metabolic consumption with the aim of answer the question: is there some mechanism, some basic principle in oscillatory networks, capable of mapping a minimum in an external physical quantity into another minimum internal to the network? It seems that the answer is affirmative. We will present this minimization point, together with an under development formalism, to embase the results.

Keywords: CPGs, Informational Entropy, Minimization 


\section{Lista de Figuras}

1.1 Reflex Chain versus $\mathrm{CPG} \ldots \ldots \ldots \ldots$

1.2 Os Resultados de Philippson $\ldots \ldots \ldots \ldots$

1.3 Respostas à Ablação do Cortex Esquerdo . . . . . . . . . . . . . . . 9

1.4 Registro de Músculos Deaferentados . . . . . . . . . . . . . . . . 10

1.5 Alguns CPGs de invertebrados . . . . . . . . . . . . . . 15

2.1 Modelo de Hodgkin Huxley . . . . . . . . . . . . . . . . . . . . . . 20

2.2 Modelos Neurais Segundo Classificação de Izhikevich . . . . . . . . . . . 23

3.1 Arquitetura de Software Proposta . . . . . . . . . . . . . . . . . 32

3.2 Classe $\mathrm{HH} \ldots \ldots \ldots \ldots \ldots$

3.3 Resposta do Modelo LIF . . . . . . . . . . . . . . . . . . . . . . . . 33

3.4 Fonte Externa de Corrente . . . . . . . . . . . . . . . . . . 35

3.5 Python versus Matlab . . . . . . . . . . . . . . . . . 36

3.6 Entropia Informacional versus bin size . . . . . . . . . . . . . . . . . 38

3.7 Janela de Sincronismo . . . . . . . . . . . . . . . . . . . . . . . . 39

4.1 Exemplo: 2 neurônios com PIR e acoplamento elétrico . . . . . . . . . . 46

4.2 Circuito Neural Pilórico da Lagosta . . . . . . . . . . . . . . . . . . 47

4.3 Circuito Neural Pilórico da Lagosta - Sinapses . . . . . . . . . . . . . . . 48

4.4 Registros in vivo e in vitro na Lagosta . . . . . . . . . . . . . . . . . 49 
4.5 Estatística Descritiva de CS16 . . . . . . . . . . . . . 52

4.6 CS1 e CS3 - Normalizados . . . . . . . . . . . . . . 53

$4.7 C_{4}$ e $C S 5$ - Normalizados . . . . . . . . . . . . . 54

4.8 CS6 e CS7 - Normalizados . . . . . . . . . . . . . 55

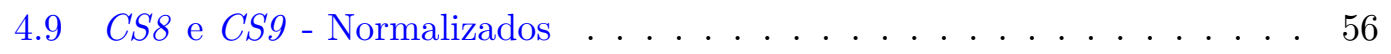

4.10 CS11 e CS14 - Normalizados . . . . . . . . . . . . . 57

4.11 CS16-Normalizados . . . . . . . . . . . . . . 58

4.12 Circuito Neural Pilórico da Lagosta - Sinapses . . . . . . . . . . . . . . . 59

4.13 Disparos da Rede . . . . . . . . . . . . . . . . . . . . . . 61

4.14 Plots de Poincaré IST _ . . . . . . . . . . . . . . . . . 61

4.15 Disparos Síncronos da Rede . . . . . . . . . . . . . . . . . . 62

4.16 Redistribuição Energética . . . . . . . . . . . . . . . . 63

5.1 Saídas Motoras . . . . . . . . . . . . . . . . . . . 67

5.2 Saídas Síncronas . . . . . . . . . . . . . . . . . . 69 


\section{Lista de Tabelas}

4.1 Tabela com Pesos das Simulações . . . . . . . . . . . . . . . . . . . 50

4.2 Estastísticas dos Padrões Basais . . . . . . . . . . . . . . . . 64

5.1 Detalhes de $C S 8$ e $C S 9 \ldots \ldots \ldots \ldots 6 \ldots$ 


\section{Sumário}

1 De Sherrington aos Centros Geradores de Padrão 1

1.1 Primórdios . . . . . . . . . . . . . . . . . . . 1

1.2 CPGs na Atualidade . . . . . . . . . . . . . . . . . . . 12

1.3 Posicionamento da Pesquisa . . . . . . . . . . . . . . 16

$\begin{array}{llr}2 & \text { Bases Matemáticas e Computacionais } & 19\end{array}$

2.1 Uma Taxonomia dos Modelos Neurais . . . . . . . . . . . . . . . . . . . 19

2.2 Formalismo Matricial do Sistema EDO . . . . . . . . . . . . . 26

3 Desenvolvimento da Infraestrutura Computacional 29

3.1 Infraestrutura Computacional . . . . . . . . . . . . . . . . 29

3.2 Arquitetura de Software Proposta . . . . . . . . . . . . . . . . . 31

3.2 .1 Organização das Classes . . . . . . . . . . . . . . . . . 31

3.2.2 Módulos Externos . . . . . . . . . . . . . . . . . . . . . 42

4 Resultados $\quad 45$

4.1 Considerações Preliminares . . . . . . . . . . . . . . . . . . 45

4.2 Variações dos Pesos Sinápticos . . . . . . . . . . . . . . . . . 49

4.3 Depressores de Informação . . . . . . . . . . . . . . . . . . . . . . 51

4.4 Rede Neural . . . . . . . . . . . . . . . . . . . . . . . . . . . 52

4.5 Condições Basais . . . . . . . . . . . . . . . . . . . . . . 62 
4.6 Redistribuição Energética . . . . . . . . . . . . . . . . . . 63

5 Discussão $\quad 65$

5.1 Reprogramação da Rede . . . . . . . . . . . . . . . . . . . . 65

5.2 Aumentos de Informação na Rede . . . . . . . . . . . . . . . . . . . 70

5.3 Biologia Relacional . . . . . . . . . . . . . . . . . . . . . 71

$\begin{array}{ll}\text { Referências Bibliográficas } & 73\end{array}$

$\begin{array}{lr}\text { A Arquivos de Configuração XML } & 78\end{array}$

B Considerações Sobre Aumento de Performance em Python 82 


\section{Capítulo 1}

\section{De Sherrington aos Centros Geradores de Padrão}

\section{$1.1 \quad$ Primórdios}

Sir Charles Sherrington, através da compilação de suas famosas aulas, The Silliman lectures (Yale, 1904), no volume intitulado The integrative action of the nervous system (Sherrington, 1906), alterou o curso da pesquisa em neurofisiologia. Experimentalista de enorme competência, foi após o contato com o espanhol Santiago Ramon y Cajal, que focou sua força de trabalho para área de neurofisiologia ${ }^{1}$. Cria na posição defendida por von Waldeyer-Hartz, a qual era altamente baseada nas observações de Ramon y Cajal $^{2}$, em que o sistema nervoso não era composto por um retículo contínuo (teoria reticular, defendida por Golgi ${ }^{3}$ ) e sim por unidades independentes, de alguma forma

\footnotetext{
${ }^{1}$ Após receber a titulação de médico em 1885, iniciou suas pesquisas na área de doenças infecciosas e seu combate através de vacinas. Retorna a Inglaterra depois de períodos na Espanha, Itália e Alemanha e abraça, em definitivo, a pesquisa em neurofisiologia após assistir a Croonian Lecture ministrada por Ramon y Cajal em 1894.

${ }^{2}$ Não apenas de Ramon y Cajal mas também de Albert von Kölliker, Camillo Golgi, Franz Nissl, Auguste Forel e outros. Imprescindível ressaltar a importância do método de coloração de tecidos descoberto por Golgi, baseado na ação do nitrato de prata.

${ }^{3}$ Mais tarde, nos anos 50, com a descoberta das sinapses elétricas por Furshpan e Potter, alguns autores argumentaram que Golgi estava parcialmente certo.
} 
interconectadas (teoria celular), a doutrina do neurônio:

"Nowhere in physiology does the cell-theory reveal its presence more frequently in the very framework of the argument than at the present time in the study of nervous reactions."

Sherrington, C. S., The integrative action of the nervous system

Sherrington advogava que o mecanismo básico de integração do sistema nervoso é o reflexo, assim definido:

"These reactions, in which there follows on an initiating reaction an end-effect reached through the mediation of a conductor, itself incapable either of the end-effect or, under natural conditions, of the inception of the reaction, are 'reflexes.'”

\section{Sherrington, C. S., Idem}

Dessa forma, o sistema nervoso deve sempre estar em constante estímulo, para que a cadeia de reações possa ser completada através das três partes constituintes do que Sherrington chamou de arco-reflexo: receptor, condutor e efetor. Esse paradigma implica que o sistema nervoso seja basicamente reativo. Ou seja, uma vez posto na sua função integrativa, esta tinha que ser baseada em reflexos e, em última instância, uma resposta coordenada como a locomoção e a respiração seria obtida através da composição de reflexos ${ }^{4}$, os chamados reflexos encadeados (reflex chain).

Em sua sexta aula, reflexos compostos: combinação sucessiva (compound reflexes: successice combination), Sherrington estabelece a ligação entre o conceito de reflexo e a locomoção. Ele inicia a aula exemplificando, através do reflexo de dardo da língua dos sapos, o que seriam sequências de reflexos. Provocado pela visualização da mosca,

\footnotetext{
${ }^{4}$ A composição de reflexos baseia-se na coordenação entre diversos reflexos simples. Reflexos simples seriam entidades abstratas. A resposta de um órgão efetor a um estímulo advindo de um receptor, estando todas as demais partes do organismo indiferentes sobre e para aquele dado estímulo.
} 
em caso de sucesso na captura, o contato da presa com a mucosa da boca desencadeia o reflexo de fechamento da mesma o que, por sua vez, assegura o reflexo de início da deglutição e assim sucessivamente. A idéia de um sistema nervoso reativo reaparece (grifo nosso):

"Yet, tracing this sequence to its external causes, we recognize that the usual thing in nature is not for one exciting stimulus to begin immediately after another ceases, but for an array of environmental agents acting concurrently on the animal at any moment to exhibit correlative change in regard to it so that one or other group of them becomes - generally by increase in intensity - temporarily prepotent. [...] It may happen that one stimulus ceases coincidently as another begins, but as a rule the stimuli overlap one another in regard to time."

Sherrington, C. S., Idem

Ora, uma sequência de reflexos pode incluir tanto reflexos aliados (allied - o que hoje chamamos de agonistas) quanto antagonistas, os quais estão (grifo no original):

"[...] linked together by more than the mere external [...] stimulus. In such a sequence the threshold of each succeeding reflex is lowered by the excitation just preceding its own."

Sherrington, C. S., Idem

Essa facilitação baseada na excitação precedente pode ser exemplificada como na Figura 1.1. O músculo em contração (vermelho), através de neurônios sensores (SN) irá excitar interneurônios (IN) de seu antagonista. O abandono à teoria de reflexos encadeados como explicação para a locomoção veio através dos trabalhos de Thomas Graham Brown. É estranho admitir que Sherrington fosse ignorante à esses resultados, uma vez que Graham Brown trabalhou durante três anos, entre 1910 e 1913, no 
laboratório de Sherrington em Liverpool. A questão fica mais clara ao observarmos o conteúdo do prefácio da edição de 1947 de The integrative action (grifo nosso):

"But reflex action presents certain advantages for physiological description. It can be studied free from complication by that type of 'nerve' activity which is called autochthonous (or 'spontaneous') and generates intrinsically arising rhythmic movements, e.g. breathing, etc. [...] Studied in that self-contained animal group, the Vertebrates, behaviour seems to become less and less reflex as the animal individual becomes more and more completely individuated. The 'spinal' man is more crippled than is the 'spinal' frog."

Sherrington, C. S., Idem

Na verdade a idéia de um controle central já aparecia nos escritos de Sherrington, em seu famoso trabalho de 1910 (Sherrington, 1910), grifo nosso:

"The seat of the rhythm is obviously not peripheral. It is not in the muscles or their motor nerves for they do not when thrown into activity in other ways show any trace of rhythm of this frequency. Nor can it lie in the receptive organs of the skin or their afferent nerve trunks for direct stimulation of the cross section of the spinal axis itself provokes the rhytmic reply. The rhythm is therefore central in its seats."

Sherrington, C. S., Flexion-reflex of the limb, crossed extension-reflex, and reflex stepping and standing

Para que possamos desenhar um retrato fiel da evolução na pesquisa em controle motor, faz-se necessário apresentarmos os resultados obtidos por Maurice Philippson, publicados em seu livro L'autonomie et la centralisation dans le système nerveux des animaux, de 1905. Philippson recebeu de Etienne-Jules Marey um mosaico de imagens 
que demonstrava o posicionamento dos membros do cachorro durante sua locomoção, baseado nas memoráveis imagens geradas por seus filmes de alta velocidade ${ }^{5}$. Analisando o ciclo de passadas do animal, Philippson desenhou pranchas (vide Figura 1.2) que organizavam os dados referentes aos ângulos formados por diversos segmentos dos membros locomotores, além de propor uma taxonomia para o que ele chamou de fases do ciclo de passadas. Talvez o ponto mais importante de seu trabalho, para o nosso foco no controle, seja a sua proposta para tipos, duração e fase de reflexos que estariam relacionados com o movimento (Clarac, 2008).

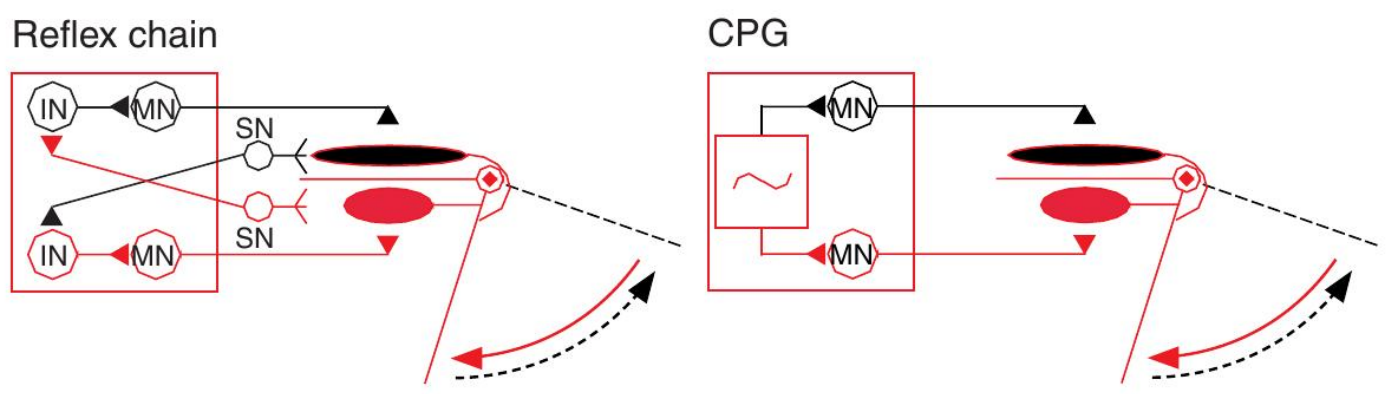

Figura 1.1: Os paradigmas, reflex chain proposto por Sherrington e CPG proposto por Graham Brown. Retirado de (Marder and Bucher, 2001).

Porém, Philippson também acreditava em um sistema composto por mecanismos centrais e reflexos, como fica óbvio nos excertos seguintes do trabalho de 1905 (tradução do francês por François Clarac em (Stuart and Hultborn, 2008), grifo nosso):

\footnotetext{
${ }^{5}$ Justiça deve ser feita que não apenas Marey, mas também Eadweard Muybridge, este inglês trabalhando nos Estados Unidos e àquele francês, desenvolveram isoladamente métodos para realizar fotos e vídeos em alta velocidade, aplicando-os à captura e posterior estudo do movimento de diversos animais. Marey chegou a fazer diversos vídeos da queda, de pequenas alturas, de gatos, cachorros, coelhos e até porquinhos da índia, na busca de compreender como os primeiros eram capazes de cair apoiados nas quatro patas.
} 
"Our experiments prove that one side of the spinal cord separated from the cerebro-spinal axis is able to produce coordinated movements in two types of locomotion, trot and gallop." "In summary, we see that locomotor coordination is an exclusive function of the spinal cord supported by a sequencing of direct and crossed reflexes, which are activated sometimes by contact with the ground and sometimes even by leg movement. [...] In conjunction with this peripherally excited coordination, there is a central coordination arising from intraspinal pathways."

Maurice Philippson, L'autonomie et la centralisation dans le système nerveux des animaux

Por que o paradigma de locomoção baseado em reflexos perdurou tanto tempo? Graham Brown, em uma série de trabalhos publicados entre 1910 e 1916 (incluindo sua dissertação de mestrado), nunca apresentou os indícios levantados por Sherrington e Philippson, de um controle central. Em suas revisões, Clarac, Stuart e Hultborn conseguem, apenas, apresentar esse fato como enigmático ( "puzzling”), ou seja, a questão acima continua sem resposta.

Vejamos, a partir de agora, como surgiu a teoria baseada em um controle espinhal central. Os centros de controle, hoje chamados de geradores de padrão centrais (CPGs, Central Pattern Generators), foram conceituados por Graham Brown através da idéia de half-centers. Em seus trabalhos, Graham Brown analisou como se comportava a movimentação dos membros locomotores de diversos animais (na maior parte, é claro, gatos) sob diferentes arranjos experimentais. Ao realizar experimentos com porquinhos da índia (Graham Brown, 1910), Graham Brown confirmou os resultados obtidos por Charles Édouard Brown-Séquard a respeito do reflexo de coçar ${ }^{6}$ (scratch-reflex).

\footnotetext{
${ }^{6} \mathrm{Na}$ verdade Graham Brown apresentou uma confirmação da epilepsia de Brown-Séquard em 1909: Studies in the reflexes of the guinea-pig. I. The scratch-reflex in relation to "Brown-Séquard's Epilepsy". Exp. Physiol, 2:243-275. Mas realizou experimentos envolvendo não apenas lesões no nervo ciático, mas
} 


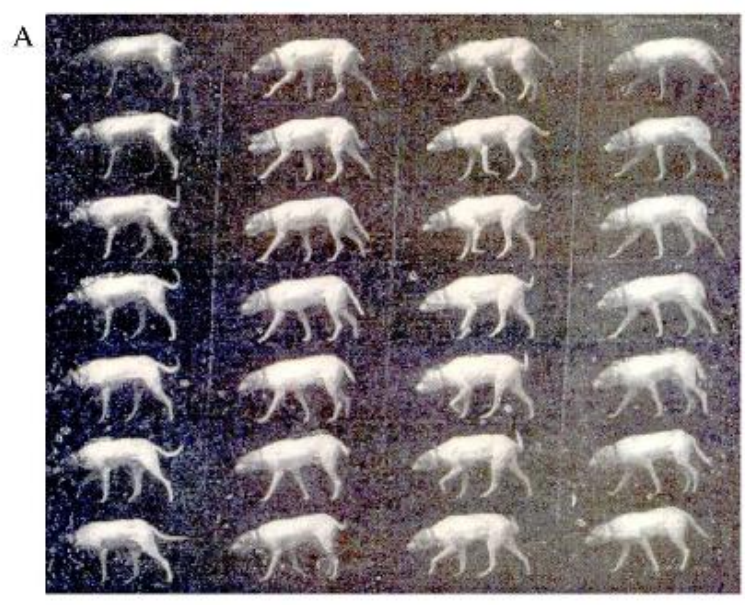

B

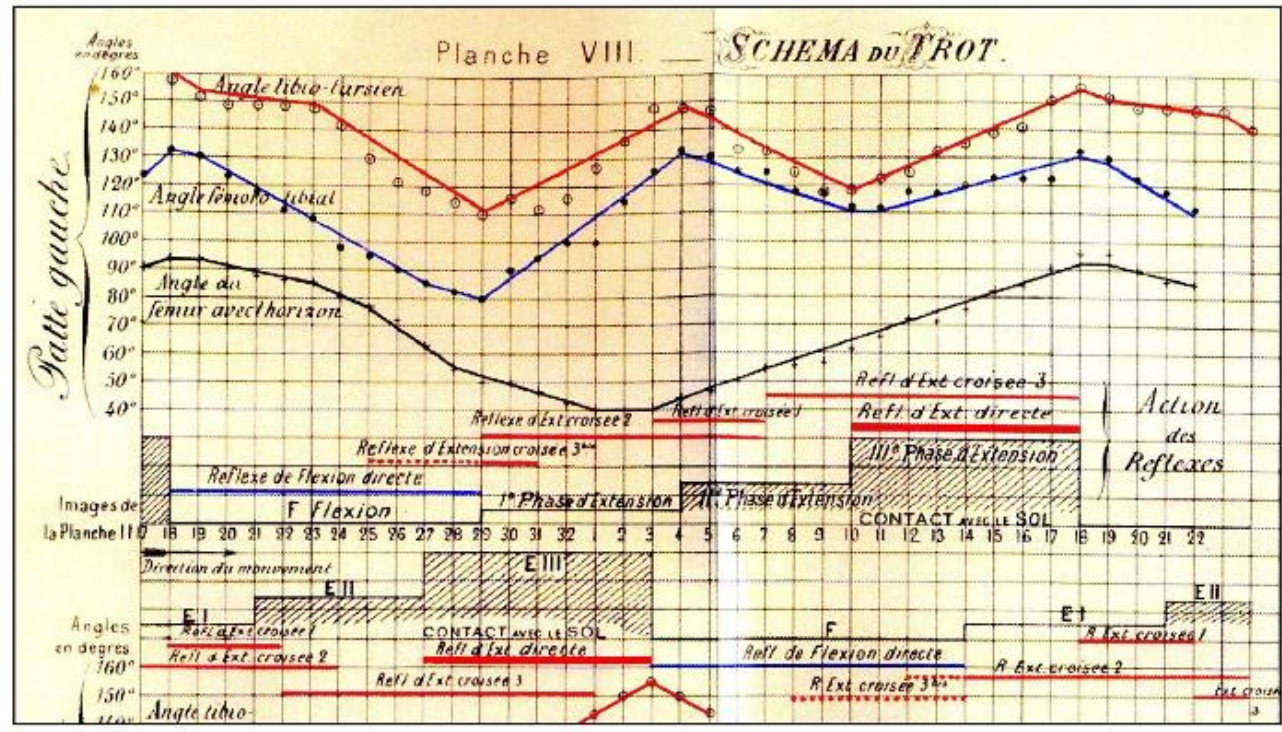

Figura 1.2: Os resultados apresentados por Philippson em seu trabalho de 1905. (A) A foto dada a Philippson por Marey. (B) A análise do ciclo de passadas do cachorro. Acima os ângulos formados por alguns segmentos dos membros locomotores, em relação à horizontal. Ao fim da prancha temos sua proposta de fases, $\mathrm{F}$ início da perda de contato do pé com o solo na fase de balanço (swing phase), EI, pé na descendente durante a fase de balanço, EII, contato do pé com o solo, início da fase de apoio (stance phase), EIII, início do deslocamento para frente (empurrão) na fase de apoio. Ao centro da prancha a relação proposta entre as fases da locomoção e os respectivos reflexos que as estariam assistindo e/ou iniciando. Retirado de (Clarac, 2008). 
Estimulando mecanicamente (pressão superficial em uma área pré-determinada, a receptive zone) animais com um de seus nervos ciáticos transecionados e, em alguns casos, também com ablação de um dos hemisférios cerebrais, Graham Brown foi capaz de evocar a epilepsia de Brown-Séquard (a Figura 1.3 apresenta uma série de respostas ao longo do tempo). Dentre outras características, um movimento cíclico e periódico de coçar se estabelece no animal. Graham Brown então notou que essa resposta se assemelhava muito com resultados obtidos por Sherrington em cães espinhalados:

"The scratching movement in these 'epileptic fits' resembles the scratchreflex which appears in various vertebrates after trans-section of the spinal cord, and, if we compare the different phenomena of this movement with those observed by Sherrington in the spinal dog, the resemblance is seen to be very close."

Thomas Graham Brown, Studies in the reflexes of the guinea-pig. I. The scratch-reflex in relation to "Brown-Séquard's Epilepsy"

A remoção de centros superiores de controle, juntamente com a lesão do principal eferente dos membros inferiores, levou Graham Brown a especular qual seria o local residente do controle primário, o mais básico, do movimento (grifo nosso):

"[...] scratching movements [...] may persist after transverse lesions at the level of the anterior margin of the pons Varolii. The mechanism of the reaction is therefore contained in centers below the level of that lesion."

Thomas Graham Brown, Studies in the reflexes of the guinea-pig. V.: some experiments on the influence exercised by the higher centres upon the scratch-reflex

também em centros mais elevados de controle, no trabalho apresentado em 1910, o quinto da série de experimentos com porquinhos da índia. 
Por fim, em seu trabalho seminal de 1911 (Brown, 1911), Graham Brown apresentou resultados obtidos com a transecção abrupta da medula de gatos. Baseemo-nos na Figura 1.4, adaptada deste trabalho, para apresentar as três fases pelas quais passa o membro locomotor. Região demarcada por pontilhado branco: contração do tibialis anterior entremeada com alguns episódios de relaxamentos incompletos (as contrações do gastrocnemius nessa fase são tidas como não usuais por Graham Brown). Região verde: período de flexões e relaxamentos regulares e em oposição de fase. Região vermelha: gastrocnemius tende para contração e tibialis anterior para relaxamento, com sessão do movimento.
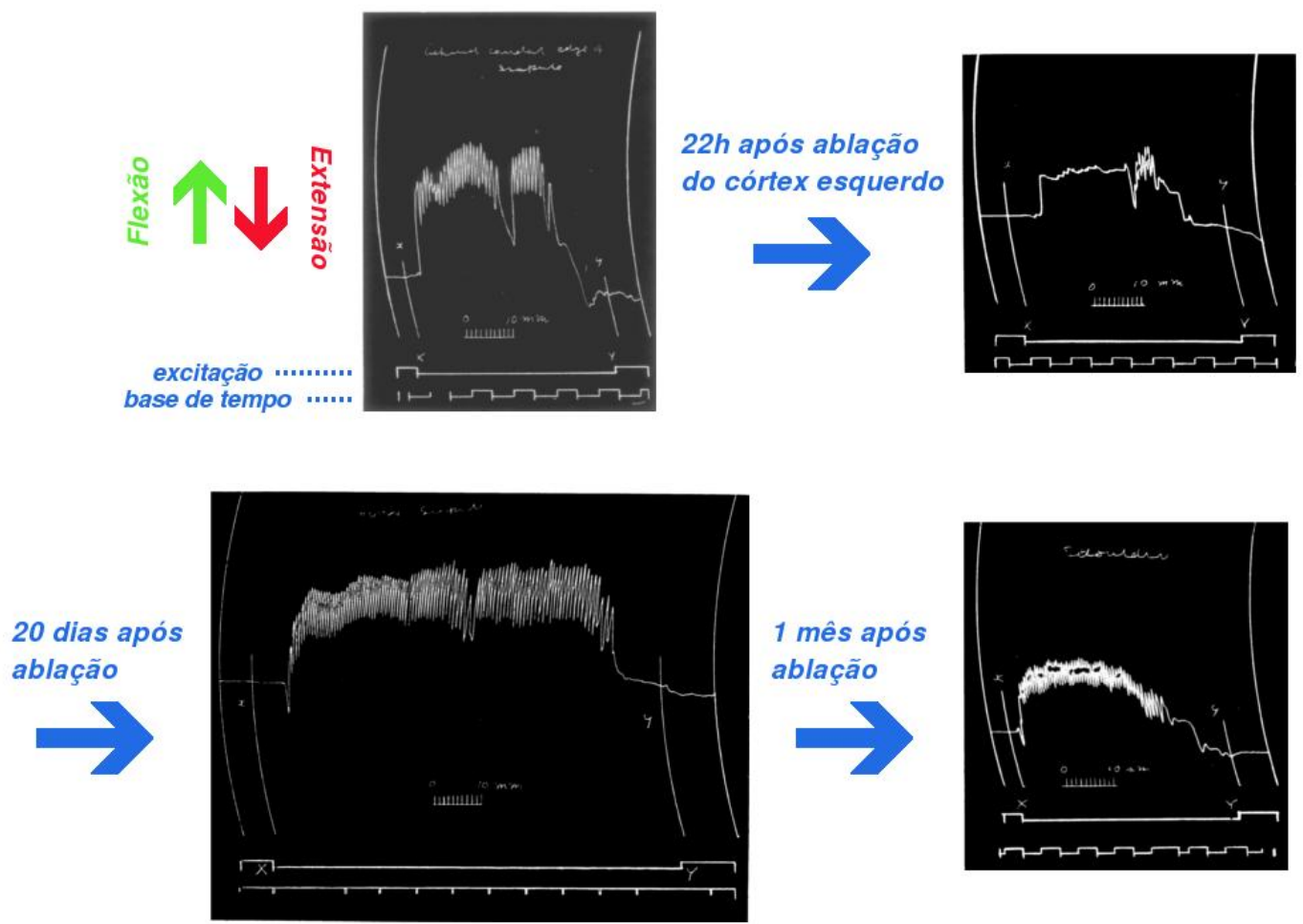

Figura 1.3: Uma série de respostas ao longo do tempo para um indivíduo. O primeiro registro (canto superior esquerdo) é para o animal com o nervo ciático direito lesionado mas ainda sem ablação do córtex esquerdo (estudo da relação contra-lateral). Logo após a ablação a epilepsia de Brown-Séquard parece banida, porém o reflexo de coçar reaparece alguns dias após a cirurgia. Adaptado de (Brown, 1910). 
Graham Brown testou, então, o comportamento ao mesmo desenho experimental, apresentado por outros animais como coelhos e pombos (Graham Brown, 1911b). Embora os resultados para pombos fossem de difícil interpretação devido à posição do animal, movimentação das asas em comparação às passadas e variações da posição da cauda (relativas ao vôo), foi possível detectar padrões oscilatórios relacionados ao vôo nesses animais ${ }^{7}$

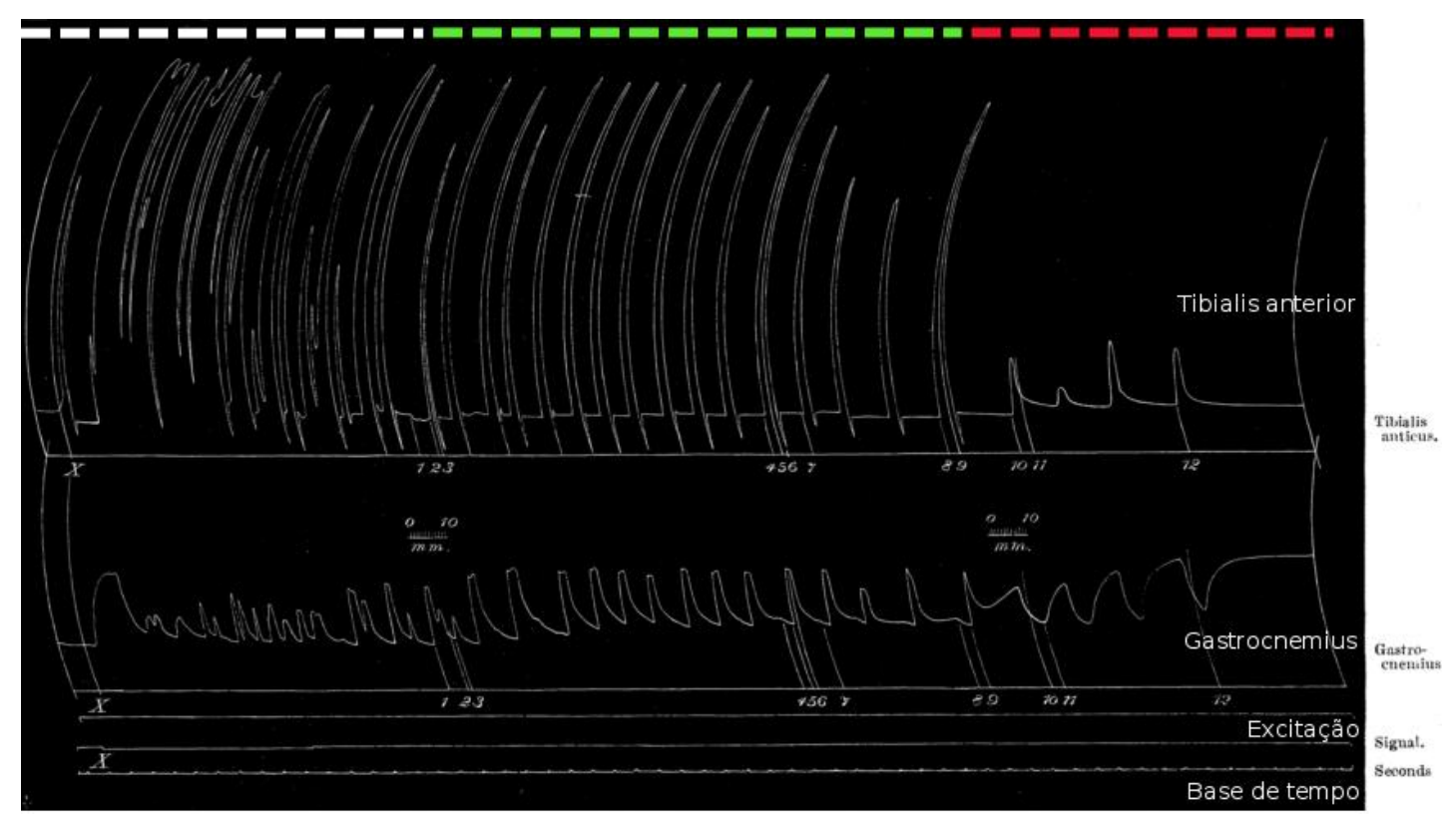

Figura 1.4: Registro obtido para os músculos tibialis anterior e gastrocnemius deaferentados, com os demais músculos do membro inferior além de deaferentados, paralisados (em alguns experimentos até mesmo removidos cirurgicamente). A coluna foi transeccionada entre os níveis de origem dos $12^{\circ}$ e $13^{\circ}$ pares de nervos torácicos, no instante denotado por X. Contração e relaxamento como na Figura 1.3. Detalhes sobre as regiões demarcadas em branco, verde e vermelho, no texto. Adaptado (Brown, 1911).

A conclusão da série de trabalhos publicados por Graham Brown entre 1908 e 1913, veio com seu artigo de 1914: On the nature of the fundamental activity of the nervous centres; together with an analysis of the conditioning of rhythmic activity in progression, and a theory of the evolution of function in the nervous system (Brown, 1914), onde é

\footnotetext{
${ }^{7}$ Importante ressaltar que, durante o vôo, alterna-se entre fases de movimentação das asas e fases em que o animal plana. Isso pode justificar algumas das observações obtidas por Graham Brown.
} 
formalizado o conceito de half-centres (grifo nosso):

"[...] it will be observed that it tends to displace the reflex as the unity of activity in the spinal centres and to put in its stead a mechanism composed of efferent neurones. Perhaps the simplest unitary mechanism is one formed of the efferent neurones to two antagonistic muscles; and as an artificial conception that of two such efferent 'half-centres' (that is, two efferent neurones to antagonistic muscles) and their mutual interconnexions may be suggested."

Thomas Graham Brown, On the nature of the fundamental activity of the nervous centres; together with an analysis of the conditioning of rhythmic activity in progression, and a theory of the evolution of function in the nervous system

Neste mesmo trabalho Graham Brown faz uma consideração, a qual retornaremos na seção 5.3, relativa à questões sobre estrutura e função (Brown, 1914), (grifo nosso):

"[...] the rhythm is not an inherent function of the efferent neurone that is, of the 'half-centre' - but that it is a function of the interrelations of the 'half-centres.' In other words, progression seems to be conditioned, by some function of their mutual relationship, during the equal and opposite activation of linked antagonistic 'half-centres.'"

Thomas Graham Brown, Idem

Fica dessa forma estabelecido que, após a investida de Sherrington à problematica da locomoção, estabelecendo um referencial teórico pautado no princípio do reflexo, Graham Brown propõe um novo referencial teórico que tem, como pilar, o conceito de half-centres. Mais ainda, removemos o controle motor primordial (ou basal) da periferia do sistema, para uma posição central. 


\subsection{CPGs na Atualidade}

Entre os feitos descritos em 1.1 e a retomada dos trabalhos na área, temos um hiato da ordem de 50 anos. Coube a Anders Lundberg, em 1965, na Sharpey-Schäfer lecture, apresentar formalmente à comunidade científica seus achados ${ }^{89}$, os quais davam suporte celular a teoria dos half-centres. Enquanto Lundberg e sua equipe investigavam o controle da circuitaria espinal descendente, pelas vias monaminergicas, noradrenergicas e serotoninergicas, em gatos espinalados, perceberam que, ao tratar os animais com L-DOPA (L-3,4-di-hidroxifenil-alanina) ${ }^{10}$, aferentes de alto limiar eram capazes de disparar eventos de contração muscular (Jankowska et al., 1967). Esses aferentes foram batizados FRA - Flexor Reflex Afferents. Lundberg e seu grupo também foram capazes de revelar a existência de redes de inibição recíproca, entre inter-neurônios de vias relacionadas a flexão e extensão muscular. Por fim, comprovaram que, quando ambas as vias são estimuladas, padrões de flexão e extensão cíclicos são estabelecidos no animal. Isso trouxe de volta à tona a pesquisa sobre locomoção gerada espinalmente.

Por volta da mesma época, em 1961, Donald Wilson (Wilson, 1961), estudando o controle neural central do vôo de gafanhotos apresenta (grifo nosso):

\footnotetext{
${ }^{8}$ Já em 1957 Lundberg demonstrou interesse em estudar os half-centres de Graham Brown, durante sua festa de despedida do laboratório de John Eccles. O qual, diga-se de passagem, não era exatamente um defensor das idéias e métodos de Graham Brown (Stuart and Hultborn, 2008).

${ }^{9}$ No mesmo ano Lundberg realizou mais duas apresentações em simpósios, Suécia e França, além de um workshop de 5 dias na extinta URSS, juntamente com o engenheiro Erling Eide(Stuart and Hultborn, 2008).

${ }^{10}$ Precursor de catecolaminas, moléculas envolvidas na interação neural.
} 
"Eliminating sensation from the wing and motor innervation of the dorsal longitudinal muscles has the definite effect of lowering the frequency of the wing-beat cycle. [...] This reduction of input did not, however, upset the basic pattern of wing movements including wing twisting and segmental phase differences. This surprising result led to the hypothesis of a built-in central pattern which is not dependent upon peripheral feedback loops for its basic operation, but which is modified by such input. This input apparently increases frequency as well as affecting small changes in pattern which control flight."

Donald M. Wilson, The central nervous control of flight in a locust.

Novamente temos um desenho experimental apresentando evidências de um controle central. Os trabalhos de Wilson e sua equipe levaram, assim, a cunhar o termo Central Pattern Generator em artigo de 1965 (Wilson and Wyman, 1965), originalmente na forma Central Nervous Pattern Generator. A partir dai o caminho foi buscar, em outros filos, circuitos neurais geradores de ritmos a fim de comprovar se esse mecanismo era, de fato, preservado ao longo da filogenia.

Revelaram-se uma infinidade de circuitos com características de CPGs, em animais como insetos, moluscos e crustáceos (Wolf and Pearson, 1987; Pearson and Wolf, 1987; Wilson, 1961; Wilson and Wyman, 1965; Cacciatore et al., 2000), todos sendo estudados sob a perpectiva de movimentos cíclicos recorrentes em detrimento, obviamente, de movimentos episódicos. O uso do sistema motor oferece a vantagem de evitar as questões de como a informação sensorial é codificada por neurônios e/ou por populações deles (Selverston, 2010). Lembrando que as pesquisas na área tiveram início com o uso de mamíferos (gatos principalmente, além de porquinhos da índia e coelhos) como seu animal modelo, a brusca mudança para animais ditos "inferiores" deve-se, segundo Selverston (Selverston, 2010) a: 
- podermos localizar todos os neurônios que compoẽm o CPG;

- conhecer a natureza das entradas que o circuito $\mathrm{CPG}$ recebe;

- conhecer o comportamento qualitativo e quantitativo das saídas e para quais músculos ou órgãos efetores estão direcionadas;

- mapear o circuito de forma a sermos capazes de estimular e gravar a resposta de dois ou mais neurônios específicos, repetidamente, e

- sermos capazes de observar atividades de sub limiar e spikes.

Através do uso de animais "inferiores", diferentes grupos de pesquisa foram capazes de mapear, com grande nível de detalhe, cada um dos neurônios presentes na rede, os tipos de canais expressos em suas membranas (e, portanto, quais correntes iônicas afetam seus potenciais) e suas conexões sinápticas. A figura 1.5 apresenta alguns exemplos de redes que foram, e continuam sendo, amplamente estudadas. Importante observar que todas essas redes estão relacionadas a sistemas motores - figuras $1.5 \mathrm{~b}$ e $1.5 \mathrm{c}$ ou, ao menos, ativação muscular, como nos casos de circuitos cardíacos - figuras 1.5a e 1.5e e circuitos de alimentação - figuras 1.5d, 1.5f e 1.5g. A peculiaridade desse desenho experimental, focado em sistemas motores, reside no que se batizou de fictive motor pattern ${ }^{11}$. Qual a melhor forma de testar se um pedaço do sistema nervoso é intrinsecamente capaz de gerar padrões motores ritmicos? Removendo-o cirurgicamente do animal e colocando-o em um banho adequado. Dessa forma, não há vias sensoriais remanscentes, tão pouco informações temporais vindas do ambiente. Além disso, os circuitos apresentado na figura 1.5 possuem a característica de que os motoneurônios, em sua esmagadora maioria, são parte do circuito CPG. Conclusão, estando o CPG ativo, gerando sinalização ritmica, esta estaria relacionada à movimentação de um determinado músculo (ou conjunto de músculos), caso o(s) mesmo(s) ainda estivesse(m) presente(s).

\footnotetext{
${ }^{11} \mathrm{Em}$ algumas literaturas também referido, apenas, como fictive pattern.
} 


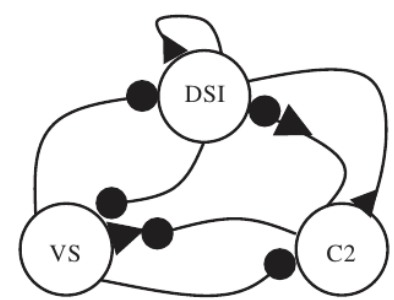

(a) Gânglio cardíaco da lagosta

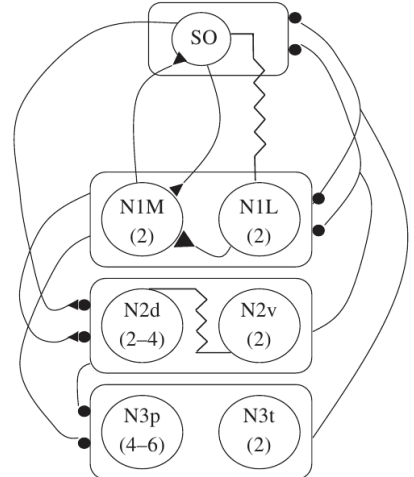

(d) Circuito de alimentação de Lymnaea sanguessuga

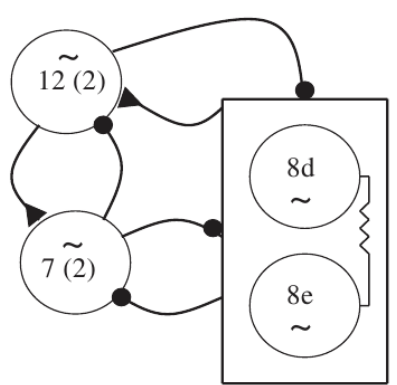

(c) Circuito natatório de Clione

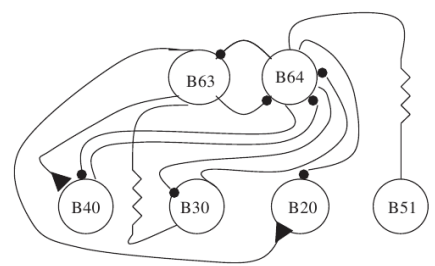

(e) Circuito cardíaco da (f) Circuito de alimentação da aplísia

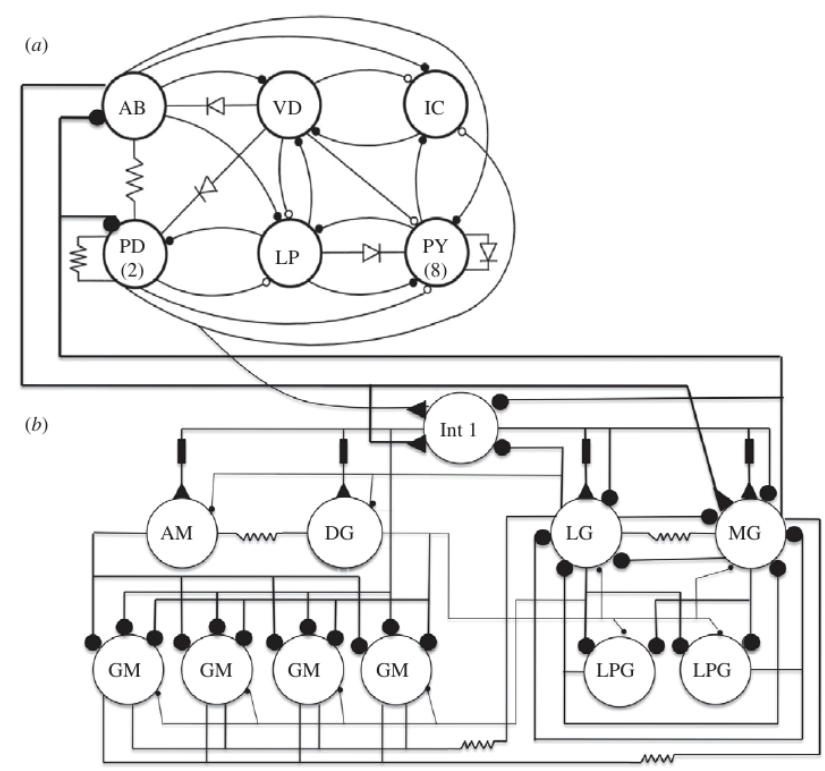

(g) Circuito stomatogástrico da lagosta

Figura 1.5: Alguns exemplos de circuitos de CPGs em invertebrados. Círculos cheios representam sinapses inibitórias, equanto triângulos cheios representam sinapses excitatórias. A presença dos dois símbolos em uma dada conexão (como na figura b), indicam sinapses que podem assumir os dois comportamentos. Símbolos de diodos indicam sinapses do tipo retificadoras e resistores do tipo elétricas. indicam neurônios com propriedades de disparo intrínsecas - intrinsic burst. Por fim, os números, quando entre parênteses, indicam a quantidade de neurônios do tipo dado pelo respectivo nome. Adaptado de (Selverston, 2010) 
Embora seja indubitável o ganho de conhecimento que se obteve com as descrições supracitadas, o seu campo de ação já fora muito bem delimitado. Isto é, nos fornecer uma descrição anatômica munida de informações

\subsection{Posicionamento da Pesquisa}

A busca por princípios básicos de funcionamento, intitulados, por Getting, princípios emergentes (Getting, 1989; Grillner et al., 2000), tem se tornado cada vez mais importante em neurociência. Especificamente na área de controle motor estamos observando uma mobilização interdisciplinar intensa, na busca por uma convergência que vai desde o laboratório até as ferramentas teóricas, passando por robótica, próteses e órteses. Questões como a comprovação da existência de centros geradores de padrão (CPGs) em mamíferos (Gordon and Whelan, 2006; Kiehn, 2006), o seu papel na locomoção, seja ela terrestre (bípede, quadrúpede e demais) (Cruse et al., 2007; Prochazka and Yakovenko, 2007; Stein, 2005), aquática (Grillner, 2006) ou aérea (Wolf and Pearson, 1989, 1987; Pearson and Wolf, 1987; Wilson, 1961; Wilson and Wyman, 1965), nos diversos filos e a unificação das plataformas de simulação neural já maduras (Davison et al., 2008; Eppler et al., 2008; Brette et al., 2007) têm impulsionado as pesquisas nessa área.

Porém, existe uma lacuna ainda pouco questionada. Busca-se por uma arquitetura dos CPGs quase que exclusivamente de forma comparativa. Obtêm-se descrições exaustivas das redes neurais nos animais ditos inferiores (Hooper and DiCaprio, 2004) e busca-se por "arquiteturas derivadas" nos ditos superiores, parecendo certo existirem mecanismos para estabelecer padrões rítmicos como respiração e locomoção, por exemplo. No outro extremo temos as simulações em larga escala. Redes neurais compostas por até centenas de milhares de nós (células), buscam desvendar o funcionamento do cérebro como um todo. Mas como que a estrutura baseada nos CPGs é capaz de estabelecer uma passada com mínimo de gasto metabólico? Como otimiza variáveis mecânicas 
como força ou trabalho? Existe algum mecanismo, algum princípio básico em redes que oscilam, capaz de mapear um mínimo de uma grandeza física externa em algum outro mínimo interno a rede? Na tentativa de responder a essas questões, viabilizamos uma plataforma de simulação de redes de pequena escala, capazes de mimetizar as redes reais já descritas, mas com a capacidade de inserção de ferramentas de medida, de forma a obter uma plataforma in silico para busca por princípios básicos relativos a essas estruturas. 



\section{Capítulo 2}

\section{Bases Matemáticas e}

\section{Computacionais}

\subsection{Uma Taxonomia dos Modelos Neurais}

Após os estudos clássicos realizados por Hodking e Huxley no axônio gigante de lula, estes apresentaram em um de seus diversos trabalhos publicado em 1952 (Hodgkin and Huxley, 1952) uma descrição quantitativa das correntes de membrana, e o seu efeito no estabelecimento do potencial de repouso e potencial de ação na membrana. Esse trabalho resultou no primeiro modelo matemático da membrana neural, conforme apresentado na Figura 2.1.

As baterias representam os potenciais de equilíbrio ${ }^{1}$ de cada um dos íons considerados no modelo (sódio, potássio e vazamento, leakage, - principalmente cloreto). As resistências, hoje mais comumente representadas por condutâncias $\left(R=\frac{1}{g}\right)$, modelam a resistência criada pela membrana à passagem da corrente iônica. $\mathrm{O}$ capacitor insere o efeito da distribuição espacial das cargas elétricas ao redor das superfícies interna e

\footnotetext{
${ }^{1}$ Calculado, para cada um dos íons, através da equação de Nernst $E_{E q, x}=\frac{R T}{z F} \ln \left(\frac{[x]_{o}}{[x]_{i}}\right)$. Onde $x$ representa um íon qualquer e $o$ e $i$ indicam concentrações dos meios externo e interno à membrana, respectivamente.
} 


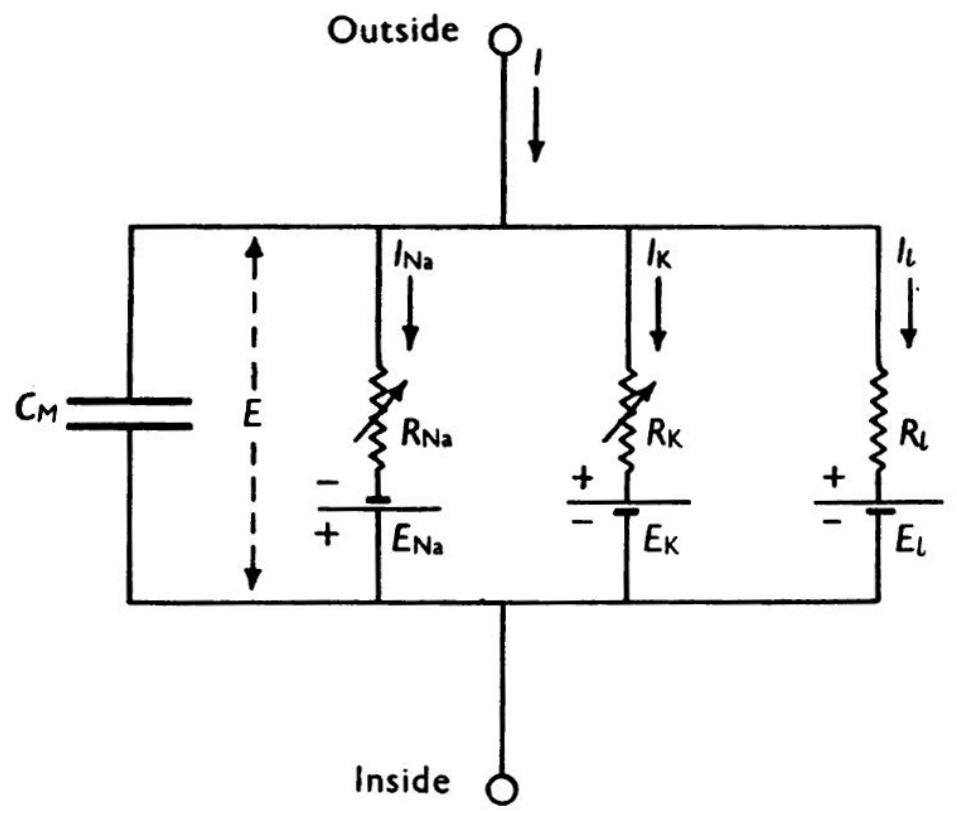

Figura 2.1: Circuito elétrico representando a membrana celular neuronal. Atente para a existência de resistências variáveis. Maiores detalhes no texto. Retirado de (Hodgkin and Huxley, 1952)

externa da membrana e, portanto, a criação de um campo elétrico através da mesma.

Uma das características mais interessantes desse modelo reside nas duas resistências variáveis apresentadas na Figura 2.1. Elas indicam que a dificuldade imposta pela membrana à passagem das correntes de sódio e potássio variam ao longo do tempo. Foi justamente o estudo dessa dinâmica que levou Hodgkin e Huxley a propor os famosos termos, $m, n$ e $h$ de suas equações que, posteriormente, seriam relacionados com o que hoje conhecemos por canais iônicos.

Matematicamente podemos representar esse modelo pelo seguinte conjunto de equações diferenciais:

$$
\begin{gathered}
I=C_{m} \frac{d V_{m}}{d t}+\bar{g}_{K} n^{4}\left(V-V_{K}\right)+\bar{g}_{N a} m^{3} h\left(V-V_{N a}\right)+\bar{g}_{L}\left(V-V_{L}\right) \\
\frac{d x}{d t}=\alpha_{x}(1-x)-\beta_{x} x, \quad x=m, n, h
\end{gathered}
$$


Juntamente com:

$$
\begin{aligned}
\alpha_{n}\left(V_{m}\right) & =\frac{0.01\left(10-V_{m}\right)}{e^{\frac{10-V_{m}}{10}}-1} \\
\beta_{n}= & 0.125 e^{\frac{-V_{m}}{80}} \\
\alpha_{m}\left(V_{m}\right) & =\frac{0.1\left(25-V_{m}\right)}{e^{\frac{25-V_{m}}{10}}-1} \\
\beta_{m} & =4 e^{\frac{-V_{m}}{18}} \\
\alpha_{h} & =0.07 e^{\frac{-V_{m}}{20}} \\
\beta_{h}\left(V_{m}\right) & =\frac{1}{e^{\frac{30-V_{m}}{10}}+1}
\end{aligned}
$$

Seguindo a evolução no estudo sobre canais iônicos, alterações no modelo anteriormente descrito puderam ser realizadas, de forma a moldar o conceito geral estabelecido por Hodgkin e Huxley para explicar casos particulares como, por exemplo, o platô no disparo das células cardíacas ${ }^{2}$ e a atividade espontânea de certas regiões cardíacas ${ }^{3}$ (nodo sino-atrial, nodo atrio-ventricular e fibras de Purkinje) (Luo and Rudy, 1991; DiFrancesco and Noble, 1985).

Mesmo após tamanho sucesso, com a extensão do modelo para formas com mais de duas dezenas de correntes iônicas diferentes, o modelo de Hodgkin e Huxley continua de difícil utilização intensiva em simulações. $\mathrm{O}$ porquê desse fato reside basicamente em duas características: aumento de escala em simulações e insight sobre os processos básicos envolvidos.

O primeiro obstáculo tornou-se claro com o advento da computação eletrônica. A simulação do conjunto de equações diferenciais obtido por Hodgkin e Huxley é com-

\footnotetext{
${ }^{2}$ Devido as correntes de cálcio que equilibram o efeito das correntes de potássio.

${ }^{3}$ Baseada na operação da funny current $\left(I_{f}\right.$ ou $\left.I_{K f}\right)$. Corrente através de um canal não seletivo de sódio e potássio, de lenta ativação causada por hiperpolarização.
} 
putacionalmente custosa. Esse fato não representa sério impedimento quando estamos estudando uma célula isolada ou, até mesmo, um pequeno número de unidades, mas torna proibitivo realizar simulações de larga escala com centenas, milhares ou até mesmo milhões de células, chegando a bilhões de sinapses. Portanto, embora o modelo de Hodgkin e Huxley apresente quase a totalidade dos diversos comportamentos observado nas diferentes células neurais, seu uso fica praticamente restrito a sistemas computacionais paralelizados de alto desempenho. Esse é o caso, por exemplo, dos simuladores SNNS (Stuttgart Neural Network Simulator) e SPLIT (Hammarlund and Ekeberg, 1998) ${ }^{4}$.

A criação de modelos simplificados que por muitas vezes não possuem correlação direta com variáveis ou processo físico-químicos, mas que guardam, mesmo que de uma forma caricaturada, alguns dos comportamentos dos neurônios, foi o caminho natural para possibilitar simulações em larga escala. Um excelente resumo, relacionando o custo computacional e as características apresentadas por diversos modelos (Izhikevich, 2004), é apresentado na Figura 2.2. Segundo o autor, o modelo de Hodgkin e Huxley pode apresentar 19 comportamentos distintos como, por exemplo, disparos unitários, salvas, adaptação de frequência de disparos e até mesmo caos. Porém isso custa 1200 FLOPS! FLOPS, Floating point Operations Per Second (Operações de Ponto Flutuante por Segundo), é um número que expressa a quantidade de operações (somas, multiplicações e etc) executadas pelo processador de um computador, ou seja, fornece uma aproximação do custo computacional envolvido. Comparativamente, um modelo mais simples, conhecido como modelo de integração e disparo, tem custo de apenas 5 FLOPS, mas é capaz de apresentar apenas 3 comportamentos diferentes em sua dinâmica.

Além do ganho em escala nas simulações, a adoção de modelos simplificados permite um estudo teórico mais aprofundado dos processos básicos envolvidos na dinâmica

\footnotetext{
${ }^{4}$ Existem outros exemplos como os sistemas paralelos NEST, NCS e PCSIM. Até mesmo arquiteturas híbridas de hardware e software, com o modelo de Hodgkin e Huxley implementado em silício (ASIC) (Zou et al., 2006) e utilização de processamento numérico em placas gráficas (GPU) () (Neurdon, 2010) foram realizadas.
} 


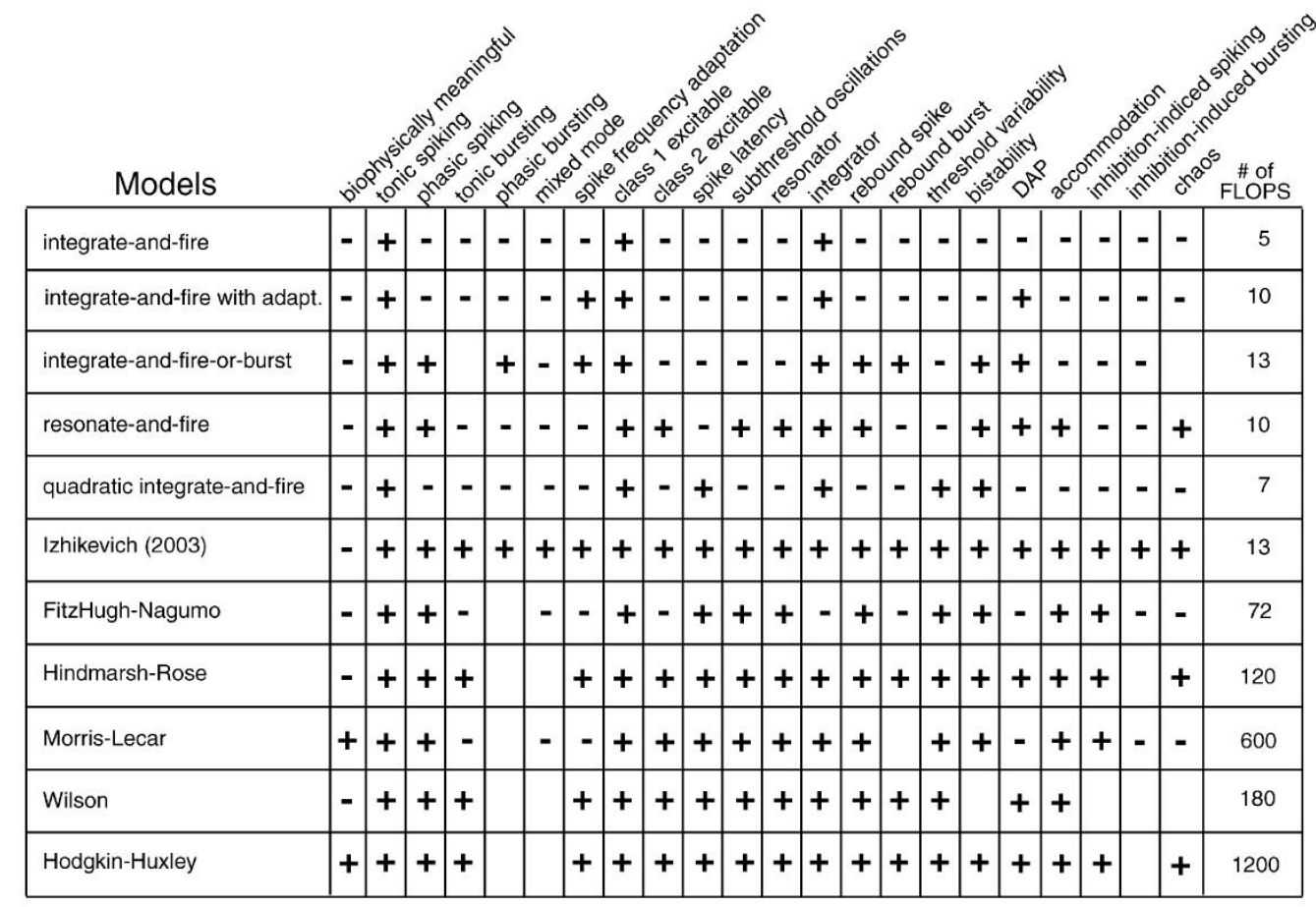

Figura 2.2: Resumo das propriedades apresentadas por 11 modelos de neurônios. A última coluna é uma medida do número de operações em ponto flutuante (adições, multiplicações e etc.), utilizadas durante $1 \mathrm{~ms}$ de simulação. Quadrados vazios indicam uma característica que o modelo deveria exibir (ao menos em teoria), mas que o autor não foi capaz de, em prazo razoável, estabelecer os parâmetros do mesmo para tal. Atente para para o custo dos dois modelos que apresentam correlação biofísica direta. Retirado de (Izhikevich, 2004). 
neural, isto é, quais as estruturas mínimas que devem estar presentes para que certo comportamento se estabeleça. Izhikevich (Izhikevich, 2007) mostra que é possível reduzir modelos baseados em condutância (Hodgkin e Huxley, por exemplo), em uma estrutura mínima baseada em dois tipos de correntes iônicas, correntes amplificadoras e ressonantes. Esse conjunto pode ser obtido através de diferentes combinações de correntes iônicas como: $I_{N a, p}+I_{K}, I_{N a, t^{5}}, I_{N a, p}+I_{h}, I_{h}+I_{K i r}$ e, até mesmo, o desafiador par, $I_{K}+I_{K i r}$.

FitzHugh também advogava a favor da simplificação, grifo nosso (FitzHugh, 1969):

"For some purposes it is useful to have a model of an excitable membrane that is mathematically as simple as possible, even if experimental results are reproduced less accurately. Such a model is useful in explaining the general properties of membranes, and as a pilot model for performing preliminary calculations."

Richard FitzHugh, Mathematical models of excitation and propagation

in nerve

Ao projetar o espaço de estados do modelo de Hodgkin e Huxley (de dimensão $4)^{6}$ em outro de dimensão 2, FitzHugh e Nagumo observaram que a geometria dessa projeção era equivalente ao espaço de estados obtido pelas equações conhecidas como modelo BVP (Bonhoeffer-van der Pol) o qual, por sua vez, é uma generalização das equações de van der Pol para osciladores de relaxação.

A redução no número de dimensões dos $\operatorname{modelos}^{7}$ (?FitzHugh, 1969; ?), permitiu mostrar estruturas físicas distintas sendo regidas por um mesmo princípio básico, ou seja, tem-se ganho real de conhecimento sobre os princípios básicos de funcionamento que permeiam diferentes sistemas e, não só, uma descrição desse funcionamento, sistema

\footnotetext{
${ }^{5} \mathrm{O}$ par, aparentemente faltante nesse caso, é composto por correntes de vazamento (leak currents).

${ }^{6}$ Hodgkin e Huxley de dimensão 4, V, m, n e h, e FitzHugh e Nagumo de dimensão 2.

${ }^{7}$ Morris e Lecar, também, de dimensão 2.
} 
a sistema.

O ápice da simplificação é atingido quando reduzimos a célula neural a um dispositivo gerador de spikes. Um centro integrador de sinapses pondera as entradas e, atingido o nível de disparo, gera o evento, i. e., o spike. Esse é o caso dos modelos de integração e disparo e seus derivados, tendo estes aparecido como resposta contra uma simplificação extrema daquele. Suas características são apresentadas na Figura 2.2 (Izhikevich, 2004) e enquanto os modelos derivados pretendiam modelar redes biologicamente reais, os primeiros especiaram-se no que hoje conhecemos como Redes Neurais Artificiais (ANNs do inglês). As ANNs tornaram-se um objeto de estudo completamente diferente das Redes Neurais Biologicas (BNNs, também do inglês). As primeiras ganharam todo um arcabouço teórico próprio, com algorítimos de "aprendizado" e arquiteturas específicas, que tiveram (e continuam tendo) enorme sucesso em áreas como reconhecimento de padrões e controle. As últimas possuem como característica primária o compromisso entre simulação do comportamento mais próximo possível de neurônios reais, com a representação computacionalmente menos custosa. O termo BNN se confunde na literatura com as chamadas SNNs (Spike Neural Networks). As SNNs são redes que tem como princípio estudar a propagação e integração da informação codificada nos disparos das células neurais, independentemente de se ocupar, ou não, dos processos físicoquímicos por trás da geração dos disparos, Brette e colaboradores apresentam excelente revisão sobre os simuladores e padronizações sendo desenvolvidos pela comunidade científica (Brette et al., 2007).

Portanto, não se trata da questão do grau de simplificação do modelo, a qual não desmerece, necessariamente, uma dada arquitetura de rede neural. Isso depende, obviamente, do problema sendo atacado pela arquitetura em questão. Trata-se da possibilidade de obter a emergência de princípios básicos, caso existam, envolvidos no processo. Ora, uma vez sendo possível simplificar um modelo e, ainda assim, manter um determinado nível de correspondência biológica sem perder a capacidade de gener- 
alização das conclusões obtidas, nos valeremos desse racional para investigar a seguinte questão: dada uma rede neural, esta é capaz de refletir a minimização de uma grandeza física externa, como força ou trabalho, por exemplo, em minimização de alguma variável interna, como entropia termodinâmica ou quantidade de informação circulante?

Isto posto, no capítulo 3, apresenta-se a infraestrutura computacional que foi desenvolvida para responder à questão proposta. Antes, porém, vejamos o formalismo matemático necessário para o processamento numérico do sistema de equações diferenciais proposto por Hodgkin e Huxley.

\subsection{Formalismo Matricial do Sistema EDO}

Reorganizando as equações 2.1 e 2.2, temos que o modelo de Hodgkin \& Huxley fica com as seguintes equações diferenciais, representando as variações do potencial de membrana $V_{m}$, e das variáveis de estado relacionadas aos canais de $N_{a}$ e $K, \mathrm{~m}, \mathrm{~h}$ e n:

$$
\begin{gathered}
\frac{d V_{m}}{d t}=\underbrace{-\frac{1}{C_{m}}\left(\bar{g}_{N a} m^{3} h+\bar{g}_{K} n^{4}+\bar{g}_{L}\right)}_{a_{11}} V_{m}+\underbrace{\frac{1}{C_{m}} \bar{g}_{N a} m^{3} E_{N a}}_{a_{13}} h+\underbrace{\frac{1}{C_{m}} \bar{g}_{K} n^{3} E_{K}}_{a_{14}} n \\
+\underbrace{\frac{1}{C_{m}} \bar{g}_{L} E_{L}}_{b_{11}}+\underbrace{\frac{1}{C_{m}} I_{e x t}}_{c_{11}} \\
\frac{d m}{d t}=\underbrace{-\left(\alpha_{m}\left(V_{m}\right)+\beta_{m}\left(V_{m}\right)\right) m}_{a_{22}}+\underbrace{\alpha_{m}\left(V_{m}\right)}_{b_{21}} \\
\frac{d h}{d t}=\underbrace{-\left(\alpha_{h}\left(V_{m}\right)+\beta_{h}\left(V_{m}\right)\right) h}_{a_{33}}+\underbrace{\alpha_{h}\left(V_{m}\right)}_{b_{31}} \\
\frac{d n}{d t}=\underbrace{-\left(\alpha_{n}\left(V_{m}\right)+\beta_{n}\left(V_{m}\right)\right) n}_{a_{44}}+\underbrace{\alpha_{n}\left(V_{m}\right)}_{b_{41}}
\end{gathered}
$$


O que nos leva à seguinte representação matricial da equação vetorial $\dot{\mathbf{y}}=\mathbf{A y}+\mathbf{B}+\mathbf{C}$, para um neurônio:

$$
\left(\begin{array}{c}
\dot{V}_{m} \\
\dot{m} \\
\dot{h} \\
\dot{n}
\end{array}\right)=\left(\begin{array}{cccc}
a_{11} & 0 & a_{13} & a_{14} \\
0 & a_{22} & 0 & 0 \\
0 & 0 & a_{33} & 0 \\
0 & 0 & 0 & a_{44}
\end{array}\right)\left(\begin{array}{c}
V_{m} \\
m \\
h \\
n
\end{array}\right)+\left(\begin{array}{c}
b_{11} \\
b_{21} \\
b_{31} \\
b_{41}
\end{array}\right)+\left(\begin{array}{c}
c_{11} \\
0 \\
0 \\
0
\end{array}\right)
$$

A equação 2.13 engloba toda a dinâmica da célula e o efeito de possíveis correntes externas, mas ainda não contempla eventuais sinapses que o neurônio possa receber de outros neurônios da rede. Para tal, iremos adicionar mais termos a equação, tantos quanto forem o número de células da rede menos 1 . Isto pois não considerar-se-a nenhuma forma de auto-excitação o que, em termos de simulação, poderia ser obtido através de uma "auto-sinapse". As matrizes sinápticas seguirão a seguinte nomenclatura:

$$
\left(\begin{array}{c}
I_{\text {syni,j }} \\
0 \\
0 \\
0
\end{array}\right)
$$

Onde $I_{s y n i, j}$ significa uma sinapse proveniente do neurônio $i$ para o neurônio $j$, com $i \neq j$. Além disso, de forma a simplificar a notação futura da equação matricial para rede, renomearemos as matrizes segundo apresentado no seguinte exemplo, para o neurônio de índice $i=1$ : 


$$
\begin{aligned}
& \overbrace{\left(\begin{array}{c}
\dot{V}_{m} \\
\dot{m} \\
\dot{h} \\
\dot{n}
\end{array}\right)}^{[\mathrm{DER}]}=\overbrace{\left(\begin{array}{cccc}
a_{11} & 0 & a_{13} & a_{14} \\
0 & a_{22} & 0 & 0 \\
0 & 0 & a_{33} & 0 \\
0 & 0 & 0 & a_{44}
\end{array}\right)}^{[\mathrm{DIN}]} \overbrace{\left(\begin{array}{c}
V_{m} \\
m \\
h \\
n
\end{array}\right)}^{[\mathrm{VAR}]}+\overbrace{\left(\begin{array}{c}
b_{11} \\
b_{21} \\
b_{31} \\
b_{41}
\end{array}\right)}^{[\mathrm{IND}]}+\overbrace{\left(\begin{array}{c}
c_{11} \\
0 \\
0 \\
0
\end{array}\right)}^{[\mathrm{IEXT}]} \\
& +\underbrace{\left(\begin{array}{l}
0 \\
0 \\
0
\end{array}\right)}_{\left[\operatorname{ISIN}_{1,1}\right]}+\underbrace{\left(\begin{array}{c}
I_{\text {syn } 2,1} \\
0 \\
0 \\
0
\end{array}\right)}_{\left[\operatorname{ISIN}_{2,1}\right]}+\underbrace{\left(\begin{array}{c}
I_{\text {syn } 3,1} \\
0 \\
0 \\
0
\end{array}\right)}_{\left[\operatorname{ISIN}_{3,1}\right]}+\ldots+\underbrace{\left(\begin{array}{c}
I_{\text {synn }, 1} \\
0 \\
0 \\
0
\end{array}\right)}_{\left[\operatorname{ISIN}_{n, 1}\right]}
\end{aligned}
$$

Para uma rede, composta por $n$ neurônios:

$$
\begin{aligned}
& \left(\begin{array}{c}
{\left[\mathrm{DER}_{1}\right]} \\
{\left[\mathrm{DER}_{2}\right]} \\
\vdots \\
{\left[\mathrm{DER}_{n}\right]}
\end{array}\right)=\left(\begin{array}{cccc}
{\left[\mathrm{DIN}_{1}\right]} & & & 0 \\
& {\left[\mathrm{DIN}_{2}\right]} & & \\
& & \ddots & \\
0 & & & {\left[\mathrm{DIN}_{n}\right]}
\end{array}\right)\left(\begin{array}{c}
{\left[\mathrm{VAR}_{1}\right]} \\
{\left[\mathrm{VAR}_{2}\right]} \\
\vdots \\
{\left[\mathrm{VAR}_{n}\right]}
\end{array}\right)+\left(\begin{array}{c}
{\left[\mathrm{IND}_{1}\right]} \\
{\left[\mathrm{IND}_{2}\right]} \\
\vdots \\
{\left[\mathrm{IND}_{n}\right]}
\end{array}\right)+\left(\begin{array}{c}
{\left[\mathrm{IEXT}_{1}\right]} \\
{\left[\mathrm{IEXT}_{2}\right]} \\
\vdots \\
{\left[\mathrm{IEXT}_{n}\right]}
\end{array}\right) \\
& +\left(\begin{array}{c}
{[0]} \\
{\left[\operatorname{ISIN}_{1,2}\right]} \\
\vdots \\
{\left[\operatorname{ISIN}_{1, n}\right]}
\end{array}\right)+\left(\begin{array}{c}
{\left[\operatorname{ISIN}_{2,1}\right]} \\
{[0]} \\
\vdots \\
{\left[\operatorname{ISIN}_{2, n}\right]}
\end{array}\right)+\ldots+\left(\begin{array}{c}
{\left[\operatorname{ISIN}_{n, 1}\right]} \\
{\left[\operatorname{ISIN}_{n, 2}\right]} \\
\vdots \\
{[0]}
\end{array}\right)
\end{aligned}
$$

Onde [0] significa uma matriz nula. 


\section{Capítulo 3}

\section{Desenvolvimento da}

\section{Infraestrutura Computacional}

\subsection{Infraestrutura Computacional}

Após testes realizados em ambiente Matlab e nos simuladores Neuron e Genesis, o primeiro foi descartado por não suportar, em tempo de simulação aceitável, modelos como os Hodgkin e Huxley e FitzHugh e Nagumo (com algumas unidades neurais) em conjunto com equações modelando algum processo mecânico. Os dois últimos, ferramentas mais voltadas para simulação de modelos neuronais de múltiplos compartimentos ${ }^{1}$, foram excluídos não apenas pela codificação extra necessária para a realização de certas simulações, mas também pelo trabalho adicional de exportar resultados para serem analisados em outros programas e maior dificuldade em integrar ferramentas próprias para análise, por exemplo, entropia aproximada volumétrica, vApen e outras não existentes nos programas como plot de Poincaré.

Uma vez que codificação extra mostrou-se necessária e mais, de forma numericamente eficiente, a opção restringiu-se a uma linguagem de programação de mais baixo nível, e.

\footnotetext{
${ }^{1}$ Mas que também podem ser utilizados para modelos de um compartimento e em grande escala.
} 
g., Fortran, C, C++ ou Java. Em ciência da computação existem dois tipos básicos de linguagens de programação. As ditas compiladas e as interpretadas. Enquanto o primeiro tipo deve ser compilado, ou seja, transformado em um programa propriamente dito, de forma hardware/sistema operacional dependente, o último necessita das chamadas máquinas virtuais (esse é o caso de linguagens como Java, Python, Perl, entre outras) e são independentes da plataforma de hardware/sistema operacional ${ }^{2}$. Pelo fato de haver mais uma camada, o interpretador, entre o sistema operacional e o programa em si, as linguagens interpretadas são mais lentas e, por esse motivo, menos utilizadas para computação numérica.

Exceção a esse fato é a linguagem Python. Embora sendo interpretada, essa linguagem fortemente orientada a objetos foi criada de forma a permitir, muito facilmente, a inserção de programas escritos em outras linguagens, em uma arquitetura de software baseada em Python. Ou seja, tarefas de alta demanda numérica podem ser delegadas a programas escritos em $\mathrm{C}$ ou Fortran (as linguagens mais rápidas no universo da computação numérica). Assim, nasceram o NumPy, o SciPy e diversas outras bibliotecas em Python voltadas à computação científica. Além disso, essas bibliotecas tornam a sintaxe da linguagem extremamente próxima à sintaxe do ambiente Matlab, agilizando a curva de aprendizagem. Não menos importante, a biblioteca Matplotlib permite a geração de imagens de altíssima qualidade gráfica e, ainda no campo da visualização de dados, criar interfaces gráficas (GUIs) em Python é mais rápido em comparação à linguagem $\mathrm{C} / \mathrm{C}++$.

Especificamente na área de neurociência, temos uma interface para o sistema NEST em Python, o PyNEST (Eppler et al., 2008), e o PyNN uma interface comum de programação para múltiplos simuladores (Davison et al., 2008), o que aumenta a produtividade na criação, execução e análise de simulações em pequena ou larga escala.

\footnotetext{
${ }^{2}$ A dependência fica a cargo da máquina virtual, a qual é específica para cada plataforma.
} 


\subsection{Arquitetura de Software Proposta}

A Figura 3.1 apresenta a arquitetura proposta para o software de simulação e análise. Ela é composta por um núcleo de módulos já existentes na linguagem Python e módulos desenvolvidos por terceiros. Ela é composta, até o presente estágio de desenvolvimento, por 4 módulos, a saber:

- CModels: responsável pelas descrições dos modelos neurais de compartimento único;

- ConnNet: sistema para interconexão entre nós da rede. Gerencia quantidade e qualidade (e. g., peso e atraso) das sinapses;

- NLT: ferramentas de análise não lineares. Esse módulo possui partes de suas rotinas implementadas em linguagem $\mathrm{C} / \mathrm{C}++$, e

- IO: gerencia toda entrada e saída de dados, sejam eles em formato de texto ou na forma de figuras.

\subsubsection{Organização das Classes}

A seguir apresentaremos, brevemente, quais classes estão contidas em cada módulo, a fim de completar nossa descrição sobre o software de simulação que foi desenvolvido para esse projeto.

\section{Módulo CModels: Classe HH}

A classe HH, pertencente ao módulo CModels, permite simular neurônios que seguem as equações do modelo proposto por Hodgkin e Huxley (apresentadas na seção 2.1 Uma Taxonomia dos Modelos Neurais) para diversos tipos de estímulos. A Figura 3.2 apresenta dois casos de teste: estímulos de mesma duração e intensidades crescentes 3.2a e estímulos de diferente duração $3.2 \mathrm{~b}$. 


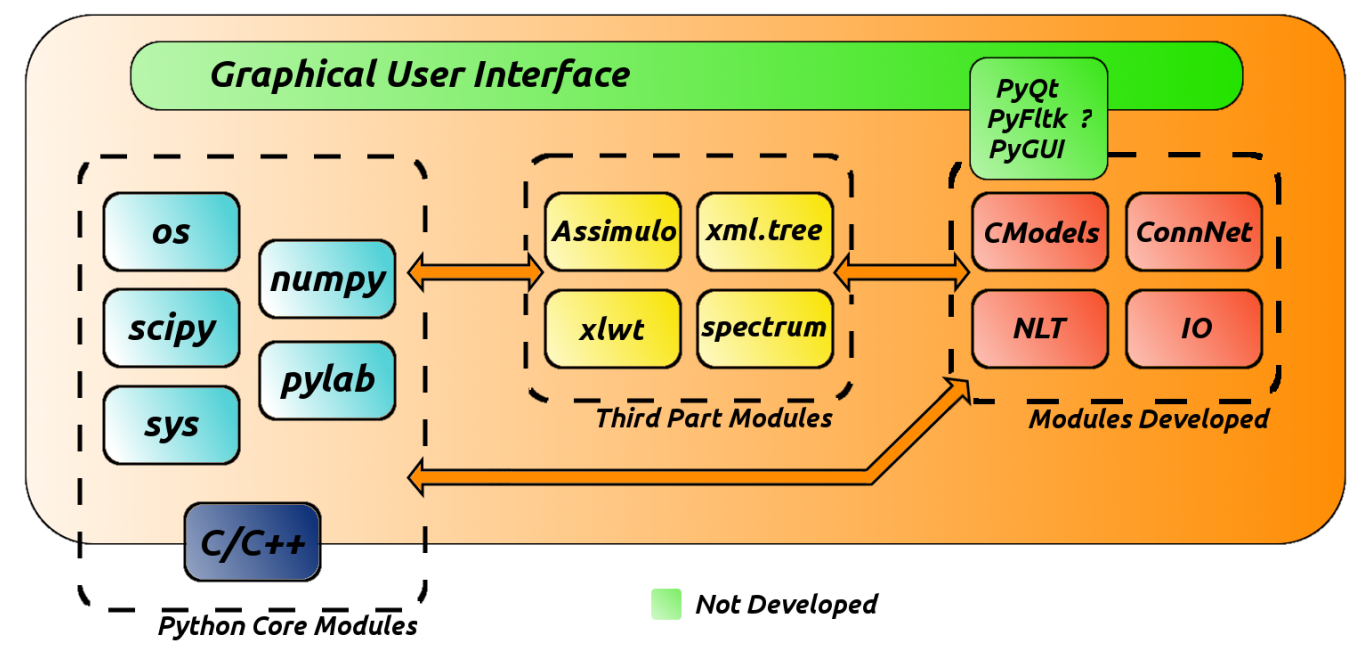

Figura 3.1: Arquitetura de software proposta. Módulos já existentes na linguagem Python, juntamente com blocos de código especificamente desenvolvidos. Interrogações referem-se a condições ainda não definidas. Maiores detalhes ao longo do texto.

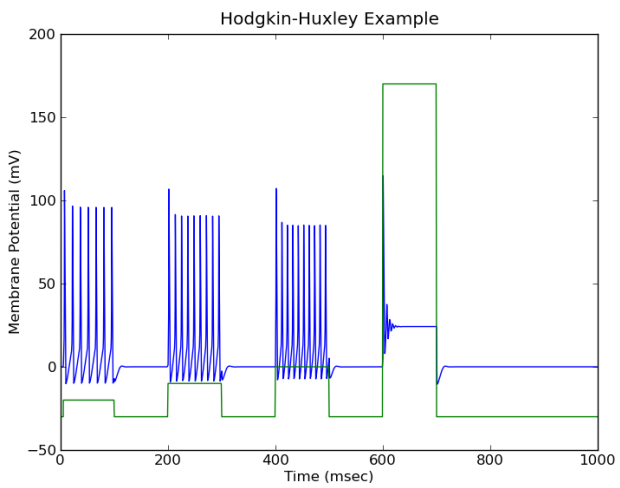

(a) Diferentes intensidades

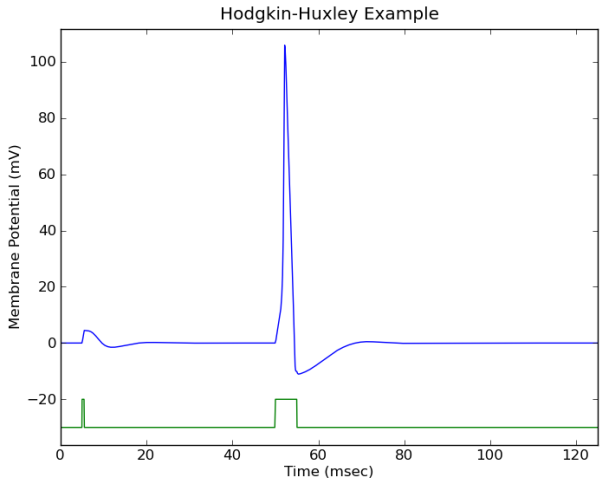

(b) Diferentes durações

Figura 3.2: Resultados de simulações (em azul) para estímulos (em verde) compostos por pulsos de mesma duração e diferentes intensidades, inclusive casos não fisiológicos, (a) e para estímulos de mesma intensidade e diferentes durações (b). Observe que a duração do primeiro estímulo em (b) não leva o neurônio ao limiar de disparo. 


\section{Módulo CModels: Classe LIF}

Também pertencente ao módulo CModels, a classe LIF (Leaky Integrate and Fire) é um dos modelos mais simples, apresentamos apenas, na Figura 3.3, o resultado de simulações preliminares, ainda sem a correção dos parâmetros $R C^{3}$, para que as escalas de corrente e tensão sejam da ordem de, respectivamente, nanoamperes e milivolts.

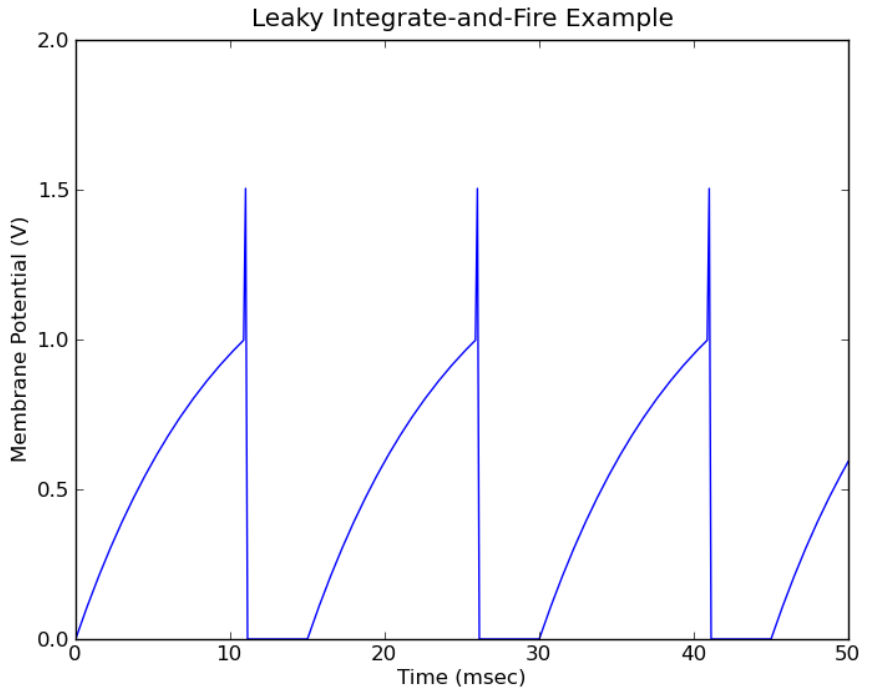

Figura 3.3: Modelo de Integração e Disparo com Vazamento (LIF). Observe as singularidades do modelo quando a carga do capacitor atinge a tensão de limiar, $1.0 \mathrm{~V}$ e, instantaneamente, é interrompida e substituída por um delta de Dirac, atingindo um valor pré-estabelecido, $1.5 \mathrm{~V}$, após o qual o sistema é levado através de nova singularidade à condição inicial de $0 \mathrm{~V}$.

\section{Módulo CModels: Classe mathTools}

É dentro da classe mathTools que se encontram todas as ferramentas de manipulação matemática necessárias às demais classes. Mais importante, é nela onde se concentram quase todos os métodos que manipulam as matrizes que serão disponibilizadas ao

\footnotetext{
${ }^{3}$ Lembrando que o modelo de Integração e Disparo e seus derivados, nos quais se inclui o modelo com vazamento LIF, são baseados nos circuitos elétricos clássicos de carga e descarga de capacitores através de cargas resistivas.
} 
módulo Assimulo (mais detalhes na seção 3.2.2), o solver utilizado para resolução numérica dos sistemas de equações diferenciais. O formalismo matricial apresentado em 2.2 é émputacionalmente obtido através das classes mathTools e $\mathrm{HH}$, que formatam a estrutura de rede, codificada nos arquivos descritivos XML (vide Classe xmlInterpreter), em matrizes a serem utilizadas pelo módulo Assimulo.

\section{Módulo ConnNet: Classe synapses}

Através da classe synapses associa-se, a cada tipo de sinapse (vide, como exemplo, a figura 4.3), suas caracterísitcas como nome, origem e destino e os modelos matemáticos específicos de seus tipos: elétrica, elétrica retificadora e química. As correntes póssinapticas das sinapses químicas são definidas via função alfa:

$$
I_{\alpha}=\frac{1}{\tau_{m}} \sum_{k} \sum_{j} w_{k} e^{-\frac{t-t_{j k}-d_{k}}{\tau_{m}}}
$$

Sendo:

$\tau_{m}$ uma constante de tempo que define a velocidade da resposta sináptica ${ }^{4}$

$w_{k}$ o peso da k-ésima sinapse que chega ao neurônio;

$t$ o tempo atual;

$t_{j k}$ o j-ésimo instante em que ocorreu um spike no neurônio pré-sináptico, associado a k-ésima sinapse, e

$d_{k}$ o atraso da k-ésima sinapse.

Enquanto as elétricas pela relação:

$$
I_{\text {syn }}=\bar{g}_{x}\left(V_{\text {mpost }}-V_{\text {mpre }}\right)
$$

\footnotetext{
${ }^{4} \mathrm{O}$ que pode ser utilizado para diferenciar entre respostas de receptores distintos como: GABA, NMDA e AMPA.
} 
Com:

$\bar{g}_{x}$ a máxima condutância de um canal x qualquer (conexina);

$V_{\text {mpost }}$ o potencial de membrana do neurônio pós-sinaptico, e

$V_{\text {pre }}$ o potencial de membrana de membrana do neurônio pós-sinaptico.

\section{Módulo ConnNet: Classe iSources}

O sistema é capaz de gerenciar fontes externas de corrente via classe iSources. É possível criar qualquer perfil de corrente que seja a soma, por partes, de diferentes funções de primeiro grau, como ilustra a figura 3.4. Nesse exemplo temos uma fonte formada por 3 subfontes $S_{1}, S_{2}$ e $S_{3}$. Cada subfonte possui 6 caracterísitcas, nome, qual neurônio alimenta, os coeficientes angular e linear da reta e os instantes em que "liga" e "desliga".

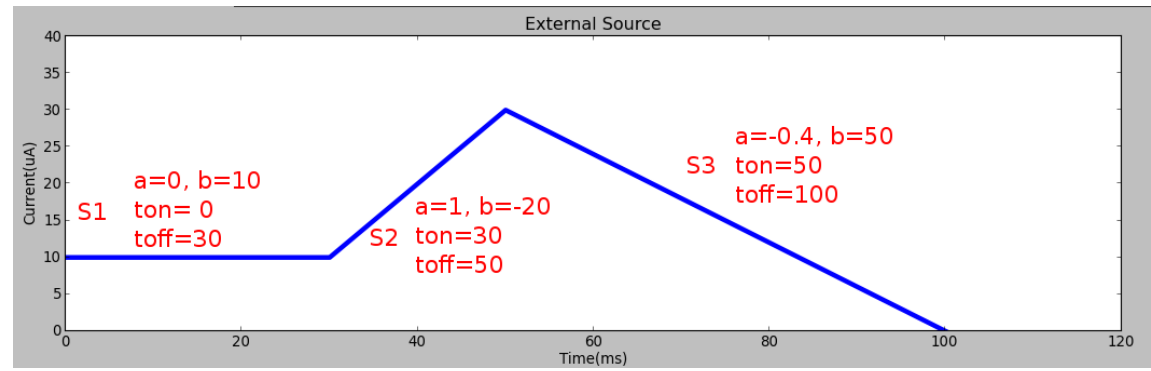

Figura 3.4: Exemplo de uma fonte de corrente externa, gerada pela classe iSources. Os trechos são formados por segmentos de reta definidos por 4 parâmetros: $a$, inclinação da reta, $b$, coeficiente linear da reta, e $t_{o n}$ e $t_{o f f}$, os instantes onde a fonte inicia e termina seu funcionamento.

A utilização de correntes externas tem, por principal função, alterar o estado dos osciladores condicionais, i. e., mimetizar a neuromodulação advinda de vias superiores.

\section{Módulo NLT: Classe vapen}

A classe vapen é a primeira ferramenta de análise não linear do módulo NLT. Desenvolvida em nosso laboratório (Santos et al., 2009), a ApEn Volumétrica (vApEn) é uma variação da análise criada por Pincus, chamada de Entropia Aproximada, ApEn. 
Durante estudos que realizamos com a análise de séries temporais criadas a partir de intervalos entre batimentos cardíacos (intervalo RR), pudemos perceber inconsistências no uso da ApEn. A partir de então passamos a estudar o método com, além dos sinais reais, séries temporais controladas geradas por computador. Propusemos, então, a vApEn como mecanismo de sobrepujar as fraquezas apresentadas pelo método original.

Utilizando a versão 2.7 da linguagem Python, juntamente com as bibliotecas NumPy e SciPy, obtivemos resultados que, em termos de velocidade de computação são equiparáveis ao Matlab, corroborando os dados de Lorenzo Bolla e Prabhu Ramachandran. A Figura 3.5 apresenta os dados obtidos por Bolla, que estendeu a análise original de Ramachandran, adicionando as informações referentes ao tempo de processamento em ambiente Matlab, juntamente com os resultados das nossas simulações. Importante frisar que Bolla e Ramachandran utilizaram a resolução de um sistema bidimensional de equações de Laplace, pelo método de Gauss-Seidel ou Gauss-Jordan, como base de comparação enquanto nós utilizamos o cálculo da ApEn Volumétrica (Santos et al., 2009).

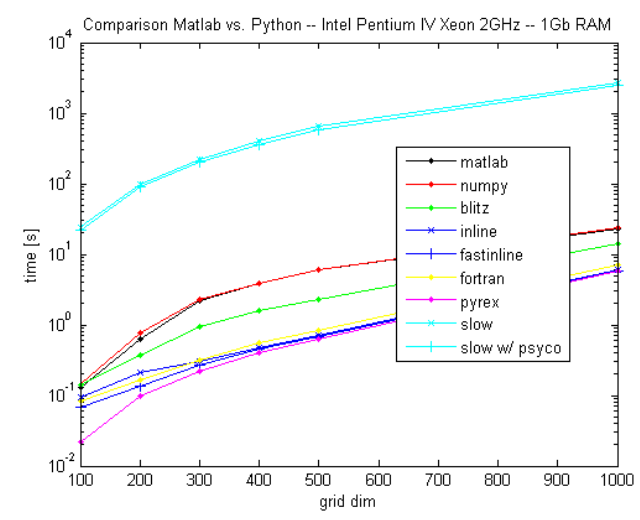

(a) Bolla

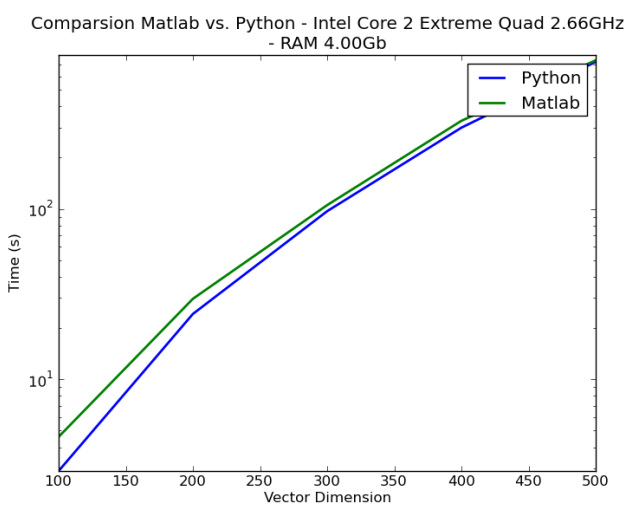

(b) Santos

Figura 3.5: Resultados de Bolla (a) e Santos (b) comparando a performance entre algoritmos executados em ambiente Matlab e em linguagem Python. Detalhes vide texto.

Em ambos os casos podemos observar a mesma tendência de, aumentando-se o 
tamanho do vetor sob análise, esmaecimento da diferença entre os tempos de computação e, mais, aproximadamente na mesma faixa de dimensão dos vetores. Tal resultado é bastante sólido uma vez que ambos os métodos de cálculo são fortemente dependentes de manipulações matriciais.

\section{Módulo NLT: Classe infoEntropy}

Os cálculos de entropia informacional das séries temporais de disparos dos neurônios, são realizados segundo Rieke e colaboradores (Rieke et al., 1999). Dividindo o tempo total de registro em intervalos menores, bins, e preenchendo cada bin com 1 ou 0 , caso haja ou não, um spike, no intervalo de tempo delimitado por aquele bin, deriva-se ${ }^{5}$ :

$$
S=\frac{-T}{\Delta \tau \ln 2}((\bar{r} \Delta \tau) \ln (\bar{r} \Delta \tau)+(1-\bar{r} \Delta \tau) \ln (1-\bar{r} \Delta \tau))
$$

Sendo:

$S$ a entropia informacional;

$T$ a duração dos registros de disparos neurais;

$N=\frac{T}{\Delta \tau}$ o número total de bins;

$\bar{r}$ a taxa média de disparos, e

$p=\bar{r} \Delta \tau$ a probabilidade de, naquele bin, ter havido um spike $e^{6}$

Da equação 3.3 fica claro que o cálculo de $S$ depende da duração $T$ e do tamanho dos bins $\Delta \tau$. A primeira delas é facilmente normalizada dividindo-se o valor de $S$ por $T$. Já a segunda leva à resposta apresentada na figura 3.6, i. e., um decrescimento do valor da entropia quanto maior o tamanho da subdivisão temporal.

As condições de existência da equação 3.3 pedem $\Delta \tau>0$ e $0<\bar{r} \Delta \tau<1$. A primeira condição está automaticamente satisfeita uma vez que, computacionalmente, não faz

\footnotetext{
${ }^{5}$ Assumindo que tenha-se uma sequência binária longa o suficiente e que spikes em diferentes bins não possuem correlação.

${ }^{6}$ Consequentemente a probabilidade de não ter ocorrido um spike fica definida por $1-\bar{r} \Delta \tau$
} 


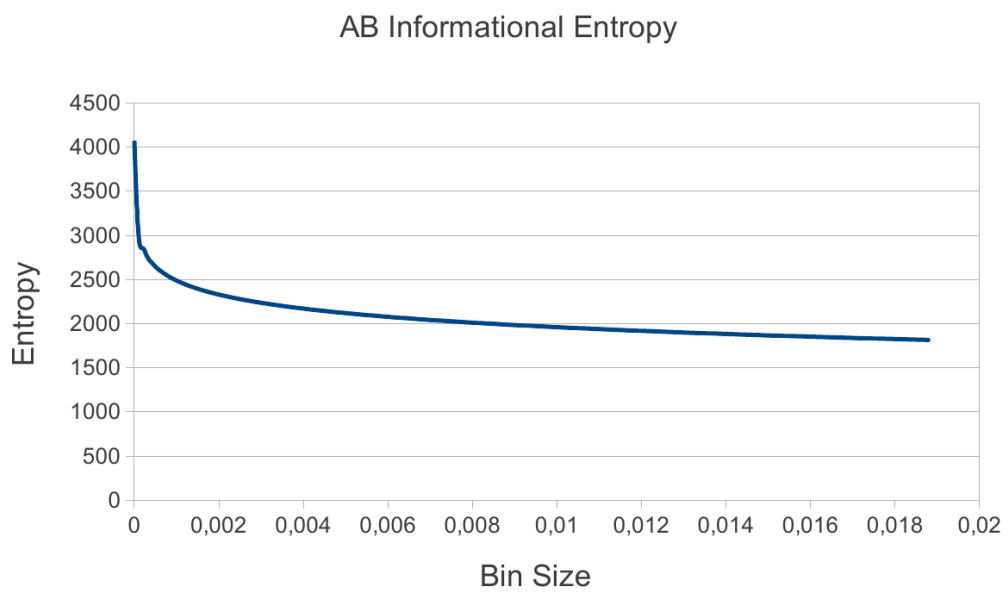

Figura 3.6: Dependência entre o valor da Entropia Informacional e o tamanho do bin adotado para a geração da sequência binária.

sentido criarmos partições temporais de tamanho nulo. A segunda condição nos leva a:

$$
0<\bar{r} \Delta \tau<1 \Rightarrow 0<\Delta \tau<\frac{1}{\bar{r}} \Rightarrow 0<\Delta \tau<\frac{T}{\psi}
$$

$\psi$, o número de spikes ao longo do tempo $T$.

\section{Módulo NLT: Classe syncFire}

Uma forma de acessar o grau de regularidade, ou de falta dela, dentro da sequência de disparos de cada neurônio, mas em nível de rede, é através da contabilização de quantos neurônios estão disparando em um dado instante de tempo. Obviamente, tanto em laboratório, quanto em simulações, dificilmente teremos diferentes células disparando exatamente no mesmo instante de tempo. Para tanto, criou-se o conceito de janela de sincronismo, conforme ilustra a figura 3.7. Dadas as séries temporais de potencial de membrana de cada neurônio e o valor do nível adotado para considerar-se que os mesmos dispararam, obtem-se os intervalos de tempo entre a primeira vez que o potencial atingiu tal limite, e quando ele retorna a esse potencial novamente. Assim define-se os intervalos $\Delta t_{1}, \Delta t_{2}, \ldots, \Delta t_{k}, \ldots, \Delta t_{n}, n$ o número total de spikes da rede. 


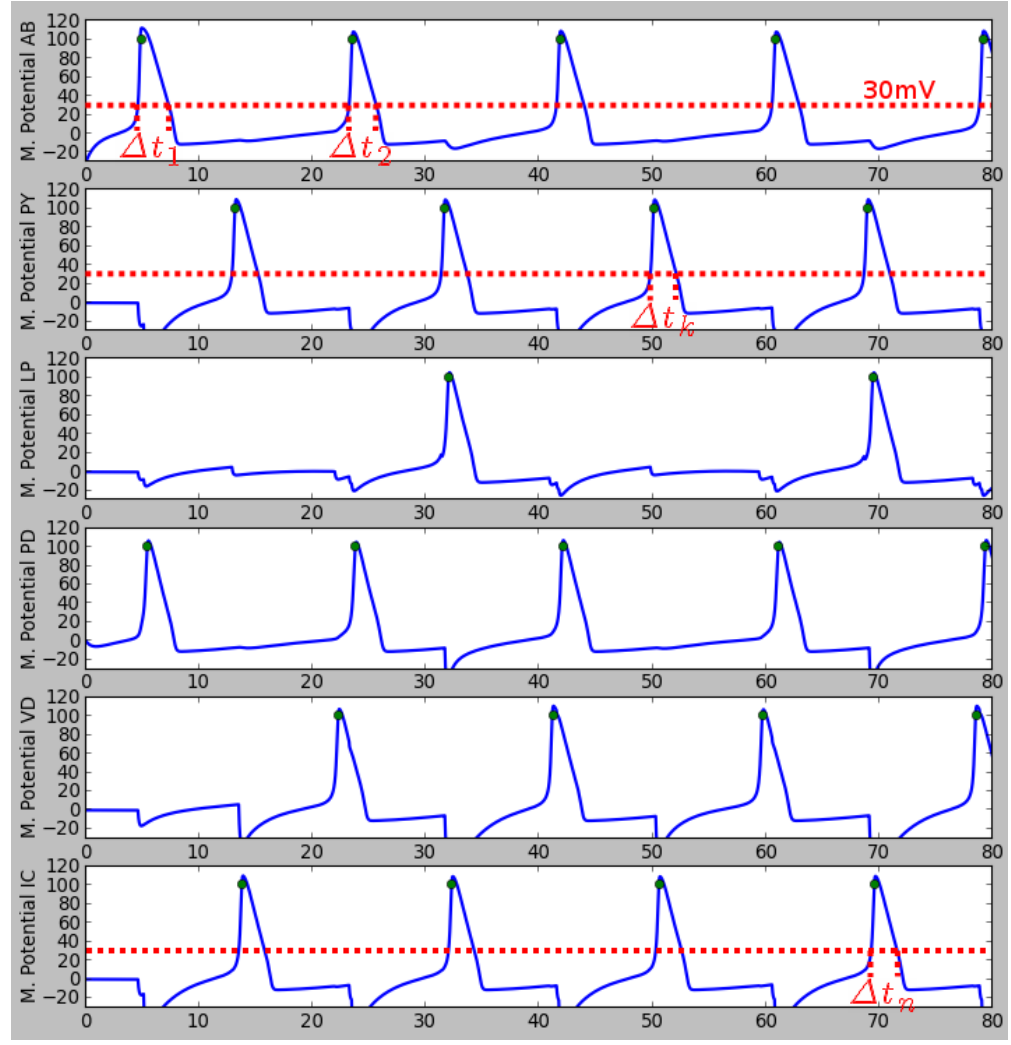

Figura 3.7: O conceito de janela de sincronismo e seu efeito em uma série de disparos neurais. 
Calcula-se, então, a média entre esses $n$ valores, obtendo-se, assim, o que chamamos anteriormente de janela de sincronismo, $S W$. Uma vez obtida essa janela de sincronismo, toma-se o primeiro instante de tempo, $t_{1}$, onde ocorreu um spike, incrementando uma variável de contagem de uma unidade. Caso o spike de outro neurônio ocorra em um instante $t_{2}$, dentro do intervalo $t_{1}+S W$, ou seja, $t_{1}<t_{2}<t_{1}+S W$, incrementa-se a variável de contagem de mais uma unidade e passa-se ao neurônio seguinte e o processo se repete. Quando os disparos não mais ocorrerem dentro do intervalo $t_{1}+S W$, i. e., $t_{k}>t_{1}+S W$, armazena-se o estado da variável de contagem, retornando-a ao valor unitário e procede-se da mesma forma até o último instante de disparo, $t_{n}$. Com esse processo cria-se uma série temporal que nos conta a quantidade de neurônios que dispararam, de forma síncrona, ao longo do tempo de simulação.

\section{Módulo NLT: Classe metabTools}

Pode-se acessar o gasto metabólico de cada célula neural através do cálculo da potência elétrica consumida por ela. O modelo de Hodgkin \& Huxley possui três elementos dissipadores, as condutâncias de cada canal, e um elemento armazenador de energia, a capacitância de membrana. Para obter a potência consumida dentro do tempo de uma simulação, calculamos as potências instantâneas de cada elemento:

$$
\begin{gathered}
p_{C_{m}}(t)=v_{m}(t) C \frac{d v_{m}(t)}{d t} \\
p_{g_{x}}(t)=v_{e q}(t) i_{x}(t), \quad x=N a, K, \text { Leakage }
\end{gathered}
$$

Sendo $v_{e q}$ o gerador equivalente entre o potencial de membrana e os potenciais de reversão de cada íon.

Integrando 3.5 e 3.6 , obtemos a energia total consumida para um tempo final de simulação, $T$ : 


$$
W=\int_{0}^{T} p_{C_{m}}(t) d t+\sum_{x} \int_{0}^{T} p_{g_{x}}(t) d t
$$

\section{Módulo IO: Classe io}

A entrada e saída de dados pode ser realizada através de arquivos texto, em padrão ASCII. Uma vez definidos os delimitadores entre os dados, espaços, tabulações, vírgulas ou outrem, pode-se alimentar a plataforma de simulação com séries temporais armazenadas previamente ou salvar o resultado de simulações.

\section{Módulo IO: Classe xmlInterpreter}

A classe xmlInterpreter permite a descrição completa de um circuito: neurônios, sinapses e fontes externas de corrente, através de um arquivo texto segundo o padrão XML (eXtensible Markup Language). O padrão XML é uma recomendação do World Wide Web Consortium, W3C, para geração de linguagens de marcação, i. e., um sistema para anotação de um texto de modo que ele seja sintaticamente distinguível. Detalhes do arquivo XML proposto podem ser obtidos no apêndice A.

\section{Módulo IO: Classe saveData}

O resultado das simulações cria uma grande quantidade de dados, a saber:

- A própria descrição do circuito, como definida no apêndice A;

- Os potenciais de membrana de cada neurônio presente na rede e seus respectivos instantes de tempo;

- Os instantes de disparo de cada neurônio;

- O cálculo da Entropia Informacional de Shannon para cada série temporal composta pelos instantes de disparo; 
- A Análise Espectral de Potência para essas mesmas séries temporais;

- Os valores de Entropia Aproximada Volumétrica para as séries temporais de: instantes de disparo de cada neurônio, da rede como um todo e do número de disparos síncronos;

- Média e desvio padrão do potencial de membrana de cada neurônio;

- Taxa de disparo média de cada neurônio;

- Média e desvio padrão do intervalo entre spikes e,

- Consumo metabólico de cada neurônio.

A classe saveData, portanto, organiza automaticamente todos esses dados em planilhas eletrônicas já devidamente configuradas em abas específicas para cada neurônio, além de organizar todas as medidas estatísticas em uma única tabela.

\section{Módulo IO: Classe plotTools}

A classe plotTools é um wrapper para acessar os métodos da biblioteca matplotlib, de forma a tornar transparente todas as configurações de um gráfico como títulos, legendas, escalas de eixos e etc. Além disso, a classe plotTools se encarrega de acessar os dados específicos que se quer plotar, dentro da estrutura de dados proposta na classe mathTools.

\subsubsection{Módulos Externos}

Além dos módulos do core da linguagem Python, utilizamos 4 módulos desenvolvidos pela comunidade, como indicado em amarelo na figura 3.1, assimulo, xlwt, xml.etree e spectrum. Rapidamente, vejamos a função de cada um deles. 


\section{Módulo Assimulo}

Em 1996 foi criada a Modelica Association ${ }^{7}$, com o intuito de desenvolver uma linguagem aberta, de nome Modelica, a ser usada na descrição do comportamento dinâmico de sistemas técnicos ${ }^{8}$. O Assimulo é um pacote desenvolvido em Cython/Python ${ }^{9}$ para resolução de sistemas de equações diferenciais ordinárias, explícitas e implícitas, distribuído no âmbito do JModelica, uma implementação de código aberto da plataforma Modelica ${ }^{10}$. Com mais de 4 centenas de artigos, mais de 20 teses e dissertações, 4 livros, 9 conferências internacionas e mais de 70 encontros científicos, a Modelica Association tem levado o Modelica a tornar-se um padrão na indústria do mundo todo.

\section{Módulo xlwt}

O xlwt ${ }^{11}$ é um pacote Python utilizado para criação de planilhas eletrônicas compatíveis com o sistema de arquivos XLS da Microsoft Excel 97/2000/XP/2003. Gera arquivos com suporte total a Unicode, compatíveis com os sistemas Microsoft Excel, OpenOffice Calc e Gnumeric.

\section{Módulo xml.etree}

XML é um formato de dados inerentemente hierárquico. Computacionalmente, a forma mais natural de representá-lo, é através de uma estrutura de dados chamada de árvore. Árvores são recursivamente definidas como uma coleção de nós (a partir de um nó raiz), onde cada um desses nós é composto por um valor e uma lista de nós derivados, os nós filhos, até que se chegue a nós sem filhos, i. e., às folhas da árvore. O pacote xml.etree ${ }^{12}$

\footnotetext{
${ }^{7}$ https://www.modelica.org/

${ }^{8}$ Por sistema técnico entende-se elementos como: motores elétricos, motores a combustão, eixos de transmissão mecânica, trocadores de calor, atuadores hidráulicos, enfim, todo tipo de subsistema elétrico, químico ou mecânico.

${ }^{9}$ Detalhes sobre Cython em B.

${ }^{10} \mathrm{http}: / /$ www.jmodelica.org/

${ }^{11}$ http://pypi.python.org/pypi/xlwt

${ }^{12}$ http://docs.python.org/2/library/xml.etree.elementtree.html
} 
fornece um conjunto de métodos para ler e escrever arquivos XML. A estrutura da árvore proposta nesse trabalho pode ser obtida no apêndice A.

\section{Módulo Spectrum}

O pacote Spectrum ${ }^{13}$ contém uma série de ferramentas para estimação da Densidade Espectral de Potência (PSD - Power Spectrum Densitie) utilizando métodos baseados em transformada de Fouries, métodos paramétricos e análise de autovalores. Além do cálculo, também fornece métodos para criação de gráficos como, por exemplo, periodogramas.

\footnotetext{
${ }^{13}$ http://thomas-cokelaer.info/software/spectrum/html/contents.html
} 


\section{Capítulo 4}

\section{Resultados}

\subsection{Considerações Preliminares}

De forma a homogeneizar a nomenclatura usada de agora em diante, vejamos como se dá uma simulação e os resultados obtidos. Toda simulação inicia-se com a definição do arquivo de configuração, o qual descreve as características de cada neurônio, suas ligações sinápticas dentro da rede, fontes externas de corrente (quando existentes), além do tempo de simulação e do nível de detecção de disparo do neurônio (maiores detalhes vide apêndice A). Os resultados podem ser obtidos de diversas formas: gráficos, séries temporais em texto, séries temporais em planilha eletrônicas, tabelas de dados estatísticos e em diversos graus de detalhe. A figura 4.1 apresenta o resultado de um circuito composto por 2 neurônios, acoplados eletricamente e com injeção de corrente externa. Nesse gráfico tem-se, além dos potenciais de membrana de cada célula, a dinâmica das variáveis de estado $m, n$ e $h$, do modelo de Hodgkin \& Huxley, e os valores de corrente externa fornecida.

As simulações realizadas no presente projeto utilizaram o circuito pilórico da lagosta, conforme apresentado na figura 4.2. Existem algumas variações, na literatura, a respeito da arquitetura desse circuito (Miller and Selverston, 1982) no que tange a algumas 


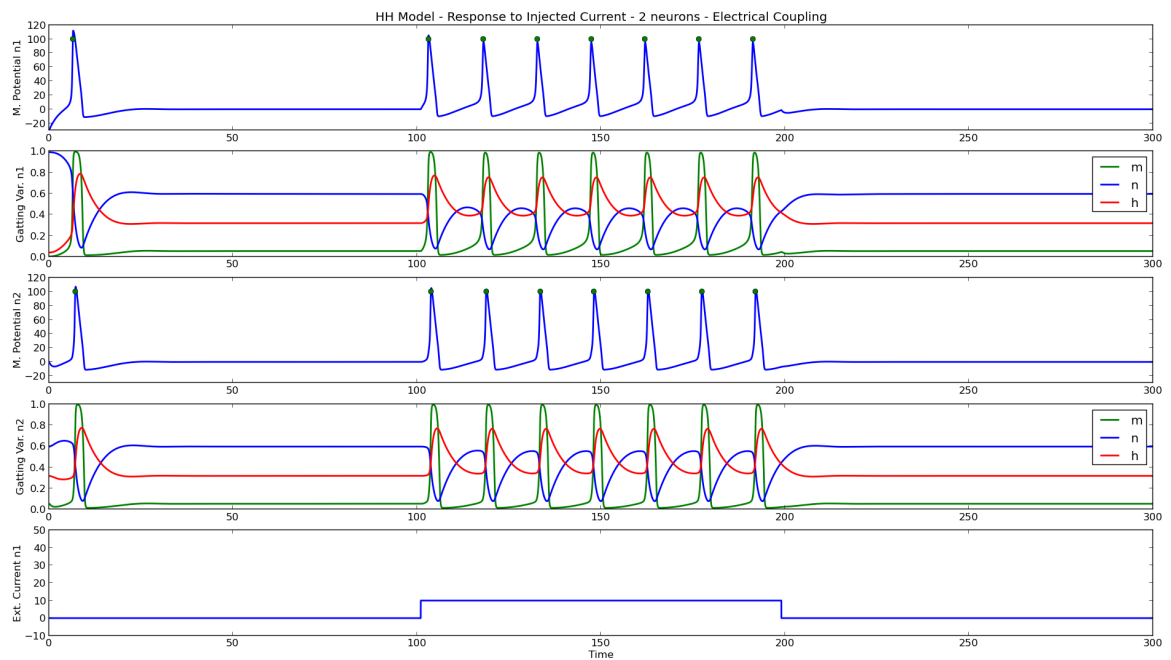

Figura 4.1: Trecho da simulação de circuito composto por 2 neurônios, acoplamento elétrico, com injeção de corrente externa. Tem-se, além dos potenciais de membrana de cada célula, a dinâmica das variáveis de estado $m, n$ e $h$, do modelo de HH e os valores de corrente externa fornecida.

sinapses, entretanto, o número de células, seu posicionamento e função no aparelho digestório do animal estão definitivamente estabelecidos. A configuração de células neurais e suas ligações sinápticas na rede, daqui em diante simplesmente chamada de arquitetura da rede, é composta, então, por seis neurônios, quatro sinapses elétricas (sendo três delas retificadoras) e desesseis sinapses químicas inibitórias. A nomenclatura adotada para cada uma dessas sinapses está apresentada na figura 4.3. A sinapse elétrica entre os neurônios $A B$ e $P D$ é representada por duas sinapses distintas $E S 1$ e $E S 2$ por motivos internos da implementação. Adotou-se que toda sinapse elétrica é, por definição, retificadora e, por assim ser, conduzir em um único sentido. Ora, para obterse, então, uma sinapse elétrcia não retificadora, basta utilizar duas sinapses retificadoras em sentidos opostos.

Mesmo a rede podendo ser considerada de pequeno porte, os números acima sugerem uma quantidade virtualmente infinita de possiblidades de ajuste da arquitetura. No 
presente estudo realizou-se, apenas, alterações em sinapses químicas e, mais, apenas nas sinapses fortes (vide 4.2). As intensidades (ou pesos) das sinapses foram variadas de forma discreta entre os valores $-30,-40,-50$ e -70 a menos de duas exceções. A primeira delas é a sinapse $C S 2$, da qual não realizou-se nenhuma simulação para tomada de dados pois a mesma, em valores entre -20 e -30 , é capaz de interromper a rede totalmente, fazendo-a parar de oscilar após dois ou três spikes de $A B$. Obviamente isso demonstra a importância dessa sinapse no controle da rede, porém insere um grande complicador em termos de simulação, demanda que sejam feitas variações muito pequenas no peso de $C S 2$ e, além disso, resulta em simulações cuja categoria númerica é de problemas fortemente stiff.

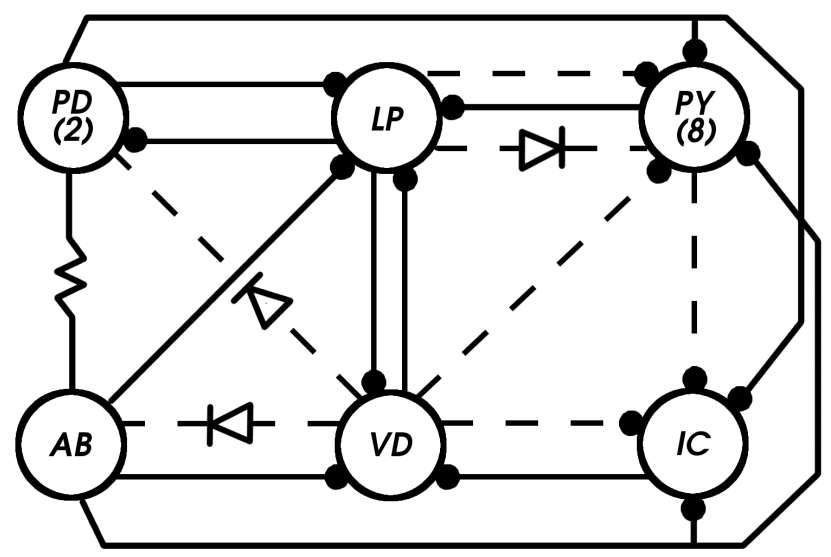

Figura 4.2: Rede neural do sistema pilórico da lagosta, adotada para as simulações. AB é interneurônio com atividade autônoma de disparos periódicos. Os demais neurônios são motoneurônios e osciladores condicionais, i. e., podem tornar-se disparadores autônomos, desde que devidamente neuromodulados pelos gânglios comissurais. Linhas cheias representam sinapses fortes e linhas pontilhadas sinapses fracas. Resistores e diodos simbolizam sinapses elétricas sendo que as do segundo tipo são retificadoras, ou seja, conduzem em apenas um sentido. Círculos cheios representam sinapses químicas inibitórias. Os números entre parênteses representam que o que aqui se chama de um único neurônio, na verdade é composto por 2, PD, ou 8, PY, células fortemente acopladas eletricamente.

A segunda exceção é a sinapse $C S 8$. Nela, ao realizar-se a simulação com peso -70 , 
tem-se um comportamento similar ao da sinapse $C S 2$, todavia com uma intensidade bem menor, i. e., a rede consegue oscilar por um intervalo de tempo maior e é possível tomada de dados. A fim de investigar com mais cuidado a região onde esse efeito ocorre, para $C S 8$, apenas, realizou-se mais uma simulação de peso -60 .

Para efeitos de comparação tomou-se três condições que chamou-se de basais, $B 0$, $B 1$ e $B 2$. A primeira delas é uma condição altamente homogênea da arquitetura onde todas as sinapses de uma dada categoria (elétricas fortes, elétricas fracas, químicas fortes e químicas fracas) possuem o mesmo valor. As demais condições basais são duas arquiteturas diferentes que levam a dois padrões, qualitativamente muito próximos, os quais mimetizam padrões biológicos dessa rede, ou seja, registros in vivo e in vitro (Marder et al., 2005; Wolf and Pearson, 1989; Wilson and Wyman, 1965).

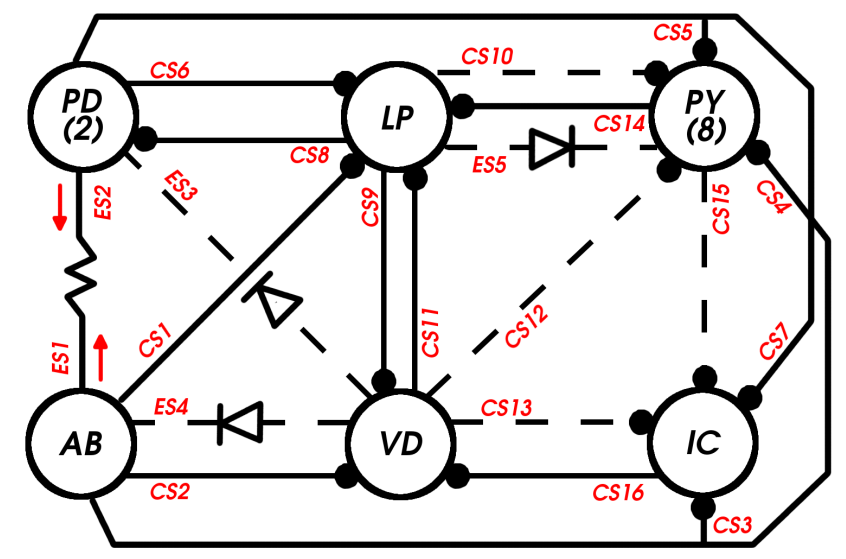

Figura 4.3: Rede neural do sistema pilórico da lagosta, adotada para as simulações. Os nomes das sinapses referem-se ao arquivo xml de configuração. Segue-se os mesmos padrões apresentados na figura 4.2 .

Por mimetizam, entende-se repetir a sequência de ativação, muscular ou fictícia, mostrada por registros reais e não uma réplica fiel do registro. A figura 4.4 apresenta registros de ambas naturezas. De fato, em virtude de utilizar-se o modelo clássico de Hodgkin \& Huxley, não é possível obter respostas de salvas em platô, como no registro 
in vitro da figura em questão (Fitzhugh, 1960). A tabela 4.1 apresenta, de forma consolidada, todos os valores sinápticos para cada uma das 48 simulações realizadas para tomada de dados ${ }^{1}$.

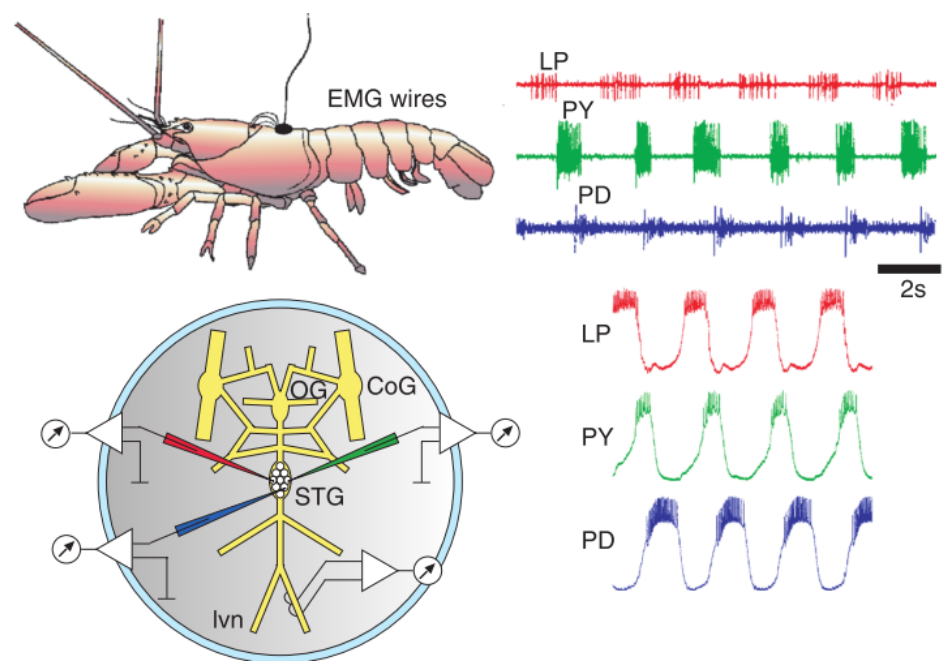

Figura 4.4: Registros in vivo e in vitro do circuito pilórico da lagosta. acima registros de EMG, abaixo registros dos motoneurônios, em preparação, i. e., movimento fictício. Adaptado de Marder \& Bucher (Marder and Bucher, 2001)

\subsection{Variações dos Pesos Sinápticos}

O conjunto de figuras de 4.6 a 4.11 apresenta os resultados obtidos, em termos de fluxo de informação acessado via vApEn e de gasto metabólico, para as 48 simulações, neurônio a neurônio, juntamente com as três condições basais. Os resultados são dados normalizados em relação à condição basal B0.

Como regra geral, as condições de gasto energético, quando observadas dentro de um mesmo neurônio, parecem sofrer pouca variação mesmo quando há significativas alterações de informação, desde que este não seja a célula que recebe a sinapse em estudo. Esse efeito pode ser observado na figura 4.7, gráfico superior, no conjunto de

\footnotetext{
${ }^{1}$ Cada uma das simulações de tomadas de dados simulam um período de 3 segundos de funcionamento da rede neural.
} 


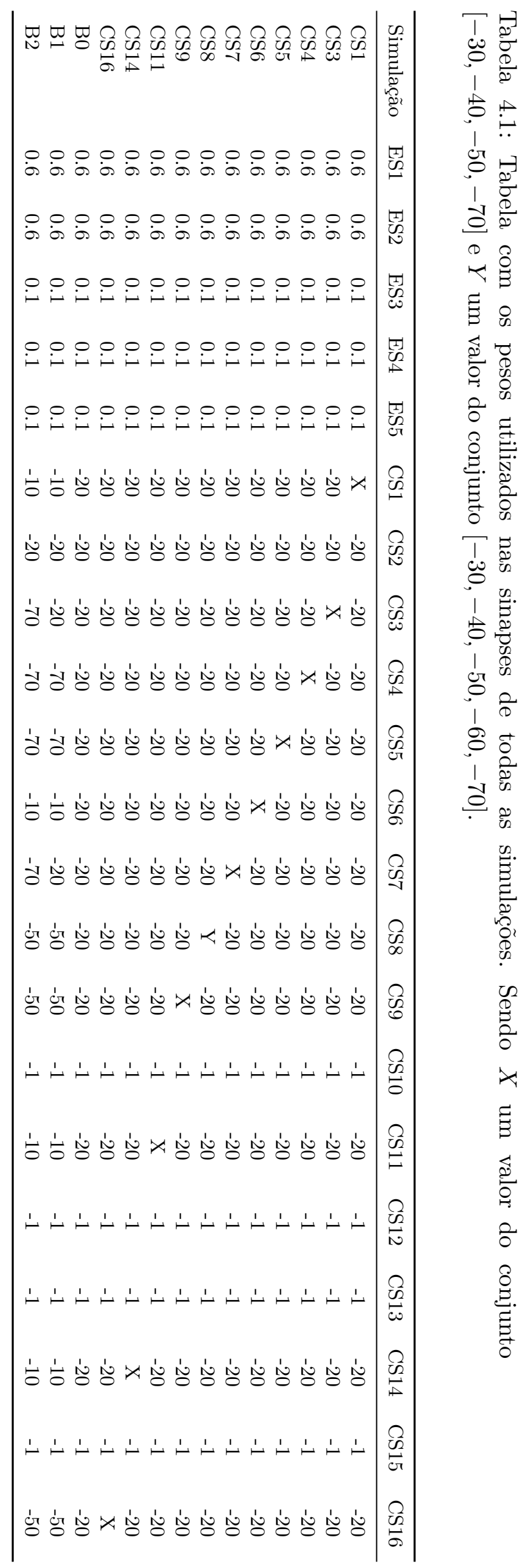


dados referentes aos neurônios $P D$ e $V D$. Os neurônios pós-sinápticos sofrem variações em seus gastos metabólicos de maneira praticamente linear, entre 5 a 15\%, a menos de $C S 14$ que não causa praticamente nenhuma alteração metabólica em $L P$ e $C S 9$ que varia o gasto energético de $V D$ em $27 \%$ (vide figuras 4.10 e 4.9, respectivamente).

Em termos de informação, alguns comportamentos merecem destaque. CS3 e CS7 causam grandes aumentos no nível de informação de $P Y$ e $V D$, sem variações perceptíveis no gasto metabólico e, mais ainda, via conexões sinápticas para o neurônio $I C$ (figuras 4.6 e 4.8, gráficos inferiores). As conexões $C S 4$ e $C S 5$ também elevam os níveis de informação em $P Y$ e $V D$ porém, com duas diferenças. Primeiramente elevam o gasto metabólico de $P Y$, uma vez que são sinapses diretas a ele e, além disso, causam uma depressão na informação de $I C$ revelando um mínimo de informação no mesmo peso sináptico do máximo de informação em $P Y$ (figura 4.7). Este segundo efeito não ocorre para as sinapses $C S 3$ e $C S 7$ que mantém os níveis de informação em $I C$ muito pouco alterados.

Ainda sobre efeitos informacionais, a sinapse CS16 apresenta uma característica muito notável. Enquanto todas as demais sinapses, quando variadas, delimitam valores de vApEn sempre inferiores a -1600 (salvo IC e PY em CS1 - 70) com média -1111.2, ao aumentar-se o peso de $C S 16, A B, P D, L P$ e $P Y$ são grampeados abaixo de -1100 $(\overline{-v A p E n(I S T)}=-982.1)$ ao mesmo tempo que $V D$ e $I C$ são postos a patamares médios de -1400.4 (atingindo máximos de mais de -1700). O boxplot apresentado na figura 4.5 resume o que ocorre com $C S 16$.

\subsection{Depressores de Informação}

A figura 4.9 apresenta o efeito de variações nas sinapses CS8 e CS9. Ambas têm capacidade de causar grande depressão na quantidade de informação circulante, em todos os neurônios. CS8, inclusive, apresenta uma resposta muito mais abrupta do que 


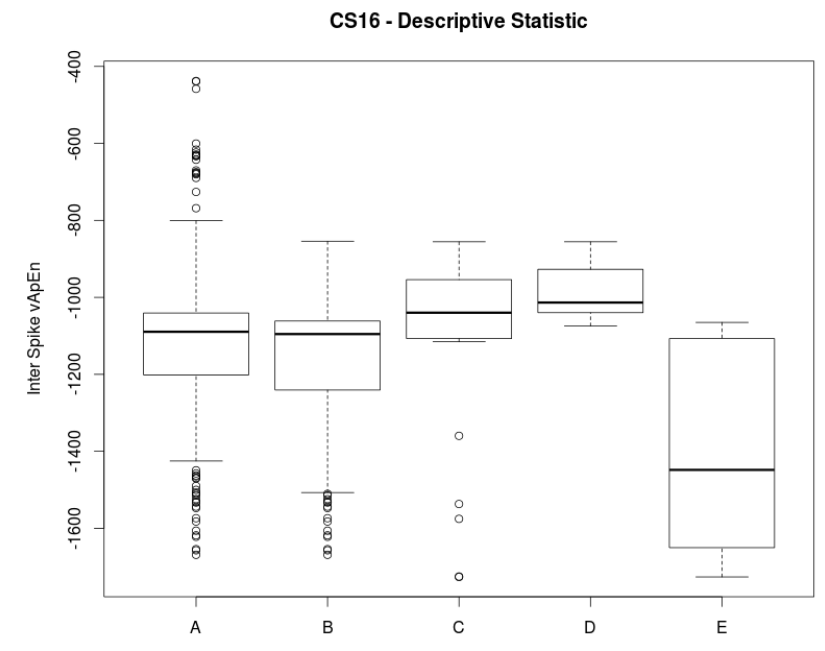

Figura 4.5: Boxplot para análise estatística de CS16. A, vApEn dos intervalos inter spike de todas as categorias excetuando $C S 16$. B, analogamente a A, removendo também $C S 8$ e $C S 9$. C, vApEn dos intervalos inter spike de $C S 16$. D e E são a separação em dois blocos de C. Em D somente os neurônios $A B, P D, L P$ e $P Y$ e em E, $V D$ e $I C$

a tida por $C S 9$. Ao chegarmos a patamares de -70 no peso de $C S 8$, a rede tende ao silenciamento, o que pode ser comprovado pelo gasto metabólico praticamente nulo nessa situação. Observe que, entre os pesos -30 e -50 , praticamente não há alterações nos valores de vApEn, nem de metabolismo, mas, ao chegar em -70 os valores já se encontram extremamente reduzidos. O fato de ter-se essa diferença tão abrupta, levounos a simular essa sinapse no peso de -60 . O resultado também foi uma grande redução da informação já em -60, porém não acompanhada de semelhante redução no gasto energético, conforme ilustra a figura 4.12.

\subsection{Rede Neural}

Enquanto as seções anteriores apresentaram resultados sob uma perspectiva particular de cada sinapse explorada, agora serão fornecidos dados através de uma óptica mais afastada, i. e., em nível de rede neural. Primeiramente é necessário definir o método 

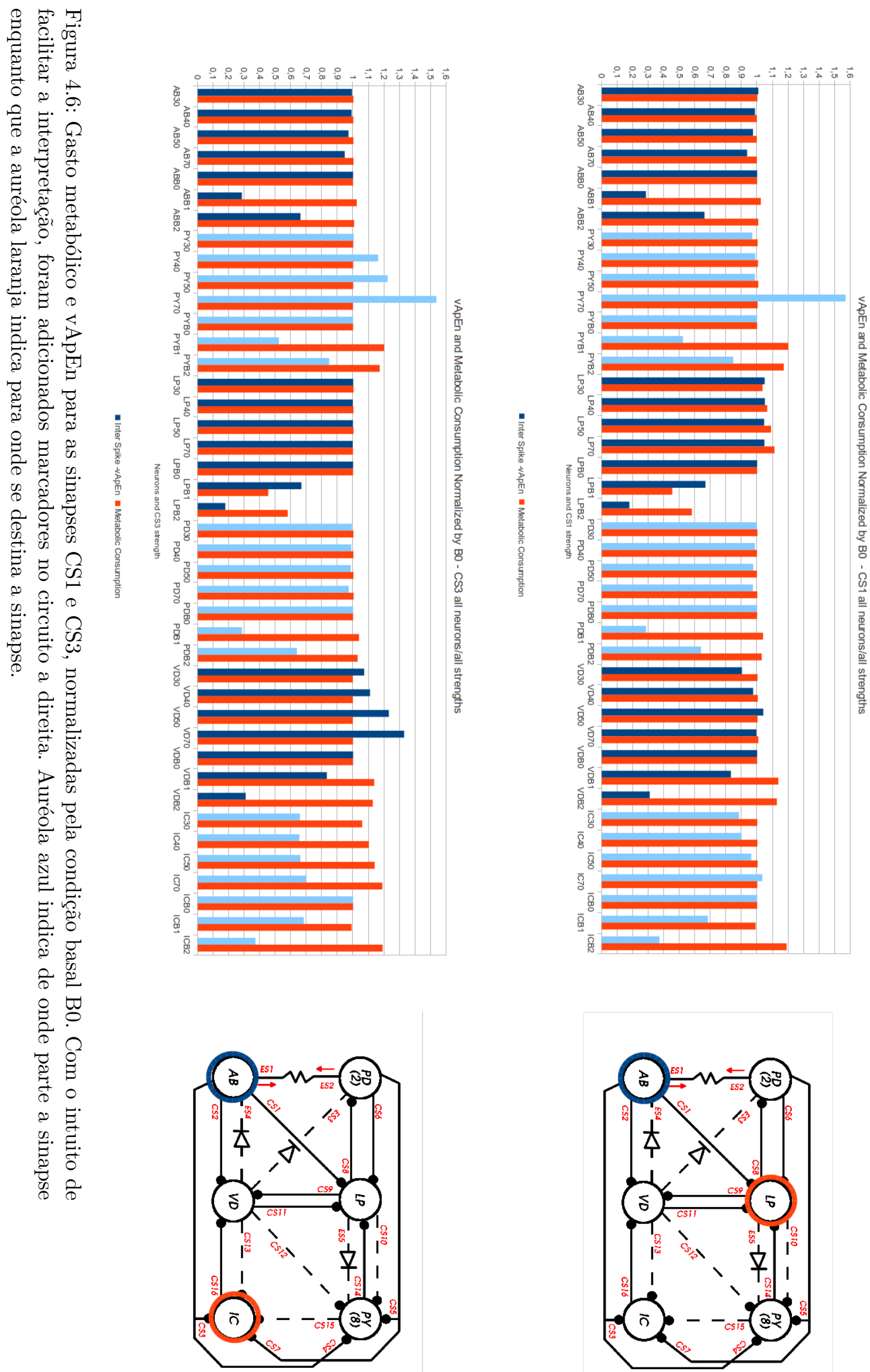

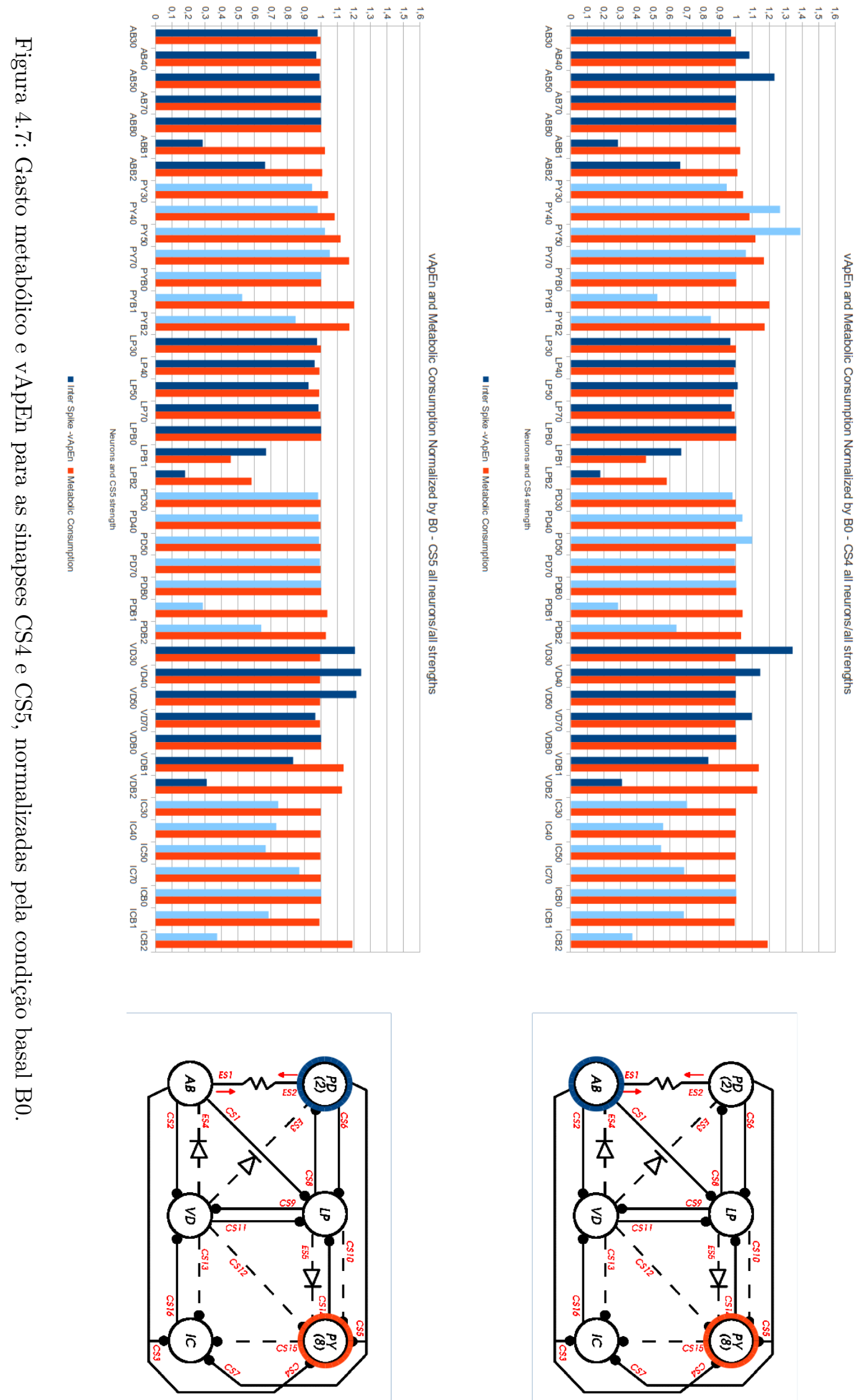

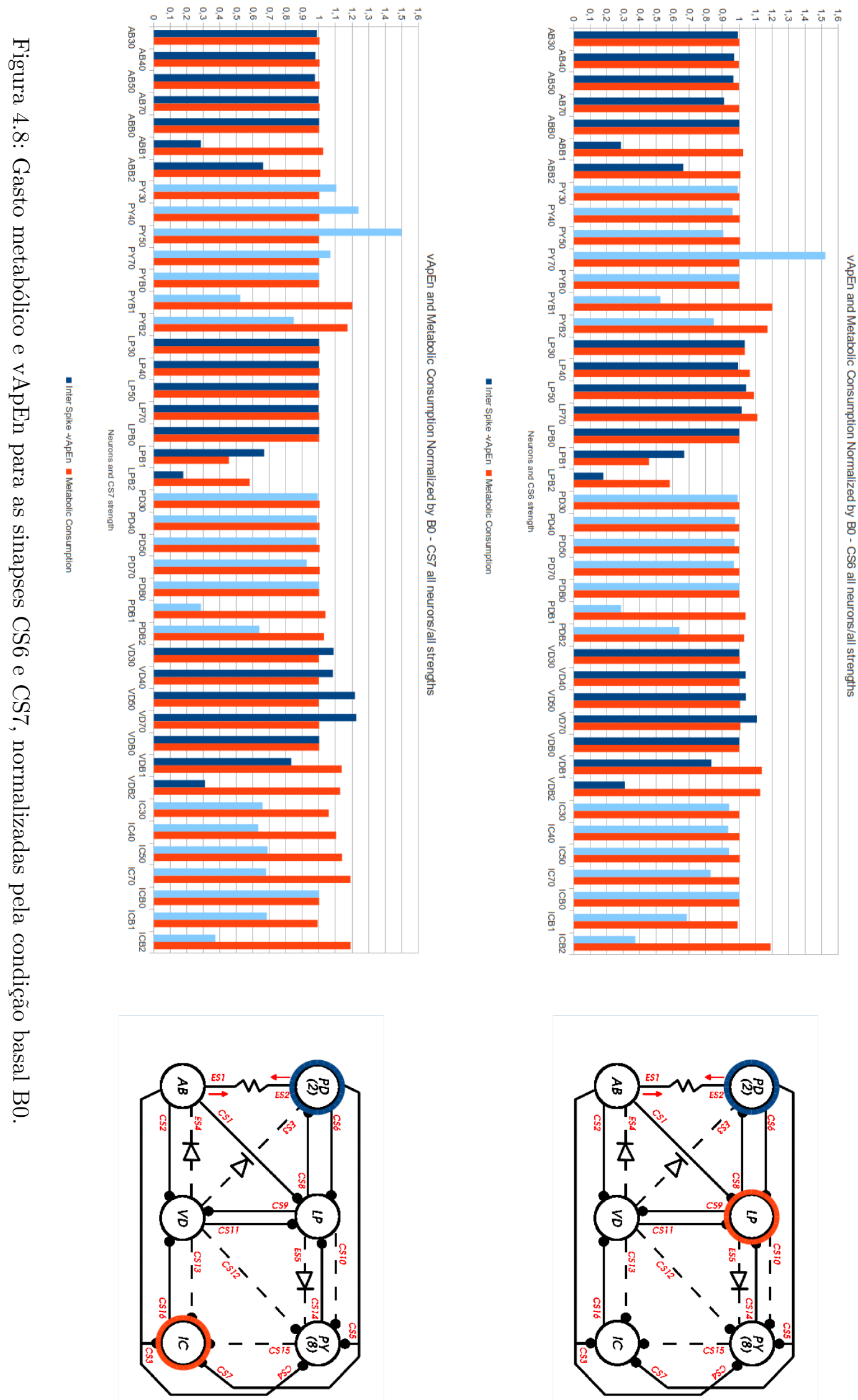

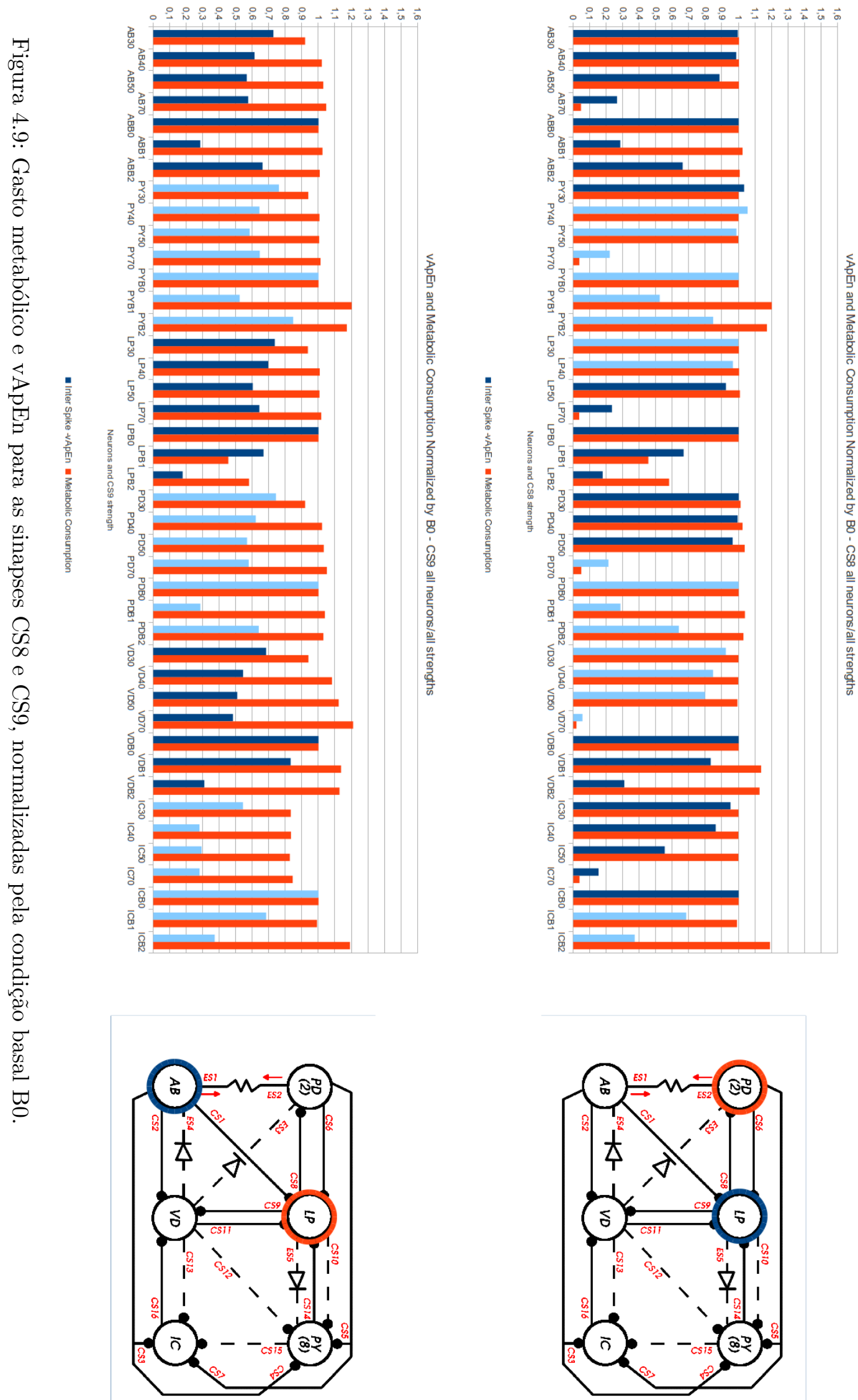

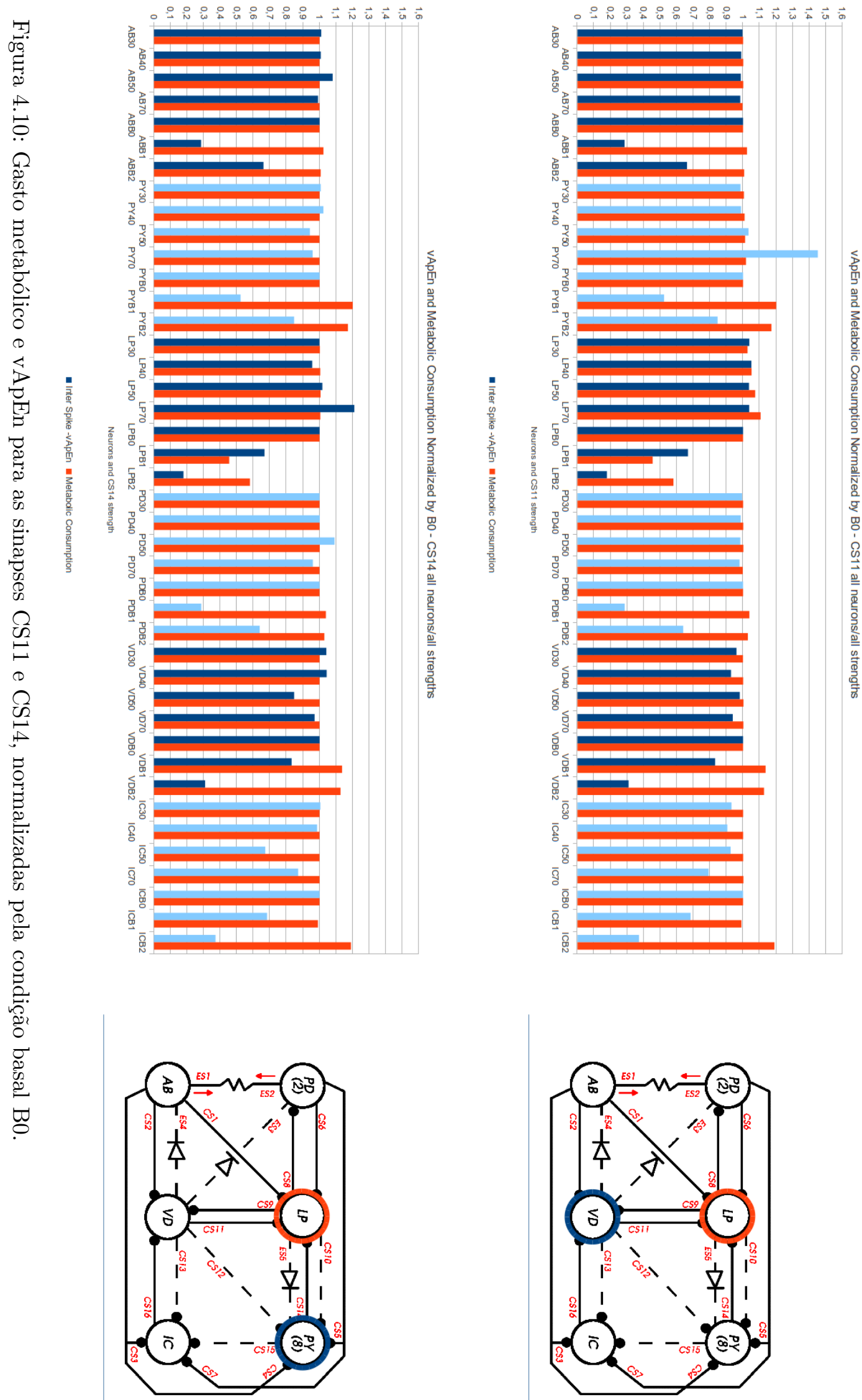


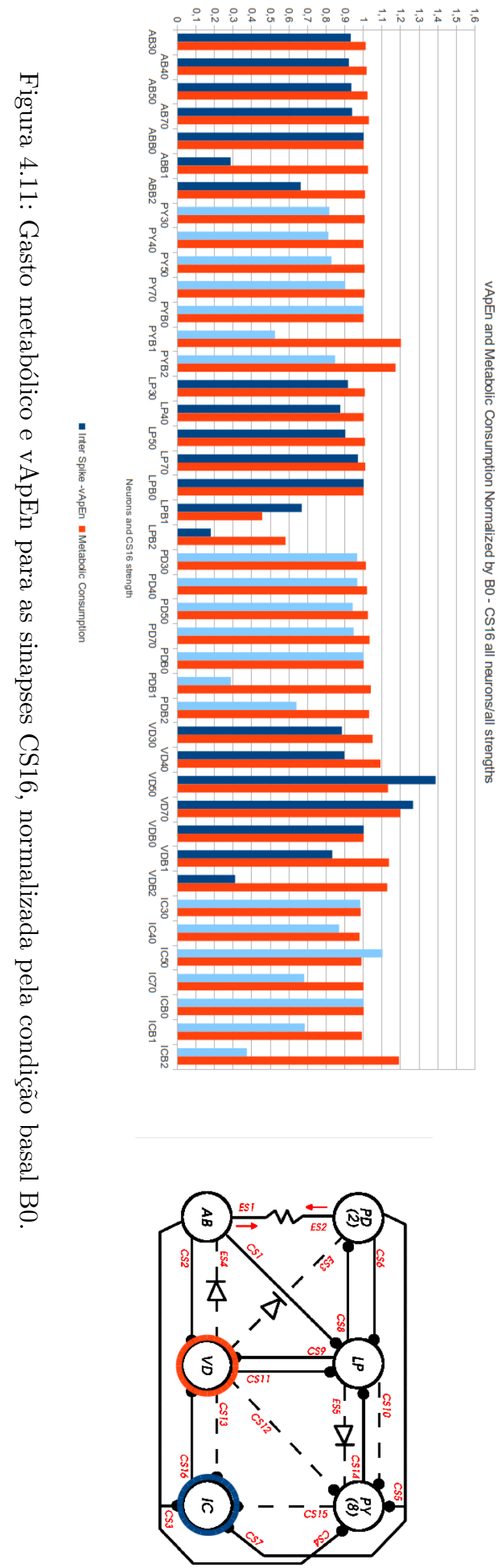



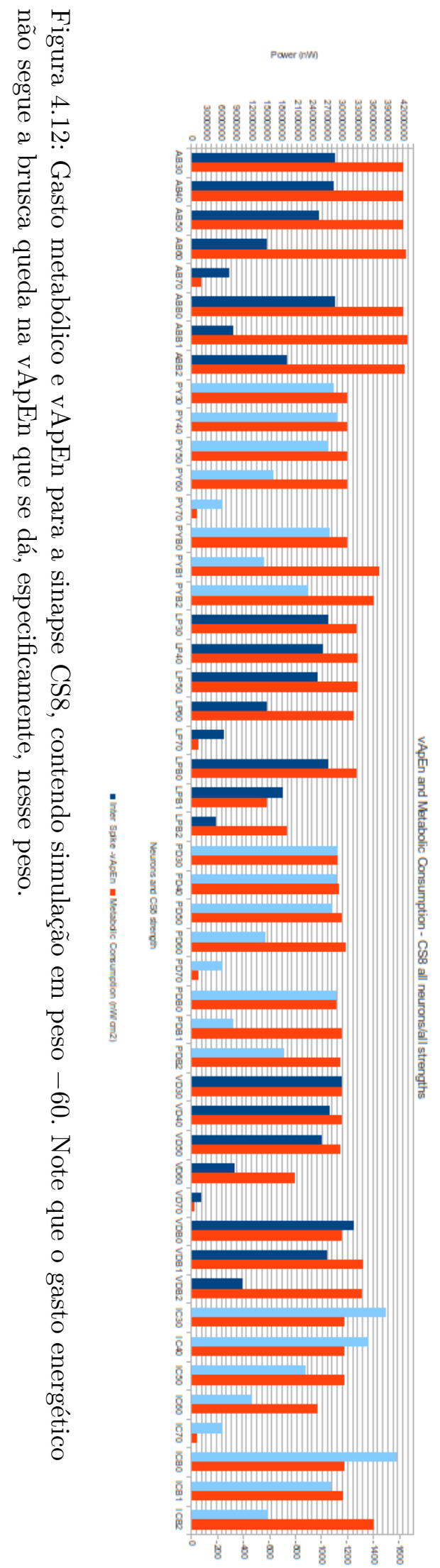
utilizado para o cálculo das grandezas estatísticas, vApEn e metabólicas para a rede como um todo. Para tal, é criada uma única série temporal composta por todos os instantes de disparo de cada neurônio da rede, formando, por assim dizer, um neurônio equivalente ou, fazendo uso de uma metáfora vetorial, projeção equivalente dos disparos em um único eixo. Seja, por exemplo, uma rede constituída por 3 neurônios $A, B$ e $C$, com os seguintes instantes de disparo, em $m s$ :

$$
A=[3.5,7.0,15.4] ; \quad B=[2.0,8.3,18.0] ; \quad C=[9.8,11.5]
$$

O vetor de disparos da rede fica, então:

$$
N=[2.0,3.5,7.0,8.3,9.8,11.5,15.4,18.0]
$$

Calculando o intervalo entre disparos, vem:

$$
\begin{aligned}
I S T_{N} & =[3.5,7.0,8.3,9.8,11.5,15.4,18.0]-[2.0,3.5,7.0,8.3,9.8,11.5,15.4] \\
& =[1.5,3.5,1.3,1.5,1.7,3.9,2.6]
\end{aligned}
$$

Computacionalmente, "adiciona-se" um vetor ao seguinte, ou seja, dado um vetor de $m$ elementos e outro de $n$ elementos, cria-se um vetor de $m+n$ elementos. Repete-se tal procedimento até o último vetor e, ao final, ordena-se o vetor resultante de forma crescente.

A figura 4.13 apresenta os resultados de vApEn, da rede, normalizados para cada uma das condições basais, em um dado peso sináptico. Percebe-se que ao longo de 38 das 48 variações sinápticas, a rede se mantém nos mesmos níveis de informação circulante. Importante ressaltar que, a faixa de categorias na qual a rede é posta em condições de aumento de informação circulante, está relacionada com as sinapses depressoras de informação (seção 4.3). O efeito na região percorrida pela série temporal de intervalos, 
inter spike, dento do mapa de estados, é apresentado na figura 4.14a e 4.14b. Perceba a redução na área visitada em 4.14a conforme cresce a força sináptica em CS9 e a inflação da região em $C S 8-60$.

Net Firing Normalized

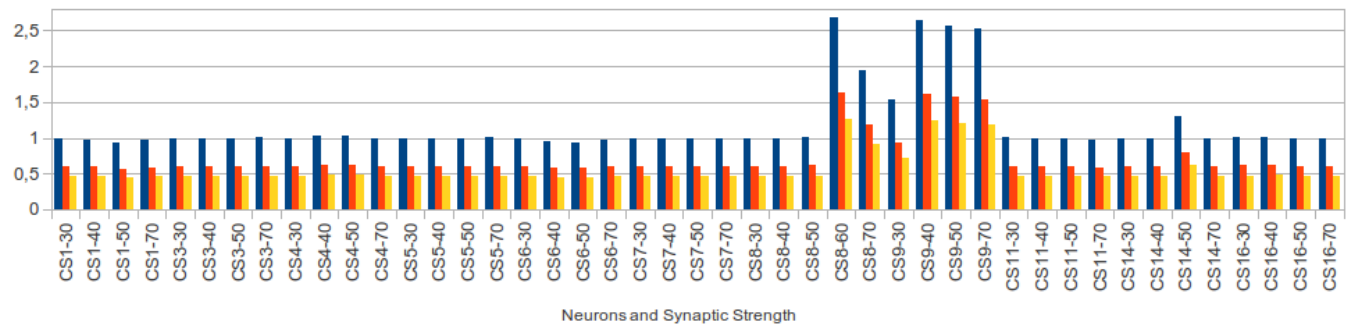

- Net Firing vapEn Norm B0 $=$ Net Firing vApEn Norm B1 $=$ Net Firing vApEn Norm B2

Figura 4.13: Valores de vApEn para os intervalos entre spikes da rede como um todo. Cada coloração representa a normalização frente a uma das condições basais.

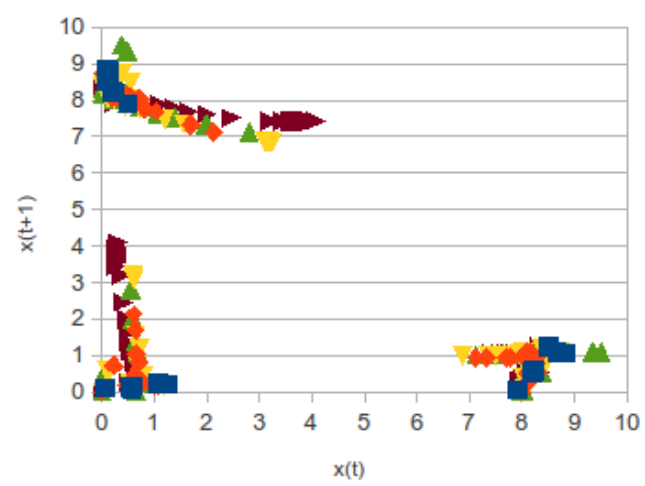

- CS1-30 Net Inter Spike CS9-70 Net Inter Spike $\nabla$ CS9-50 Net Inter Spike $\Delta$ CS9-40 Net Inter Spike - CS9-30 Net Inter Spike

(a) Plot de Poincaré $C S 9$

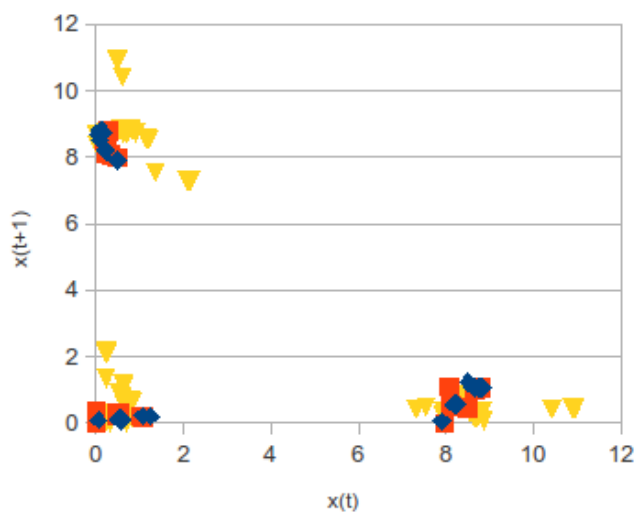

- CS1-30 Net Inter Spike $\quad$ CS14-50 Net Inter Spike ₹ CS8-60 Net Inter Spike

(b) Plot de Poincaré $C S 8$ e $C S 14$

Figura 4.14: Espaço de estados para os casos de aumento de vApEn apresentados na figura 4.13 .

Finalizando os resultados apresentados pela rede frente a variações nas sinapses, temos os dados expostos na figura 4.15. Devido a artefatos do método da vApEn, séries 
temporais da forma:

$$
\begin{array}{lllllllll}
x & y & y & y & \cdots & y & y & y & z ;
\end{array} \quad x, y, z \in \mathbb{R} ; \quad x=z \text { ou } x \neq z
$$

possuem valores de vApEn comparáveis a ondas senoidais, mesmo sendo, obviamente, de baixíssima complexidade.

Portanto, devemos nos fixar nos valores expostos nas categorias CS8-60 e CS9-30 a $C S 9-70^{2}$, os quais nos mostram grande redução de informação quando acessamos a rede observando o sincronismo entre as células (4.15), ao invés do "neurônio equivalente" (4.13).

Synchronous Net Firing Normalized

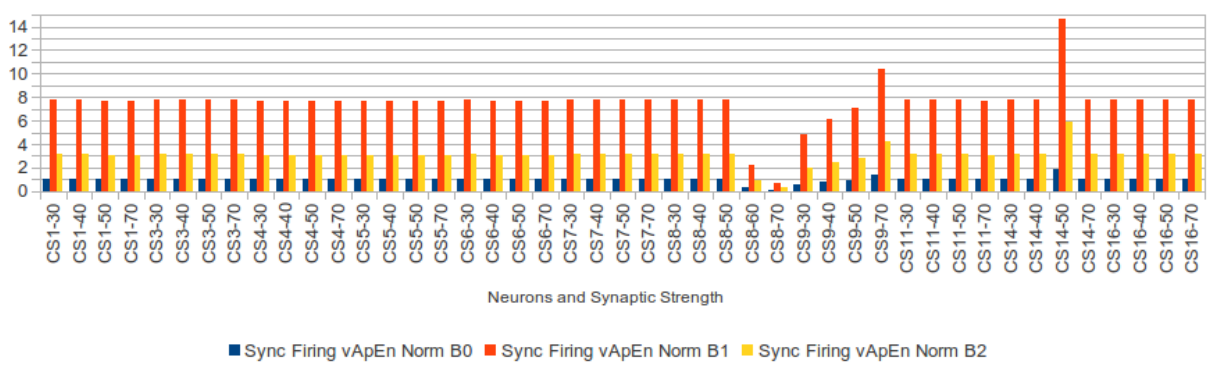

Figura 4.15: Valores de vApEn para as séries temporais de número de células em disparos síncronos, na rede como um todo. Cada coloração representa a normalização frente a uma das condições basais. Devido a artefato de análise, as únicas categorias que devem ser analisadas são $C S 8-60$ e $C S 9-30$ a $C S 9-70$.

\subsection{Condições Basais}

Resultados interessantes surgem da comparação entre as três condições basais. A tabela 4.2 mostra os dados oriundos do software de simulação para $B 0, B 1$ e $B 2$. Observe que algumas medidas não fazem sentido para a rede $N E T$ e para a série de sincronismo SYNC e, portanto, não aparecem na tabela. Inicialmente constata-se que a condição

\footnotetext{
${ }^{2}$ Lembre-se que $C S 8$ - 70 é um caso no qual a rede já está praticamente silenciada e, assim, em um estado bem longe da operação contínua ritimada que queremos estudar.
} 
homogênea das sinapses em $B 0$, leva a uma também homogeneidade em praticamente todos os parâmetros da tabela. Importante chamar a atenção para o fato de que, valores altos de vApEn sináptica não são, obrigatoriamente, condicionadores de altos valores para a rede.

Comparando-se as duas formas basais biológicas, percebe-se que as três variáveis centrais da tabela são, praticamente, iguais entre as duas. Além disso, as relações de informação são, de certa forma, complementares. As sinapses que possuem máximo de informação em uma arquitetura, na outra representam mínimos informacionais e vice-e-versa. Mesmo com tamanhas similaridades, obsserve que medidas de rede são bastante diferentes.

\subsection{Redistribuição Energética}

Observando como se comporta a distribuição de energia consumida na rede, entre as três condições basais propostas, conforme aponta a figura 4.16, pode-se perceber que a energia total sofre pouca alteração entre as condições $B 0$ e $B 2$, porém apresenta uma redução em $B 1$. O mesmo não se pode falar do local onde essa energia é consumida.

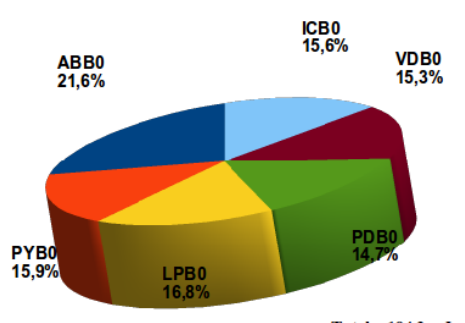

Total $=194,3 \mathrm{~mJ}$

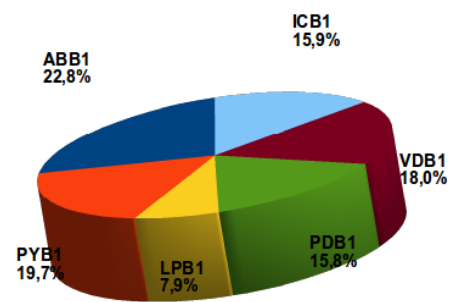

Total $=188,5 \mathrm{~mJ}$

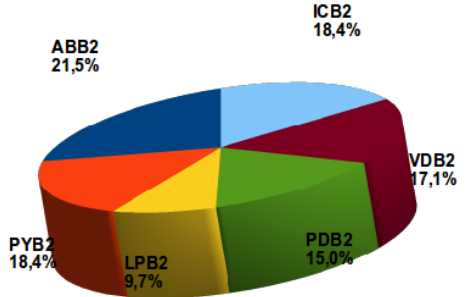

Total $=196,5 \mathrm{~mJ}$

Figura 4.16: Porcentagem de energia, em relação ao total da rede, consumida por cada neurônio. Observe a redistribuição entre as condições $B 0$ (à esquerda), $B 1$ (ao centro) e $B 2$ (à direita).

Tomando como partida o gráfico em pizza referente a $B 0$, que é uma arquitetura altamente homogênea, inclusive quanto à sua energética (perceba os valores muito 
Tabela 4.2: Dados de potencial médio e desvio padrão do potencial de membrana, $\bar{V}_{m}$ e $\sigma_{V_{m}}$, taxa de disparos $\dot{S R}$, intervalo médio entre disparos e seu desvio padrão, $\overline{I S T}$ e $\sigma_{I S T}$, vApEn do intervalo entre disparos, $v A p E n(I S T)$ e gasto metabólico, $\int \dot{V}_{O_{2}}$, para cada neurônio, para a rede e para a série temporal de sincronismo, em cada um dos 3 casos basais.

\begin{tabular}{|c|c|c|c|c|c|c|c|}
\hline Neuron & $\bar{V}_{m}(m V)$ & $\sigma_{V_{m}}(m V)$ & SiR(spikes/s) & $\overline{I S T}(m s)$ & $\sigma_{I S T}(m s)$ & $-v A p E n(I S T)$ & $\int \dot{V}_{\mathrm{O}_{2}}(m J)$ \\
\hline $\mathrm{ABB} 0$ & 14.46 & 35.77 & 53.00 & 18.9500 & $4.56 \cdot 10^{-2}$ & -1102 & 41.90 \\
\hline PYB0 & 8.46 & 36.83 & 52.67 & 18.9521 & $1.56 \cdot 10^{-2}$ & -1056 & 30.93 \\
\hline LPB0 & 11.63 & 46.28 & 52.67 & 18.9489 & $4.99 \cdot 10^{-2}$ & -1045 & 32.73 \\
\hline PDB0 & 7.77 & 29.41 & 53.00 & 18.9483 & $6.78 \cdot 10^{-2}$ & -1113 & 28.60 \\
\hline VDB0 & 11.90 & 38.41 & 52.67 & 18.9546 & $4.92 \cdot 10^{-3}$ & -1245 & 29.82 \\
\hline ICB0 & 4.93 & 30.33 & 52.67 & 18.9538 & $4.27 \cdot 10^{-3}$ & -1567 & 30.33 \\
\hline NETB0 & & & 316.67 & 3.1552 & 3.75 & -338 & 194.31 \\
\hline SYNCB0 & & & & & & -443 & \\
\hline $\mathrm{ABB} 1$ & 18.20 & 39.45 & 53.00 & 18.8936 & $4.27 \cdot 10^{-1}$ & -313 & 42.89 \\
\hline PYB1 & -5.63 & 57.50 & 53.00 & 18.8922 & $2.80 \cdot 10^{-1}$ & -552 & 37.13 \\
\hline LPB1 & 4.61 & 31.06 & 26.33 & 37.8030 & $1.63 \cdot 10^{-2}$ & -697 & 14.86 \\
\hline PDB1 & 10.72 & 34.07 & 53.00 & 18.8917 & $4.53 \cdot 10^{-1}$ & -317 & 29.69 \\
\hline VDB1 & 12.96 & 47.33 & 52.67 & 18.9026 & $2.85 \cdot 10^{-2}$ & -1035 & 33.88 \\
\hline ICB1 & 3.05 & 30.59 & 53.00 & 18.9007 & $6.25 \cdot 10^{-3}$ & -1070 & 30.03 \\
\hline NETB1 & & & 291.00 & 3.4344 & 3.82 & -555 & 188.47 \\
\hline SYNCB1 & & & & & & -57 & \\
\hline ABB2 & 17.30 & 39.61 & 51.67 & 19.3313 & $3.66 \cdot 10^{-1}$ & -729 & 42.18 \\
\hline PYB2 & -3.98 & 56.83 & 51.67 & 19.3292 & $2.46 \cdot 10^{-1}$ & -894 & 36.23 \\
\hline LPB2 & 5.25 & 31.46 & 34.33 & 28.9735 & 8.68 & -186 & 18.97 \\
\hline PDB2 & 9.09 & 33.81 & 51.67 & 19.3297 & $3.42 \cdot 10^{-1}$ & -710 & 29.43 \\
\hline VDB2 & 11.35 & 49.19 & 51.33 & 19.3157 & $3.47 \cdot 10^{-1}$ & -384 & 33.60 \\
\hline ICB2 & -10.29 & 50.99 & 51.67 & 19.3289 & $4.97 \cdot 10^{-1}$ & -582 & 36.08 \\
\hline NETB2 & & & 292.33 & 3.4102 & 3.82 & -717 & 196.48 \\
\hline SYNCB2 & & & & & & -142 & \\
\hline
\end{tabular}

próximos na figura 4.16) tem-se uma queda de $53 \%$ e $42 \%$ na energia consumida em $L P$ quando a arquitetura encontra-se em $B 1$ e $B 2$, respectivamente. Além disso, o "excesso" liberado por $L P$, vai para $P Y+V D$ em $B 1$ e $P Y+V D+I C$ em $B 2$. 


\section{Capítulo 5}

\section{Discussão}

\subsection{Reprogramação da Rede}

Os resultados apresentados fornecem um bom alicerce para afirmar que, dada uma arquitetura de rede neural biológica, i. e., seus neurônios munidos das descrições de suas dinâmicas, juntamente com suas interligações sinápticas, é possível direcionar o fluxo de informação e a distribuição energética da mesma. Recompilemos alguns dados na forma da tabela 5.1. Ela traz dados referentes às 5 categorias de sinapses que levam a rede a diferentes patamares de fluxo de informação e gasto metabólico, conjuntamente com dados paras as 3 condições basais. Em relação a condição basal homogênea, $B 0$, tem-se que os padrões biologicamente plausíves, $B 1$ e $B 2$ possuem, obrigatoriamente, menor entropia informacional da sequência síncrona e maiores entropias da rede como um todo ("neurônio equivalente"). Essa situação é coerente uma vez que, no estado homogêneo, a rede mantém o mesmo conjunto de células em sincronia $^{1}$, com praticamente os mesmos padrões de disparo (veja tabela 4.2, primeiro conjunto de dados, coluna - vApEn(IST)).

Partindo dessa condição referente a $B 1$ e $B 2$, temos ao menos 3 candidatos a possíveis reprogramadores da rede, que a levem a padrões próximos dos biologicamente

\footnotetext{
${ }^{1}$ Lembre-se da questão relacionada ao artefato de análise, para sequências do tipo 4.1.
} 
plausíveis: $C S 8-60, C S 9-30$ e $C S 9-40$. Porém, como realizar uma escolha entre esses candidatos? Não seria correto, embora muito atrativo, de antemão simplesmente escolher o de menor gasto metabólico, ou seja, CS9-30. Será que CS9-30 possui um padrão de ativação muscular próximo ao padrão de $B 1$ ou $B 2$ ?

Tendo em mente que, exluindo o neurônio $A B$, todos os demais são formadores do padrão de ativação da rede, além de serem os próprios motoneurônios, podemos acessar a saída motora da rede analisando diretamente os instantes de disparo dos neurônios e, assim, observar possíveis semelhanças entre as diferentes arquiteturas. A figura 5.1 nos mostra as 5 saídas motoras em questão, é possível observar que os padrões em CS8 - 60 e $C S 9$ - 40 são sensivelmente diferentes dos de $B 1$ ou $B 2$ sendo, o mais próximo deles, o padrão encontrado em $C S 9-30$.

Tabela 5.1: Recompilação de dados referentes às sinapses CS8 - 60 e CS9-30 a $C S 9-70$.

\begin{tabular}{crrr}
\hline Sinapse & $-v A p E n(S Y N C)$ & $-v A p E n(N E T)$ & $\int \dot{V}_{O_{2}}(m J)$ \\
\hline CS8-60 & -125 & -910 & 181 \\
CS9-30 & -276 & -521 & 178 \\
CS9-40 & -354 & -898 & 193 \\
CS9-50 & -403 & -870 & 195 \\
CS9-70 & -598 & -854 & 200 \\
\hline \hline B0 & -443 & -338 & 194 \\
B1 & -57 & -555 & 188 \\
B2 & -142 & -717 & 196 \\
\hline
\end{tabular}

Porém, como conciliar o perfil da saída motora, com os dados da tabela 5.1? É possível extrair, das sequências motoras, os conjuntos de neurônios que estão disparando sincronamente, naquele instante. Chamemos essas sequências de unidades padrão. 


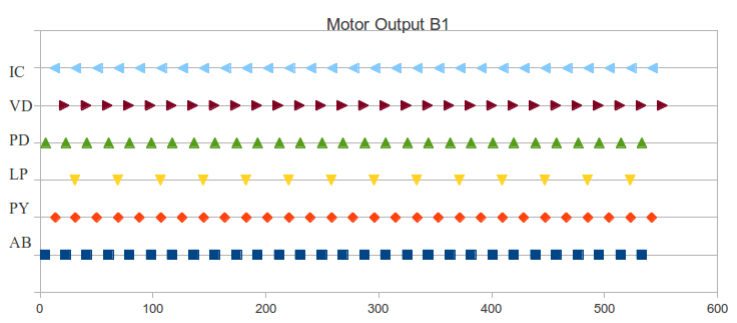

(a)

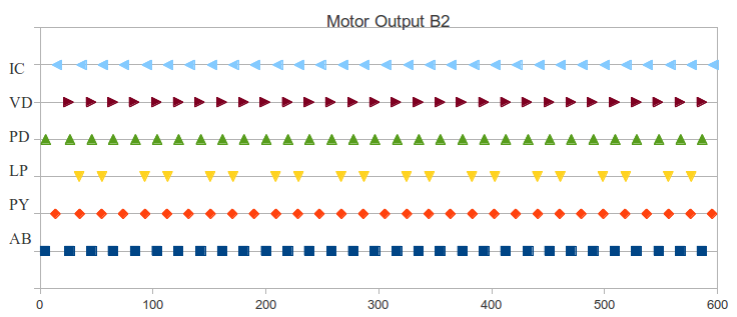

(b)

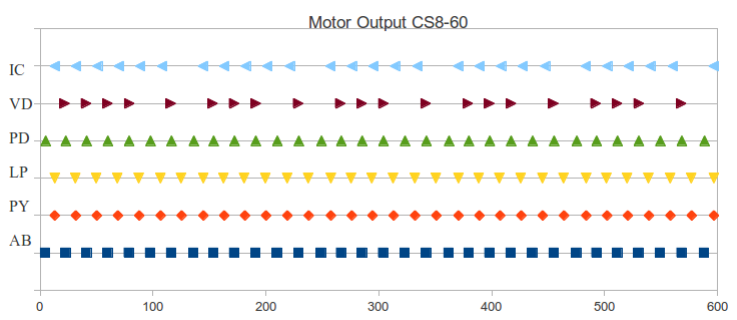

(c)

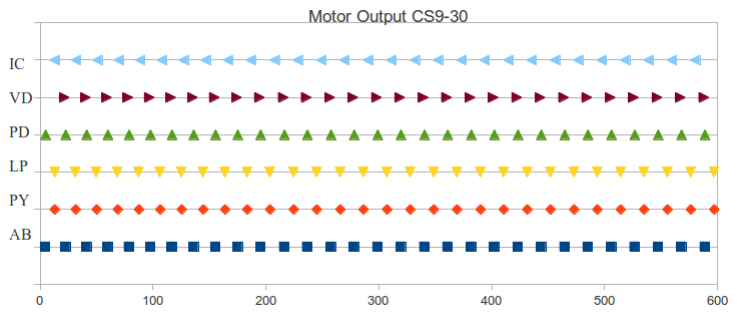

(d)

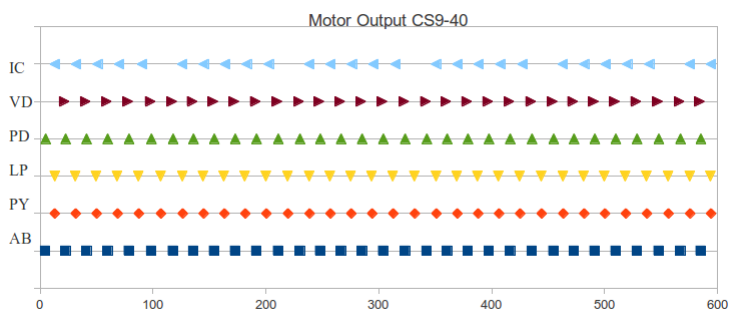

(e)

Figura 5.1: Saídas motoras para (a) e (b), as duas condições basais $B 1$ e $B 2$, respectivamente, (c) $C S 8-60$, (d) $C S 9-30$ e (e) $C S 9-40$. 
Da figura 5.1, define-se as unidades padrão como:

$$
\begin{aligned}
& \alpha=A B / P D / V D \\
& \beta=L P / P Y / I C \\
& \gamma=P Y / I C \\
& \theta=L P / P Y \\
& \lambda=I C \\
& \sigma=A B / P D
\end{aligned}
$$

Agora, se observamos a sequência numérica que origina a série temporal $S Y N C$, apresentada na figura 5.2, poderemos reconstruir as respostas síncrona/motora das categorias apresentadas na tabela 5.1, desconsiderando transientes iniciais quando existirem, como:

$$
\begin{aligned}
& B 1 \Rightarrow 3332 \Rightarrow \alpha \beta \alpha \gamma \\
& B 2 \Rightarrow 333332 \Rightarrow \alpha \beta \alpha \beta \alpha \gamma \\
& C S 8-60 \Rightarrow \overbrace{33 \ldots 3}^{7 \times} 23322 \Rightarrow \beta \alpha \beta \alpha \beta \alpha \beta \sigma \beta \alpha \theta \sigma \\
& C S 9-30 \Rightarrow 321 \Rightarrow \alpha \theta \lambda \\
& C S 9-40 \Rightarrow \overbrace{33 \ldots 3}^{9 \times} 2132 \Rightarrow \alpha \beta \alpha \beta \alpha \beta \alpha \beta \alpha \sigma \lambda \alpha \theta \\
& C S 9-50 \Rightarrow \overbrace{33 \ldots 3}^{9 \times} 2132 \Rightarrow \alpha \beta \alpha \beta \alpha \beta \alpha \beta \alpha \theta \lambda \alpha \theta \\
& C S 9-70 \Rightarrow \overbrace{33 \ldots 3}^{11 \times} 2 \Rightarrow \alpha \beta \alpha \beta \alpha \beta \alpha \beta \alpha \beta \alpha \theta
\end{aligned}
$$

Vajamos algumas conclusões que podemos obter dessa formulação: 


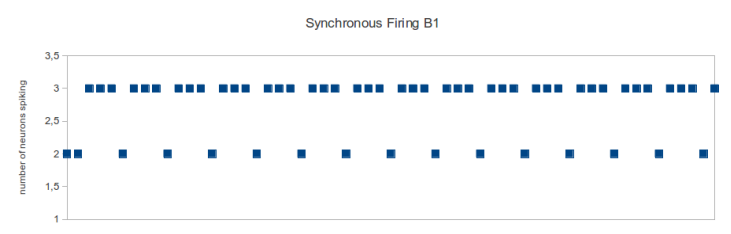

(a)

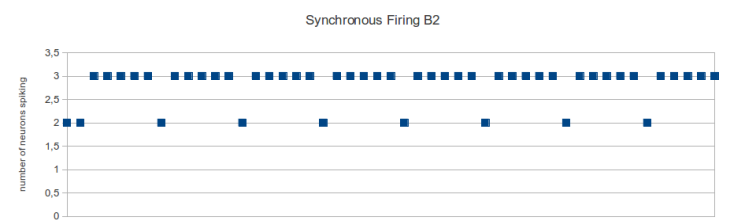

(b)

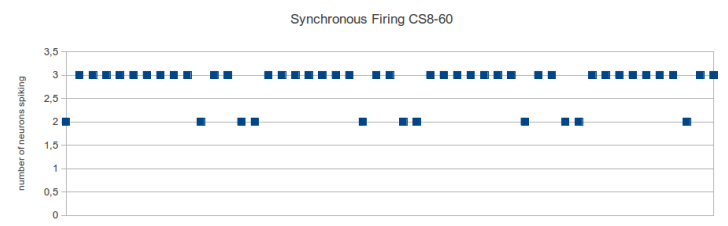

(c)

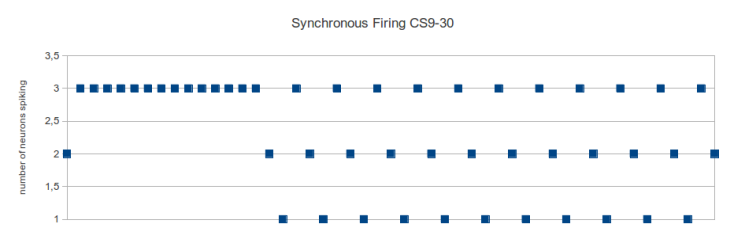

(d)

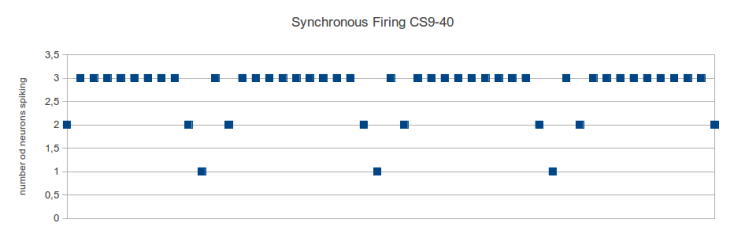

(e)

Figura 5.2: Saídas síncronas para (a) e (b), as duas condições basais $B 1$ e $B 2$, respectivamente, (c) $C S 8-60$, (d) $C S 9-30$ e (e) $C S 9-40$. 
1. B1 possui os menores valores de vApEn, afinal, apresenta as sequências mais simples, ou menos complexas, tanto numérica quanto de unidades padrão;

2. CS8 - 60 possui uma sequência numérica bem mais complexa que $B 2$ tendo, dessa forma, valores mais altos de $-v A p E n(N E T)$, comparáveis aos de $C S 9-40$ e $C S 9-50$;

3. Embora $C S 8$ - 60 possua alta complexidade sob o ponto de vista de unidades padrão, sua sequência numérica é mais simples do que as apresentadas por CS9-40 e $C S 9-50$ e,

4. CS9 - 30 é o melhor candidato à compatibilização com os sistemas biológicos, possui sequências simples de ambas as naturezas e, só não possui valor menor de $-v A p E n(N E T)$, devido ao transiente inicial que pode ser visto na figura 5.2d.

Importante frisar agora que, ter sequências síncronas não garante uma condição de menor metabolismo ou fluxo de informação, ou seja, não basta estar síncrono para ser capaz de mapear grandezas da saída motora em grandezas internas a rede. Essa visão é suportada pelo fato de que $B 0$ e $B 1$ operam a valores de vApEn mais baixos do que outras configurações e, além disso, quando temos outras configurações se aproximando do perfil motor dado por $B 0$ e $B 1$, isso ocorre a valores compatíveis (reduzidos) de informação.

\subsection{Aumentos de Informação na Rede}

Exclua as condições basais e CS9-30, todas as demais categorias constituintes da tabela 5.1 possuem alta quantidade de informação no "neurônio equivalente". Apresentaremos, então, nossa hipótese do Poço Informacional. Da mesma forma que em mecânica é necessário um aumento na energia potencial de um corpo, para removê-lo de um certo poço e lançá-lo a outro poço vizinho, como forma de vencer o bloqueio do morro que 
separa as duas regiões de mínimos energéticos, algo equivalente deve acontecer em relação à informação circulante na rede neural.

Partamos de uma rede sincronizada em um dado padrão, usando nosso formalismo anterior, por exemplo: $\alpha \beta \alpha \gamma$. Para que agora, ela execute o padrão $\beta \gamma \gamma \alpha$, é necessário energia extra.

Suponhamos a rede no estágio $\beta$ do padrão inicial, suas sinapses estão configuradas para, então, causar a despolarização de $A B, P D$ e $V D$, alcançando o estágio $\alpha$. Porém, a reprogramação pede que agora se vá para o estágio $\gamma$, ou seja, despolarize-se $P Y$ e $I C$, em algum lugar da rede se iniciarão novas despolarizações e, em outros, repolarizações. Por mais rápidas que possam ser executadas, algum grau de superposição nesses dois eventos ocorrerá e, por si só, isso já aumentará valores de vApEn, pois insere uma descontinuidade no padrão exetudado até então ${ }^{2}$. Muito provavelmente, a troca entre padrões mais complexos do que o do nosso exemplo, deve pedir estágios intermediários de transição (e esses estágios devem poder ser alcançados pela arquitetura da rede) aumentando mais ainda a complexidade da informação circulante.

Acreditamos, assim, que só seremos capazes de trocar padrões, mesmo sendo de complexidades similares, ao custo do aumento, ao menos momentâneo, do nível de informação da rede como um todo. É necessário que se visite outras regiões do espaço de estados, ampliação de área como na figura 4.14, antes de se retornar a uma nova região de minimização.

\subsection{Biologia Relacional}

A Biologia Relacional foi um ramo de pesquisa criado pelo físico teórico, russo de nascença e naturalizado norte americano, Nicolas Rashevsky. Rashevsky teve uma

\footnotetext{
${ }^{2}$ Um dos pontos observados por nós, relacionado ao artefato metodológico mencionado no capítulo 4, é justamente a capacidade do método da vApEn de detectar eventos catastróficos em uma série temporal, i. e., uma brusca descontinuidade no padrão.
} 
carreira intensa na criação dos subsídeos ${ }^{3}$ para a instauração de uma linha de estudo que amalgamasse a matemática com a biologia, de forma a criar um arcabouço teórico com a finalidade de buscar por princípios básicos nos sistemas biológicos.

Estabelecer uma apropriação, no universo da biologia, dos conceitos de álgebra, mais especificamente da Teoria de Grupos, fornece um poderio tremendo ao permitir o intercâmbio entre estudar um sistema com ênfase em sua estrutura, ou com ênfase em suas funções e relações. Isso foi feito por Rosen quando criou os chamados sistemas $(M, R)$. Utilizando a estrutura algébrica das Categorias, ele formalizou uma maneira de estudar a dinâmica de degradação/reconstrução enzimática em redes metabólicas, buscando por uma resposta de como elas, as redes, são capazes de se autoregularem e manter sua estrutura, se partes de si próprias são constantemente removidas (degradação).

O ponto principal, aqui, é a possibilidade de seguirmos, em trabalhos futuros, um caminho semelhante tentando alinhar teoria de grupos com os conceitos de mapeamento entre arquitetura da rede e fluxos de informação. Um dos pontos iniciais do desenvolvimento desse ramo da matemática, a álgebra abstrata, se deu com problemas discutidos por Abel, Galoi, Lagrange e Ruffini relacionados a grupos de permutação e formas de se obter soluções fechadas para equações polinomiais de grau elevado. O formalismo iniciado em 5.1 pode representar o início de uma tratativa nessa área.

\footnotetext{
${ }^{3}$ Em 1938 publicou o livro Mathematical Biophysics: Physico-Mathematical Foundations of Biology, seguido, em 1940, pelo livro Advances and Applications of Mathematical Biology e, finalmente, em 1947 publica Mathematical Theory of Human Relations. Em 1939 funda o periódico The Bulletin of Mathematical Biophysics (BMB). Também em 1947, cria o primeiro programa de doutorado em Biologia Matemática, na Universidade de Chicago. Teve como alguns de seus mais brilhantes orientados George Karreman, Herbert Landahl, Robert Rosen e Anatol Rapoport.
} 


\section{Referências Bibliográficas}

Brette, R., Rudolph, M., Carnevale, T., Hines, M., Beeman, D., Bower, J. M., Diesmann, M., Morrison, A., Goodman, P. H., Harris, F. C., Zirpe, M., Natschläger, T., Pecevski, D., Ermentrout, B., Djurfeldt, M., Lansner, A., Rochel, O., Vieville, T., Muller, E., Davison, A. P., El Boustani, S., and Destexhe, A. (2007). Simulation of networks of spiking neurons: a review of tools and strategies. Journal of computational neuroscience, 23(3):349-98.

Brown, T. G. (1910). Studies in the reflexes of the guinea-pig. V.: some experiments on the influence exercised by the higher centres upon the scratch-reflex. Experimental Physiology, 3(3):319-353.

Brown, T. G. (1911). Studies in the physiology of the nervous system VII: Movements under narcosis in the pigeon. Movements under narcosis in the rabbit-progressionscratching-flexion. Experimental Physiology, 4(2):151-182.

Brown, T. G. (1914). On the nature of the fundamental activity of the nervous centres; together with an analysis of the conditioning of rhythmic activity in progression, and a theory of the evolution of function in the nervous system. The Journal of Physiology, 48(1):18-46.

Cacciatore, T. W., Rozenshteyn, R., and Kristan, W. B. (2000). Kinematics and modeling of leech crawling: evidence for an oscillatory behavior produced by propagating 
waves of excitation. The Journal of neuroscience : the official journal of the Society for Neuroscience, 20(4):1643-55.

Clarac, F. (2008). Some historical reflections on the neural control of locomotion. Brain research reviews, 57(1):13-21.

Cruse, H., Dürr, V., and Schmitz, J. (2007). Insect walking is based on a decentralized architecture revealing a simple and robust controller. Philosophical transactions. Series A, Mathematical, physical, and engineering sciences, 365(1850):221-50.

Davison, A. P., Brüderle, D., Eppler, J., Kremkow, J., Muller, E., Pecevski, D., Perrinet, L., and Yger, P. (2008). PyNN: A Common Interface for Neuronal Network Simulators. Frontiers in neuroinformatics, 2(January):11.

DiFrancesco, D. and Noble, D. (1985). A model of cardiac electrical activity incorporating ionic pumps and concentration changes. Philosophical transactions of the Royal Society of London. Series B, Biological sciences, 307(1133):353-98.

Eppler, J. M., Helias, M., Muller, E., Diesmann, M., and Gewaltig, M.-O. (2008). PyNEST: A Convenient Interface to the NEST Simulator. Frontiers in neuroinformatics, 2(January):12.

Fitzhugh, R. (1960). Thresholds and plateaus in the Hodgkin-Huxley nerve equations. The Journal of general physiology, 43:867-96.

FitzHugh, R. (1969). Mathematical models of excitation and propagation in nerve. Biological engineering, 1.

Getting, P. A. (1989). Emerging principles governing the operation of neural networks. Annual review of neuroscience, 12:185-204.

Gordon, I. T. and Whelan, P. J. (2006). Deciphering the organization and modulation 
of spinal locomotor central pattern generators. The Journal of experimental biology, 209(Pt 11):2007-14.

Grillner, S. (2006). Biological pattern generation: the cellular and computational logic of networks in motion. Neuron, 52(5):751-66.

Grillner, S., Cangiano, L., Hu, G. Y., Thompson, R., Hill, R., and Wallén, P. (2000). The intrinsic function of a motor system - from ion channels to networks and behavior. Brain Research Interactive, 886:224-236.

Hammarlund, P. and Ekeberg, (1998). Large neural network simulations on multiple hardware platforms. Journal of Computational Neuroscience, 5:443-459.

Hodgkin, A. and Huxley, A. (1952). A Quantitative Description of Membrane Current and its Application to Conduction and Excitation in Nerve. The Journal of Physiology, $117: 500-544$

Hooper, S. L. and DiCaprio, R. a. (2004). Crustacean motor pattern generator networks. Neuro-Signals, 13(1-2):50-69.

Izhikevich, E. M. (2004). Which model to use for cortical spiking neurons? IEEE transactions on neural networks / a publication of the IEEE Neural Networks Council, $15(5): 1063-70$.

Izhikevich, E. M. (2007). Dynamical Systems in Neuroscience: The Geometry of Excitability and Bursting. The MIT Press.

Jankowska, E., Jukes, M. G. M., Lund, S., and Lundberg, A. (1967). The effect of dopa on the spinal cord 6 . half-centre organization of interneurones transmitting effects from the flexor reflex afferents. Acta Physiologica Scandinavica, 70(3-4):389-402.

Kiehn, O. (2006). Locomotor circuits in the mammalian spinal cord. Annual review of neuroscience, 29:279-306. 
Luo, C. and Rudy, Y. (1991). A model of the ventricular cardiac action potential. Depolarization, repolarization, and their interaction. Circulation Research, 68(6):15011526.

Marder, E. and Bucher, D. (2001). Central pattern generators and the control of rhythmic movements. Current biology, 11(23):986-996.

Marder, E., Bucher, D., Schulz, D. J., and Taylor, A. L. (2005). Invertebrate central pattern generation moves along. Current biology : CB, 15(17):R685-99.

Miller, J. and Selverston, A. (1982). Mechanisms underlying pattern generation in lobster stomatogastric ganglion as determined by selective inactivation of identified neurons. iv. network properties of pyloric system. J Neurophysiol, 48(6):1416-32.

Pearson, K. G. K. and Wolf, H. (1987). Comparison of motor patterns in the intact and deafferented flight system of the locust I Electromyographic analysis. ... Physiology A: Neuroethology, Sensory, Neural, and .., 160(2):259-268.

Prochazka, A. and Yakovenko, S. (2007). Predictive and reactive tuning of the locomotor CPG. Integrative and Comparative Biology, 47(4):474-481.

Rieke, F., Warland, D., de Ruyter van Steveninck, R., and Bialek, W. (1999). Spikes: exploring the neural code. MIT Press, Cambridge, MA, USA.

Santos, B., Martins, R., Natali, J., Rodrigues, V., Marques, F., and Chauí-Berlinck, J. (2009). Consistency in approximate entropy given by a volumetric estimate. Chaos, Solitons 83 Fractals, 42(1e):322-334.

Selverston, A. I. (2010). Invertebrate central pattern generator circuits. Philosophical transactions of the Royal Society of London. Series B, Biological sciences, $365(1551): 2329-45$. 
Sherrington, C. S. (1906). The integrative action of the nervous system. Yale University Press, 1 edition.

Sherrington, C. S. (1910). Flexion-reflex of the limb, crossed extension-reflex, and reflex stepping and standing. The Journal of Physiology, 40(1-2):28-121.

Stein, P. S. G. (2005). Neuronal control of turtle hindlimb motor rhythms. Journal of comparative physiology. A, Neuroethology, sensory, neural, and behavioral physiology, 191(3):213-29.

Stuart, D. G. and Hultborn, H. (2008). Thomas Graham Brown (1882-1965), Anders Lundberg (1920-), and the neural control of stepping. Brain research reviews, 59(1):7495.

Wilson, D. and Wyman, R. (1965). Motor Output Patterns during Random and Rhythmic Stimulation of Locust Thoracic Ganglia. Biophysical Journal, 5(2):121-143.

Wilson, D. M. (1961). The central nervous control of flight in a locust. The Journal of experimental biology, 38:471-490.

Wolf, H. and Pearson, K. G. (1987). Comparison of motor patterns in the intact and deafferented flight system of the locust II Intracellular recordings from flight motoneurons. Journal of Comparative Physiology A, 160(2):269-279.

Wolf, H. and Pearson, K. G. (1989). Comparison of motor patterns in the intact and deafferented flight system of the locust III patterns of interneuronal activity. Journal of Comparative Physiology A, 165(1):61-74.

Zou, Q., Bornat, Y., Tomas, J., Renaud, S., and Destexhe, a. (2006). Real-time simulations of networks of Hodgkin-Huxley neurons using analog circuits. Neurocomputing, 69(10-12):1137-1140. 


\section{Apêndice A}

\section{Arquivos de Configuração XML}

A seguir apresentamos um arquivo de configuração XML exemplo, juntamente com uma descrição, linha a linha, de seu conteúdo.

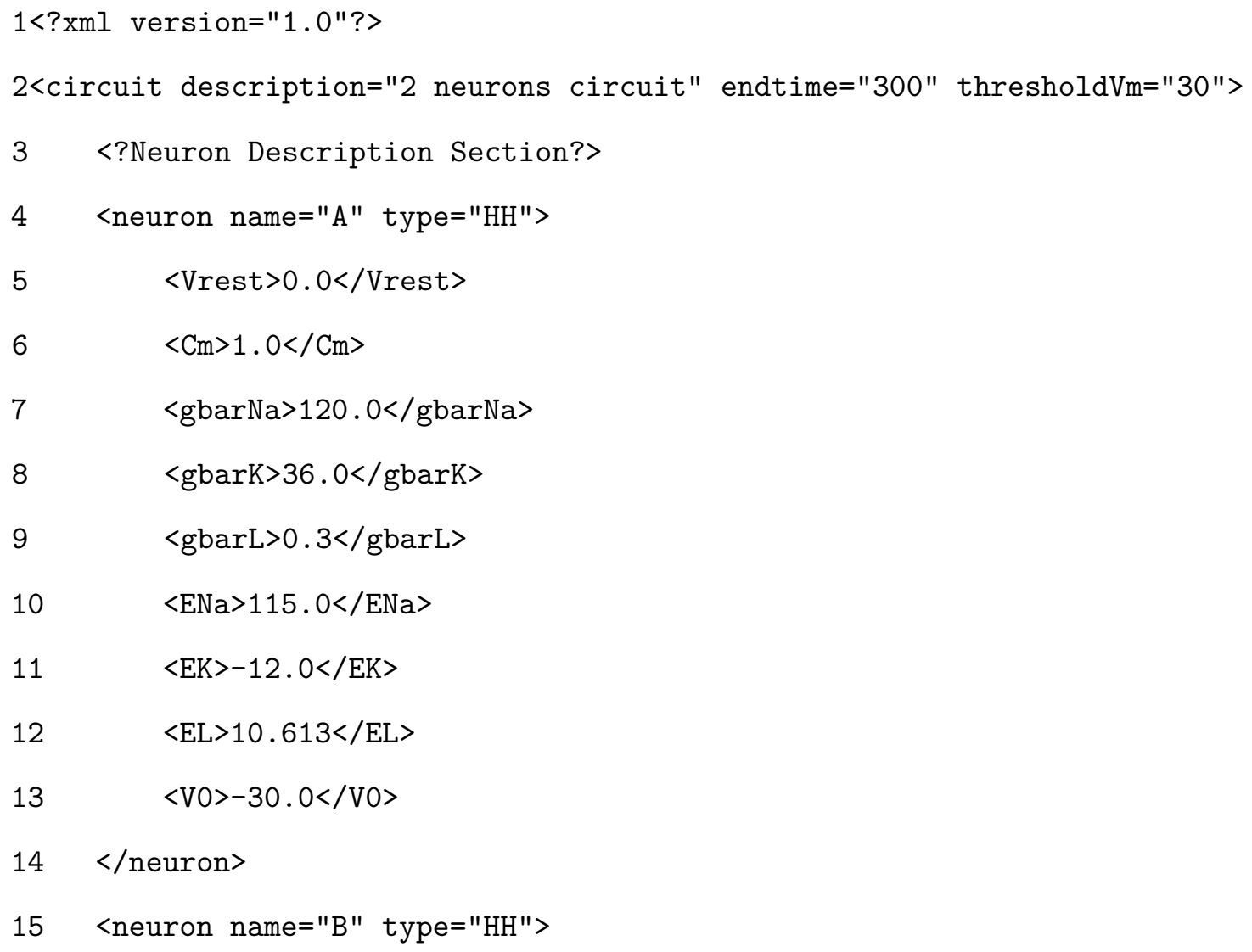



<gbarK>36.0</gbarK>

$</$ neuron $>$

27

<?Chemical Synapses Description Section?> $<$ Taum $>0.1</$ Taum $>$ 


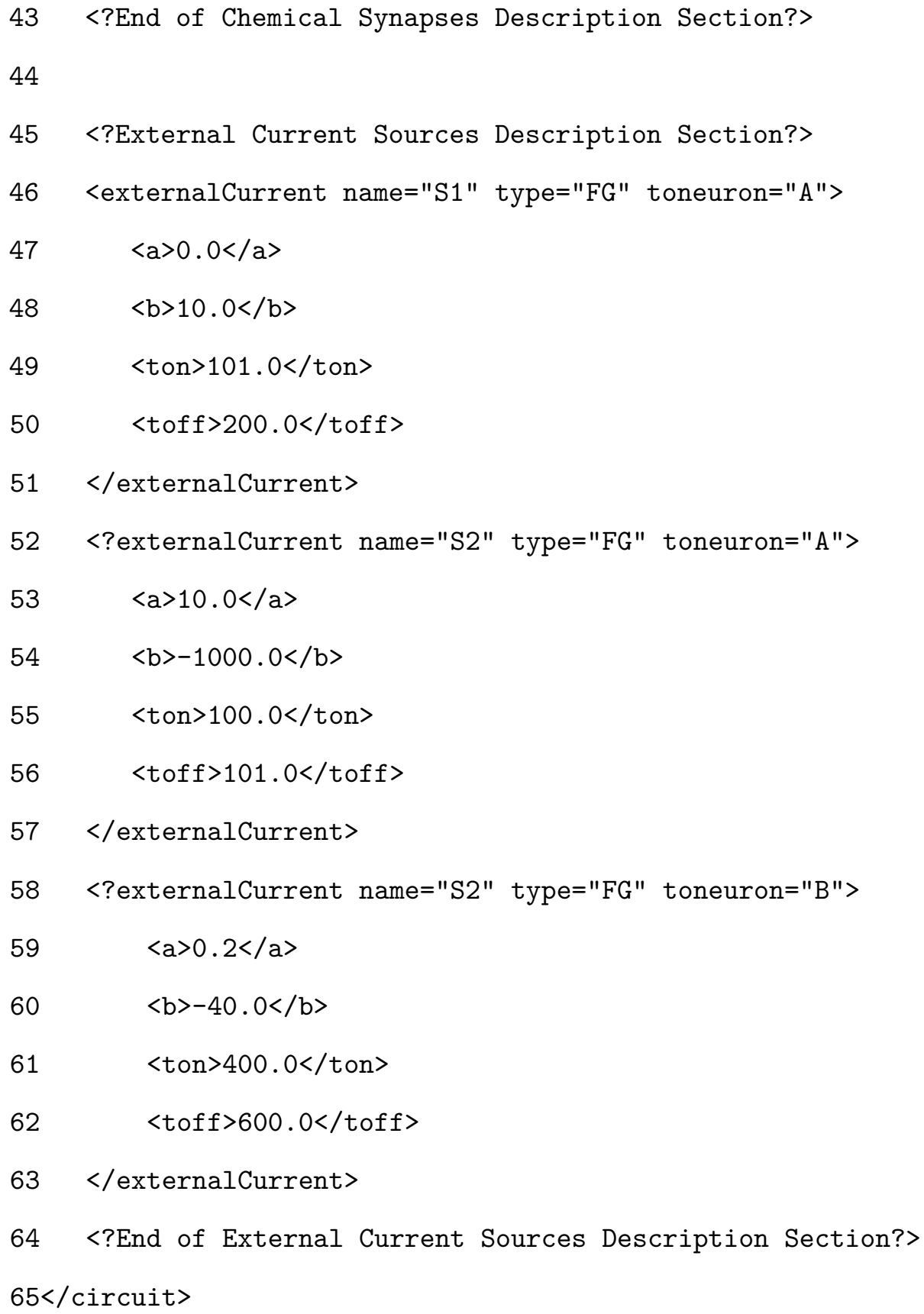

Os valores a esquerda representam o número das linhas e são, apenas, para facilitar a referência durante a explanação.

A linha 1 é um cabeçalho obrigatório para qualquer arquivo xml. A linha 2 apresenta o nome do circuito - 2 neurons circuit, o tempo final de simulação - 300, em milisegundos 
e o nível para detecção de um spike - 30, em milivolts. O bloco composto pelas linhas de 4 a 14 definem um neurônio. Na linha 4 configuramos o nome, A, e o tipo do neurônio, HH - Hodgkin \& Huxley. A linha 5 define o potencial de repouso de membrana, as linhas de 6 a 12 definem as caracterísitcas de capacitância de membrana, condutância máxima dos canais e potenciais de reversão dos íons. Por fim, a linha 13 configura o potencial de membrana inicial do neurônio em questão. O bloco seguinte (linhas 15 a 25) realiza os mesmos passos que acabamos de descrever, porém, para um novo neurônio, B.

A linha 29 define uma sinapse elétrica: seu nome, ES1, quem são os neurônios pré e pós sinapticos, A e B, respectivamente e qual a condutância máxima do canal (conexina), $0.4 \mathrm{mS} / \mathrm{cm}^{2}$. Ainda na configuração das sinapses, o bloco de 33 a 37 especifica uma sinapse química de nome CS1, o tipo da função que calcula a corrente sinaptica, alpha e, novamente, quem são os neurônios pré e pós sinapticos. As linhas 34 a 36 definem a constante de tempo da sinapse 0.1 , o peso e atraso da mesma, 1 e 0 , respectivamente. Analogamente, as linhas de 38 a 42 definem nova sinapse química.

O último bloco, de 46 a 63, define um conjunto de fontes externas de corrente. Todas possuem um nome, um tipo (no caso todas representeam funções de primeiro grau FG), e a qual neurônio do circuito se destinam. Os blocos internos, como o das linhas 47 a 50, definem os coeficientes angular e linear de uma função afim e o intervalo de tempo que essa fonte deve estar funcionando. Perceba que temos duas fontes destinadas ao neurônio A. Isso nos permite definir um perfil qualquer de correntes para esse neurônio uma vez que, no momento da simulação, todas as correntes externas definidas a um mesmo neurônio são somadas (vide figura 3.4). 


\section{Apêndice B}

\section{Considerações Sobre Aumento de Performance em Python}

Tanto as simulações das classes pertencentes ao módulo CModels quanto da VapEn foram baseadas no trinômio Python 2.7 - NumPy - SciPy. Isto significa que foram utilizadas as melhorias de performance oriundas da biblioteca NumPy, as quais aceleram os cálculos matriciais implementando algumas das manipulações em linguagens de mais baixo nível (como linguagem $\mathrm{C}$, por exemplo). Porém o ganho de performance não se limita ao uso da biblioteca NumPy. Observemos novamente a figura 3.5a. Os traçados referentes a blitz, inline, fastinline e pyrex mensuram mecanismos para aumento de performance em Python, visando sua utilização em computação de alto desempenho. Aqui, uma rápida explanação de como esses aceleradores de desempenho realizam sua tarefa:

- Weave.blitz: cria, a partir de um código inicialmente em Python puro, subrotinas em linguagem $\mathrm{C}++$. Após armazenar esses novos "subprogramas $\mathrm{C}++$ " utiliza-os para a realização dos cálculos computacionalmente mais intensos; 
- Weave.inline: fornece uma forma do programador inserir ele próprio, "pedaços" de código em linguagem $\mathrm{C}++$ diretamente no código fonte em linguagem Python, $\mathrm{e}$

- Pyrex: atualmente chamado de Cython, permite a criação de extensões em linguagem $\mathrm{C}$, porém utilizando uma sintaxe muito próxima da sintaxe da linguagem Python, possibilitando, inclusive, a chamada direta de funções e o uso dos tipos de dados nativos da linguagem $\mathrm{C}$. 